QL

133

C67

1861

MOLL

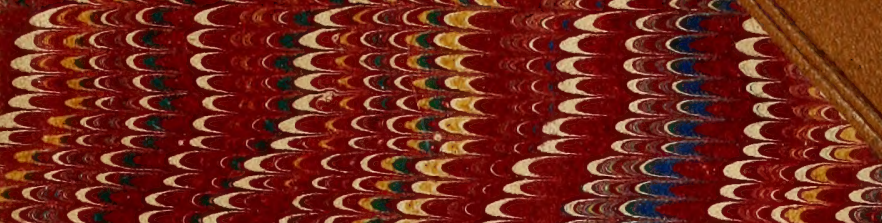

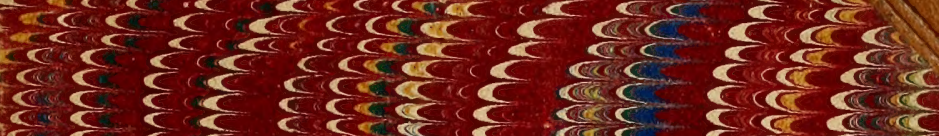

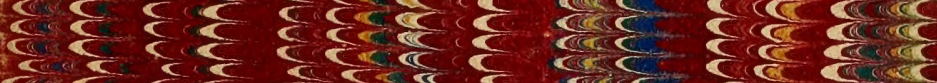

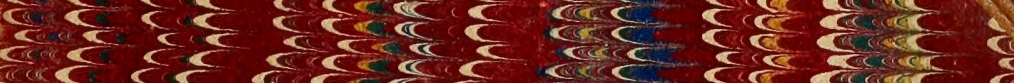

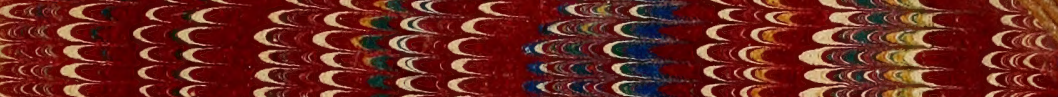

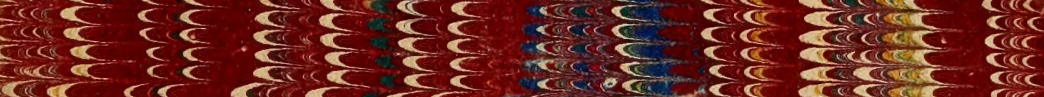

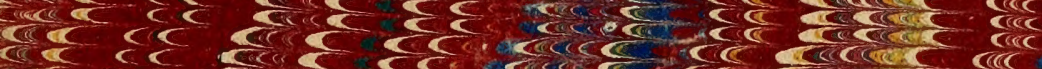

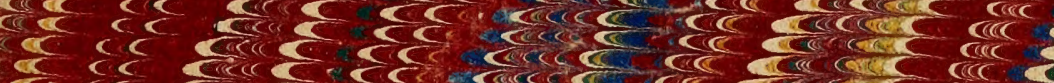

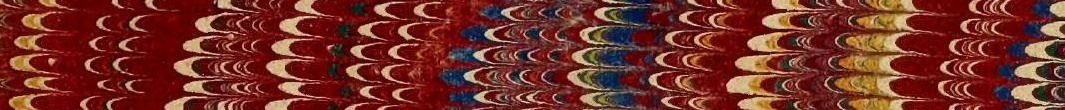

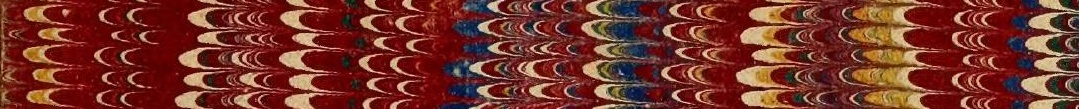

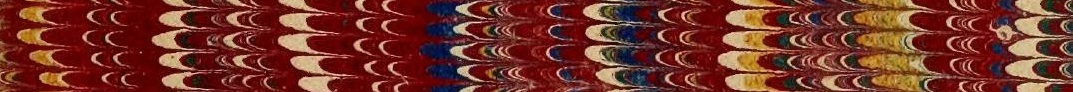

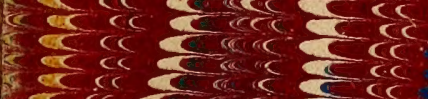

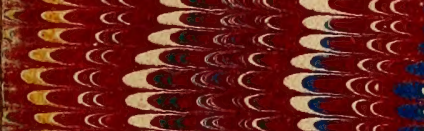

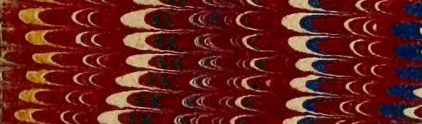

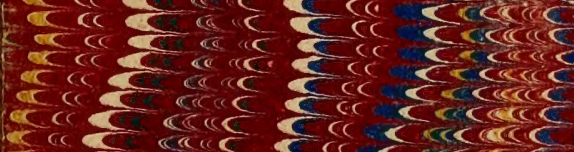

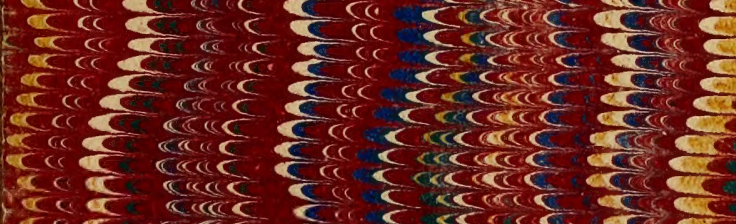

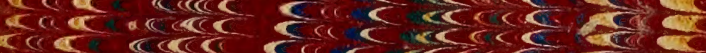

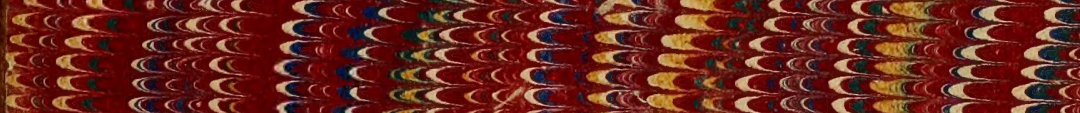

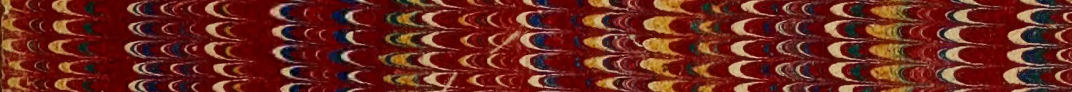

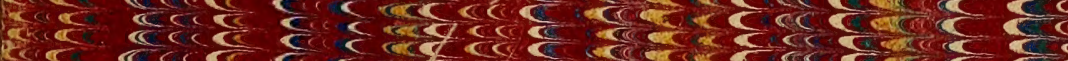

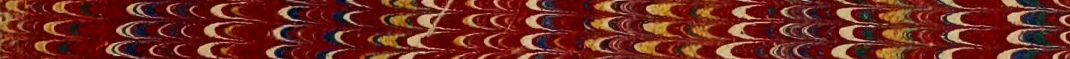

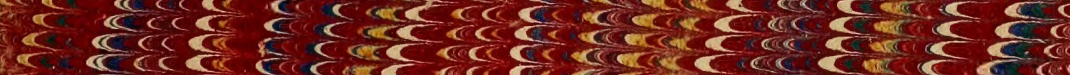

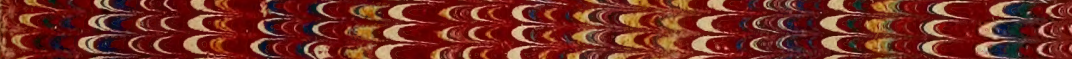

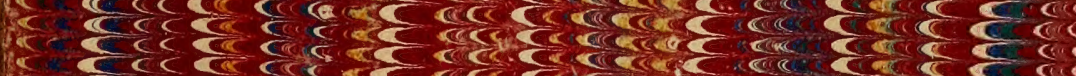

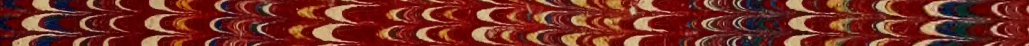

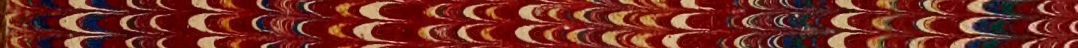

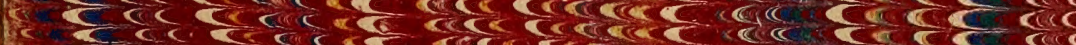

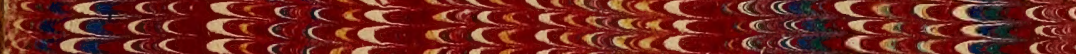

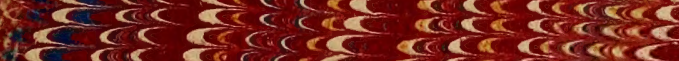

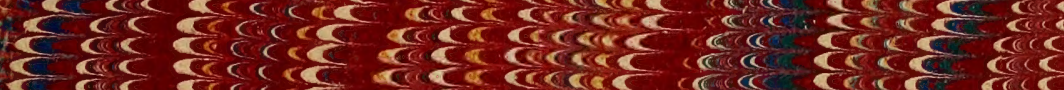

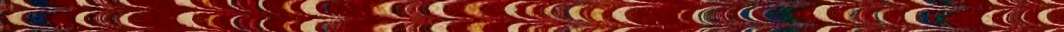

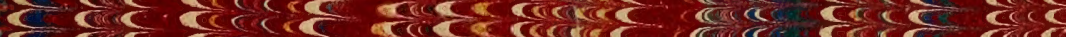

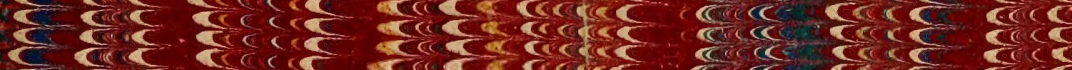

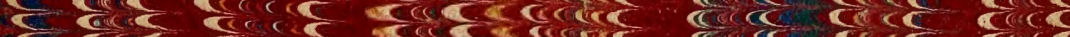

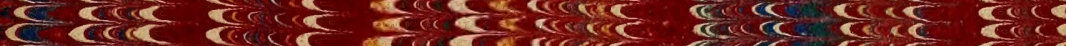

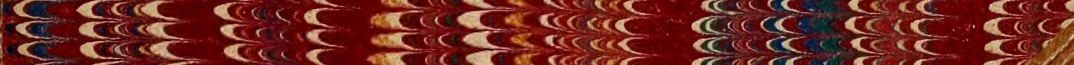

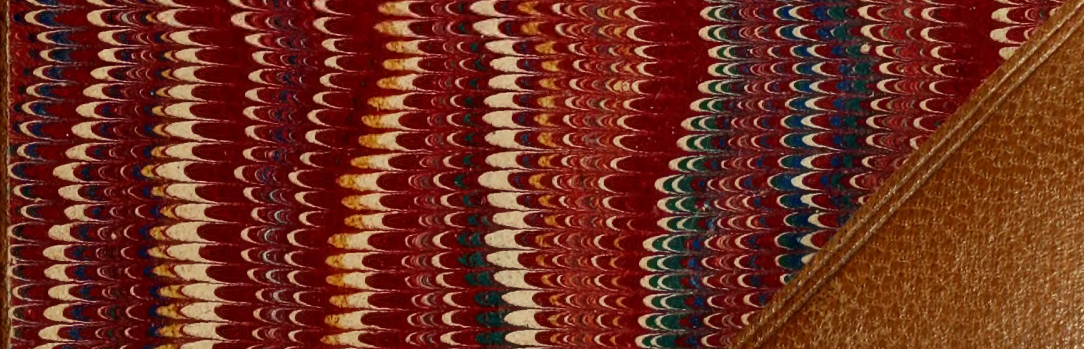




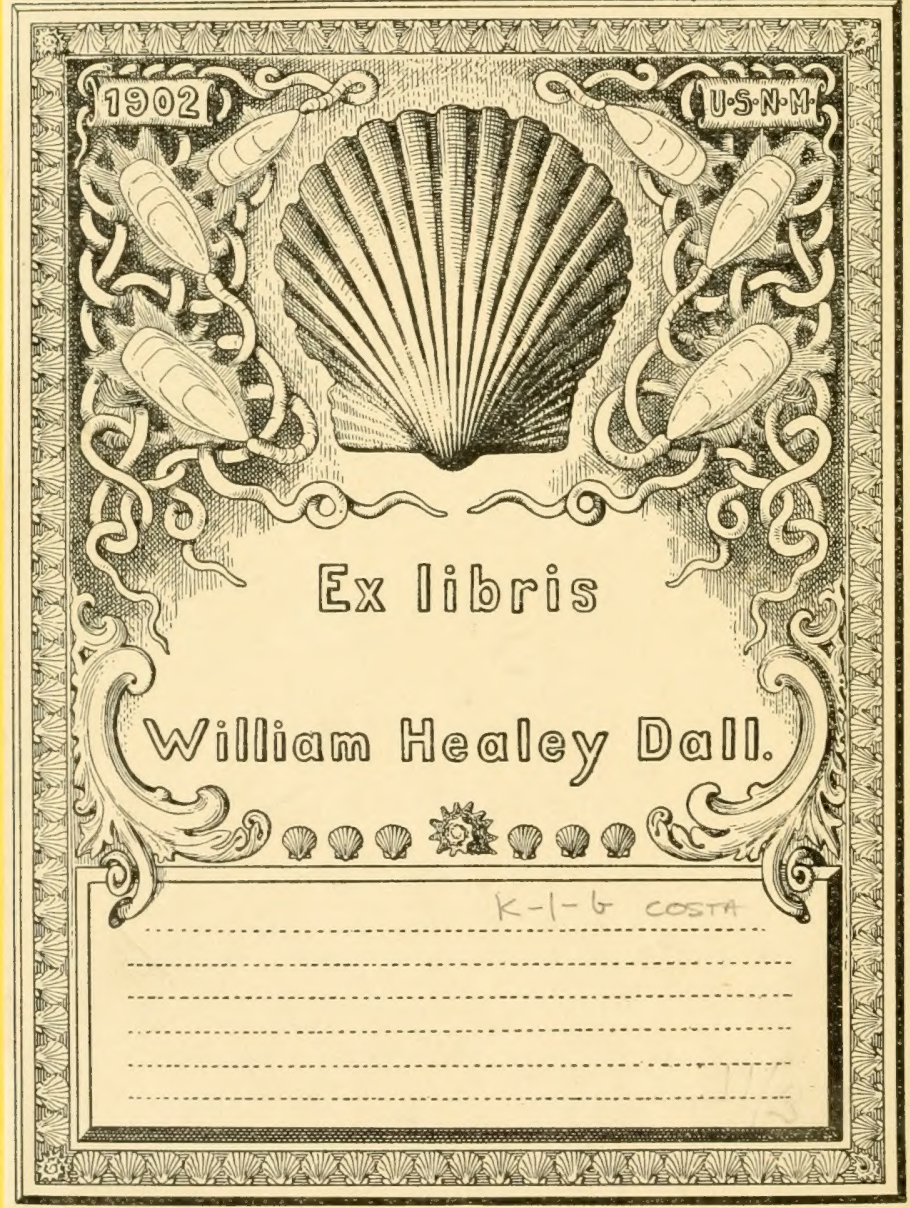


Division of Mollusks Sectioncal Librorngy 







\section{IICRODORIDE MEDITERRINEA}

\section{DESCRIZIONE}

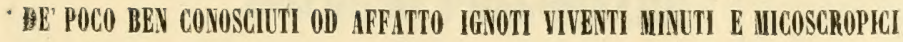

\section{DEL MEDITERRANEO}

Pel Professore

\section{A. COST}

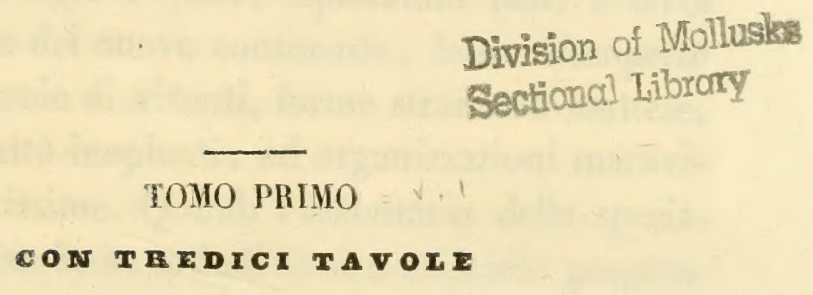

NAPOLI

DALLA STAMPERIA DELL'IRIDE

1861 


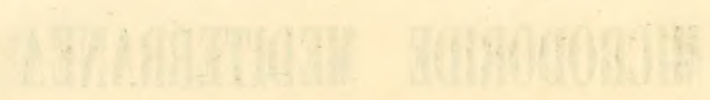

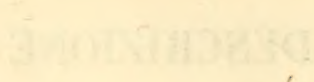

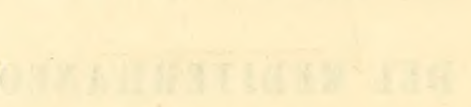




\section{MISCORSO PRELIIINARE}

1. La storia della Zoologia non segnò mai nei suoi annali tanti cultori, quanti ne vanta la metà del secolo che volge. I quali, esplorando mari e terre dell' antico e del nuovo continente, ànno discoperto numerose genic di viventi, forme strane ed inattese, coslumi affatto inopinati, ed organizzazioni maravigliose e novissime. Quindi l'inventario delle specialità numerosissimo, quindi lo straordinario progresso della scienza, quindi l'incremento di ogni sua branca, e quindi ancora le difficoltà di appararle e di seguirne a passo a passo il progressivo cammino.

2. D'altro lato, la facilezza della stampa, seguendo con celerità proporzionale la moltiplicità degli scrittori, fa crescere di tanto lo svolgimento de pensieri, la creazione de' nomi, lo accozzamento delle specialità, ed i mutamenti de'sistemi e dei metodi, che le difficoltà aumentano a dismisura, mentre la durata del river nostro sembra abbreviarsi. 
3. E però in mezzo a tanto sapere va mancando l' unità de' principî, l' uniformità de' sistemi, l'armonia nelle specialità riunite, la reciprocanza nello scambio delle nozioni e delle idee, e la buona intelligenza fra gli stessi vicini scrittori: e tutto è isolatamenie o forzato o spontaneo! Ecco il maggior degli ostacoli al vero e ben ordinato progresso. Se mal non mi avviso, tulto sembra annunziare, che l' altezza maggiore della parabola fosse oramai oltrepassata.

4. A fronte di un grande numero d'investigatori e delle numerose scoperte de' giorni nostri, chi dir potrà di avere esplorato il vastissimo fondo degli oceani? E neppure di un mare racchiuso fra angusti confini potrà asserirsi che stati fossero esplorati il fondo e le sponde. Siccome fra grl'incommensurabili spazî de' Cieli si aggirano innumerevoli astri e pianeti, che alla vista più acuta sottraggonsi, per la immensa loro distanza; così nella vastità de' mari, da cui la nostráa terra per la maggior parte è inondata, abitano miriadi di viventi che sfuggono all' occhio umano per la estrema loro mobilitì e picciolezza. Fra questi due estremi, non comparabili fra loro che per gli effetti soltanto, l'intelletto umano vanamente si aggira, non potendo concepirne nè il termine, nè il numero, e molto meno il destino. Laonde, dopo tanti sudori versati, è l' uomo costretto rientrare in se stesso umiliato.

5. Restringendo ancor questa idea, e riferendola 
alle acque soltanto del Mediterraneo, di gran lunga minori e circoscritte di quelle dell' Oceano europeo, potrebbe presumere un solo di mostrarsi appieno in formato de' suoi abitatori? Eppure è questo che innanzi tutto è slato ed è ogni giorno dai naturalisti di Europa frugato. E volendo più sempre circoscrivere il campo ed i calcoli, i mari delle due Sicilie sono stali sempre prescelti, e per ogni modo solloposti a ricerche, come i più comodi, e più feraci di viventi di classi diverse. Nondimeno porto opinione, che tulto l'immenso lavoro riducesi ad una superficiale cucchiajata di acqua e di melma; perciocchè la immensa maggioranza della loro estensione è ancor vergine, e le sue profondità non toccale.

6. Ne' giorni testè passatiè stata avvertita per molti quest' ultima lacuna, e si è inteso il bisogno di colmarla. Si sono studiati taluni di trovar modo e mezzi onde raggiungere il fondo del mare, per cercarvi i più reconditi de' suoi abitatori; ma gli sforzi sono rimasti inefficaci, e la lusinga è andata delusa.

7. La natura non si arresta solto alcun limite nei tipi delle sue produzioni, ma progressivamente ella passa dall' una all'altra dimensione, fino a che i germi reslano quasi confusi colle molecole primordiali. Queste sono le vere monadi, le quali sfuggono ai nostri sensi, e pare che svanisca la loro esistenza.

8. In siffatte degradazioni le forme subiscono anch' esse successive modificazioni; talchè, negl' in- 
linitamente piccoli, gli esseri di un medesimo tipo originale restano trasformati quasi per modo, che sembrano appartenere ad una sfera diversa da quella della quale realmente fan parte.

I corpi viventi si vanno mutando nella loro forma, ed anche nella loro organizzazione, a norma che provano dei cangiamenti forzati nelle loro abitudini, nelle loro maniere di vivere, e nelle impressioni che loro vengono cagionate da corpi circostanti e da potenze sopravvenienti; e sono soggetti a cangiamenti, anche quando le circostanze delle di loro abitazioni si trovano mutate di troppo (1).

9. La breve durata di nostra vita non permette accorgerci di simili cangiamenti, i quali si succedono lentamente. Ma quando si paragonano esseri che distano troppo tra loro, per l' epoca della esistenza attiva, siccome $\mathrm{i}$ fossili, ed $\mathrm{i}$ viventi di una medesima località àn cangiato di stato; noi possiamo concepire o presumere il tempo che à dovuto interporsi, e la intensità degli agenti che ànno dovuto influire sopra di loro, perchè tali mutamenti si fossero avverati, a seconda delle differenze più o meno notevoli che ci presentano.

10. La delicatezza estrema, e la integrità di molti di questi fossili ci convincono, che àn dovuto vivere nel medesimo luogo ore si trovano, come

(1) Consulta Lamarck, Annali del Museo di Storia Nat. p. 500, in Nole. 
ben l'avvertiva Lamarck ( Hydrogeologia, p. 54).

11. Per determinare l'età de' diversi terreni, i Geologi ricorrono all' oracolo della Paleontologia : e questa va cercando ne'terreni medesimi i vestigi che la natura à lasciati con gli avanzi organici delle generazioni estinte, o semplicemente trascorse, ed in quei terreni rinchiusi. Questa parte delle scienze naturali, comparando le spoglie e gli avanzi delle specie fossili con le congeneri o affini della età presente, ricava la differenza in più od in meno tra le une e le altre, sia numericamente, e sia sostanzialmente.

12. Viè dunque nella creazione pertanto una scala diesseri infinitamente piccoli, in opposizione degli estremamente grandi, i quali vivono nell' aria e nelle açue, in seno della terra, e nella profondità de' mari, e questi sfuggono ai sensi nostri, ma non per ciò sono essi meno importanti nel mantenimento dell' ordine ed armonia del creato : chè il numero in essi compensa la mole, come fu detto.

13. Il Soldani ebbe il felice pensiero di ricercare nelle terre senesi e nelle sabbie del mar Tirreno le più minute spoglie testacee, e compararle tra loro; con che intendeva per lo appunto risolvere il sopra espresso problema. Il Planco esplorava le sabbie dell'Adriatico, per discoprire le specie di minuti e sconosciuti viventi di quelle acque. Io, facendo altrettanto, per compiere della nostrale Paleontologia e della Fauna vivente la serie, sono pervenulo a discoprire 
Ina lunga serie di spoglie teslacee minutissime, $e$ sconosciute, oltre i numerosi Foraminiferi, nellex maggiori profondità del Mediterraneo.

14. Studiandomi ancor io da gran tempo di vincere in parte gli ostacoli che allo scoprimento de' piu minuti abitatori de' mari frappongonsi, ò cercato nella natura stessa qualche valevole mezzo : e, soccorso dall' arte e dalla sperienza, sono in lusinga di esservi riuscito. Senonchè, il tempo che ci sfugge d'innanzi a larghi passi, non lascia neppure la speranza di svolgere quel poco che si è potuto rapire alle gelose Nereidi.

15. Della copiosa raccolta già fatta, buon mumero di specie sfuggite all' occhio sagace de' zoologi mi sembra essere ignoto; e non poche son pure di tipo ancor sconosciuto: e tulte provengono dal Mediterraneo in generale, ed in particolare dalle coste settentrionali dell' Affrica, dall' Adriatico e dal Tirreno. Forse talune saranno già descritte in qualche opera delle tante che non mi è stato concesso consultare, od in memorie inserite in Alli Accademici, che non sono a noi perrenuti, o finalmente in alcuna di quelle Effemeridi, che nascono e muojono nel giorno stesso, come appunto gli Efemerini. Se ciò si avvera, non è certo l' effetto di non curanza o malizia ; ma è colpa de' tempi e del luogo; sono le condizioni che ci circondano la più polente barriera che si frappone. Quindi senź altro indugio andrò pubblicando quan- 
to credo o nuovo, o raro, o sibbene da merilare sehiarimenti maggiori.

16. Ė a tal lavoro che ò creduto poter convenire il titolo di Microdoride, comechè esso si aggira esclusivamente intorno a specie minime, e per lo più tali, che a ben vederne la struttura non è sufficiente la vista ordinaria; ed esclusivamente sono abianti del mare. Per la qual cosa, rigorosamente parlando, sarebbe improprio il nome di Fauna, quantunque per convenzione generalmente si accella. Le Faune marine altronde non possono essere così circoscrilte come le terrestri si vogliono, talchè abbracciar non polessero specic spettanti a più continenti vicini ed opposti. Cresce ancor più e per molti lati cotesta difficoltà per rapporto agli abilanti del mare; perocchè altri, emigrando, si trasferiscono da luogo a luogo per lontanissimi seni e golfi, altri son traghetlati dalle onde stesse del mare, o da' marosi quà e colà rigettati ; e quei che abitualmente si tengono fissi in luoghi limitati, diffondono la propria prole per lo mezzo delle nova, che galleggianti vanno per le acque medesime trasinesse. Che se ciò non si avvera ne'vasti oceani, è cosa cerla per i mari ristretti, e meglio ancor circoscrilli. Tal'è il Mediterraneo e le sue dipendenze. Per tale ragione il Mediterraneo può somministrare le stesse specie nella parte settentrionale dell' Affrica, dell' Asia, siccome di quelle della Spagna, della Francia, dell' Ttalia ed alcun poco ancora del- 
l'Austria, nel golfo Adriatico, e le Isole Jonie.

17. Tullo questo poi va crescendo tanto maggiormente, per quanto più si scende nella profondità dei mari. Avregnachè ivi si sentono meno quelle influenze climatiche, che si sperimentano ne'bassi fondi, le quali influiscono potentemente sull' organismo, e 10 modificano in guisa da sorgere razze diverse, od almeno rendono alle stesse specie comuni una impronta diversa ed una fisonomia molto frizzante. La sperienza e le osservazioni vengono pur confermando questi nostri ragionamenti. Abbiamo avuto occasione ben spesso di avvertirci delle differenze sensibili de'Testacei, Crostacei ed altri tali dell'Affrica, e dell'Asia minore, comparativamente a quelli della Sicilia, e maggiormente a questi de' nostri mari, quantunque tutte coteste regioni fossero bagnate dalle acque stesse del Mar Mediterraneo: e tali differenze riduconsi a qualitì esteriori ed eventuali, senza che l' organismo ne fosse punto alterato. Con ciò per altro non s'intende negare, che in ciascuna di tali diverse regioni esistano specie e generi propri ed esclusivi. Nei fondi coralligini altronde s' incontra tanta uniformità ne' piccoli viventi che vi amnidano, da non potersi rilevare alcun che, capace d'avvertirci della loro diversa patria; e quindi atlo a por limite tra regione e regione. Potrei anche aggiungere alcuni fatti per $\mathrm{i}$ quali si congiungono regioni immensamente lontane, come il mar delle Indie, quello dell' America ed il 
Mediterraneo. Avremo occasione in quesio lavoro, siccome nella specialità de' così detti Foraminiferi, di dimostrare questa asserzione.

18. Sembra poi molto dissita al nostro sguardo la costa meridionale d' Italia da quelle dell' $\Lambda$ sia minore e dell'Affrica settentrionale. $\mathbf{E}$ pure a prescindere che quelle si congiungono quasi con la penisola spagnuola, non trovandosi separate che per lo stretto di Gibilterra; e che le coste orientali della Spagna sono in continuazione con quelle della Francia, e poscia con queste dell' Italia; sono le acque stesse del Mediterraneo quelle dalle quali son tutte coleste parti bagnate; e le maggiori distanze svaniscono quando si considerano in rapporto alla vasta superficie del globo.

19. Per farsi un'idea almen grossolana di tali relazioni; e vedere ad un tempo quanto piccolo sia lo spazio frugato da tutti i naturalisti insieme presi nella vastità de' mari, basta limitarsi al seguente calcolo approssimativo e sommario.

La superficie intera del pianeta che noi albitiamo è calcolata per $148,521,609$ miglia quadrate di 60 a grado.

Di queste il mare ne occupa 110,849,000

Le restanti miglia quadrate $37,673,000$ appartengono all' arida terra.

Quindi le terre sono ai mari come 1:3; val quanto dire che la superficie occupata dalle acque è tripla di quella della terra scorerla; o che questa è 
la quarta parte della intera superficie del globo terrestre.

20. Il Mediterraneo pertanto non è che uaa frazione piccolissima dello spazio oecupato dalle acque : e di questa frazione può dirsi francamente che appena una millionesima parte è stata frugata, unendo insieme $\mathrm{i}$ diversi punti visitati da naturalisti esploratori. Eppure è questo Mediterraneo il mare meglio esplorato per frequenza di osservatori, e per facilezza di dragarlo.

E poichè il nesso delle idee lo comporta, piacemi qui addurre un altro computo, dal quale emerge la pochezca di quanto è stato operato finora per discoprire le numerose genie di viventi.

Per esaminare un piede cubo di roccia coralligena, nelle cui cripte e cellole albergano animaletti di generi diversi, ed a molte famiglie appartenenti, si esige non meno di due mesi di assidua ed oculatissima orcupazione: quindi sei piedi cubici in un anno (non il cubo di sei piedi). Che sono mai sei piedi cubici relativamente alla sola scogliera de' fondi coralligeni dell' Isola di Sardegna? e per rapporto a quella delle coste di Affrica? appena un punto matemalico.

Dalle quali considerazioni è facile persuadersi, moltissimo esser quello che ci resta ignolo; onde sapientemente diceva Seneca: Multum adhuc restat operis, multumque restabit, nec ulli nati post mille 
saecula praeclandetur occasio aliquid adhuc adjiciendi-Epist. 64.

21. Che se io ò assunto di andar discoprendo i più minuti animali che albergano nelle acque del Mediterranco; quanlunque vero esser questo un improbo lavoro da non potersi portare troppo oltre, per le tante difficoltà che racchiude; voglio sperare che non per questo meritar dovessi i sarcasmi di cui renne onorato il pazientissimo e diligente Soldani : e dico onorato, perchè onorevole cosa è da stimarsi l' essere vilipeso dal volgo, il quale è uso tributare il suffragio ed il plauso a quel che materialmente solletica i grossolani suoi sensi.

22. Ma qual pro si attende la scienza dalla conoscenza comunque numerosa di tali perissemi della creazione? Quella stessa, risponderò francamente, che proviene dalla storia naturale della Balena, dell' Elefante, dell' Epiornis, del Boa, della Testuggine gigantesca, del Carcaria ec. Se la mole soltanto è bastevole per colmare le lacune che la storia della creazione ci lascia, una immensilà di esseri sarebbero affatto inutili per questa scienza. Eppure $\mathrm{i}$ sapienti dell' antichilà riconobbero nei minimi degli esseri la maggiore sapienza di Dio: In his tam parvis, atque tam nullis quae ratio, quanta vis, quam inestricabilis sapientia, scriveva Plinio.

23. Se le sole gigantesche specie bastassero allo scopo che il Creatore si prefisse in origine, non a- 
vreble certo crealo tante miriadi di viventi, che non vi è spazio disponilile per l'uomo onde segnarne la cifra. Ne i primi hastar potrebbero a soddisfare pienamente i bisogni dell' ordine. Per lo contrario, le schiatte minori sono tanto più numerose, per quanto maggiormente nella mole decrescono, fino a soltrarsi alla nostra vista ordinaria, mentre che quasi colmano lo spazio. Or se siffatto inconcepibile numero di animaletti fosse vano e soverchio, avrebbe fatto opera vana Couvi che lor diede esistenza, fattezze, e ragione. Che se noi non giungiamo col nostro intelletto a comprendere gli alti disegni della creazione, soffermiamoci almeno a contemplare le forme e gli effetti, alimentando così l' intelletto.

24. Primo e piì importante di tulti egli è queslo, che per lo mezzo di lale reciprocanza di mole e di numero, à il supremo Architetto stabilito e mantiene eterno ed inalterabile l' equilibrio dell' Universo. Gli atomi impercetlibili tramezzano le immense sfere celesti, e ne rendono costante ed imperturbabile il moto. Microscopici viventi ingombrano le acque del mare, e per essi i fondi sollevansi, le acque traboccano, e mostruose e gigantesche balene ricerono il maggiore alimento.

25. Tulte le classi ànno un rappresentante gigantesco ed un pigmeo. Così fra i vertebrati, la classe dei mammali à la Balena nello estremo superiore, ed it Sorex etruscus nell' inferiore, essendo questo it 
pigmeo di tutta la classe. Nella classe de' rolatili l' $\boldsymbol{E}$ piornis segna lo estremo superiore, ed il Trochilus l'opposto ed inferiore. Il Boa è il gigante de' rettili, e la Salamandra Imperati Cos. il pigmeo; a queste quasi si associa lo Scincus pannonicus. Fra i pesci i due Xiphias segnano il massimo, ed il Branchiostoma il minimo. Scendendo la scala, tali estremi si notano negli ordini e non più fra le classi. Così nei crostacei il Palinurus locusta è la specie gigantesca, ed il genere $P$ ychnogonum è uno de' pigmei. La Migale avicularia e gli Acari gli estremi degli Aracnidi. E poi fra gli Entomati queste differenze si fanno avvertire nelle famiglie e finalmente nei generi.

26. Al modo stesso nelle diverse classi de' Molluschi troviamo il massimo ed il minimo; ma questi minimi molteplici e svariati abitano la profondità dei mari, e sfuggono alle indagini degli scrutatori della Natura. Per lo che, le nostre conoscenze si arrestano fra certi limiti, i quali non ci àn dato sì enormi differenze tra loro distanti, quanto quelle che si sono avvertite nelle classi superiori. Sicchè diresti che la legge di successione si arrestasse negli articolati senza farsi sentire nei Molluschi. Ma nò; il difetto è in noi, e non già nella natura. Essa à mantenute costanti le norme; noi abbiamo trascurato cercarle, oppure ci son venuli meno i mezzi da poterle scoprire.

27. I fatti che noi veniamo sponendo dimostrano, che anche nei molluschi conchigliferi, dalle gran- 
di specie si scende alle minime e microscopiche quasi in ciascun genere.

L'uomo che non vede al di lì de' suoi materiali bisogni è il solo che si fa lecito ripetere sovente il vieto cui bono; ma colui ch'eleva l'intelletto al di là delle cose visibili, trova di che alimentare il suo spirito tanto maggiormente, per quanto meno vede, sente, e palpeggia. Bastar potrebbe anche pe' primi il ricordar loro, che in natura tutto è connesso, e quindi non vi è atomo, non fibra, non aura che agitar si polesse, senza far sentire i suoi movimenti su quanto altro loro circonda. Che se tanto si avvera nelle grandi masse satto i nostri occhi, non diversamente procede nell' infinitamente piccolo ed invisibile. Anzi del moto molecolare e di sostanza imponderabili risultano i più grandi e strepitosi fenomeni della natura.

28. L' uomo fu creato da Dio per signoreggiare alle cose terrene. Quanto v’à di sensibile sopra la terra è proprio del suo dominio : e lo starsene freddo spettatore è degradante bassezza, siccome il non curare la esistenza di tutto ciò che immediatamente ai nostri sensi non cade è colpa gravissima. L'opera della creazione reputata fu sempre dagli uomini di alta intelligenza come il migliore soggetto delle loro contemplazioni. Dal meditare il sensibile si ascende all'invisibile e sovrumano; nè per altra via si pnò giungere a concepire la grandezza del Crea- 
tore, se non per la conoscenza delle sue creature. Rammentiamo in proposito il precetto di Salomone: ut in diebus juventutis et antequam mala adveniant tempora de Creatore nostro cogitemus. Nè vi è certo via più breve e sicura per rimontare alla contemplazione di quello immenso sapientissimo Io, da cui tutto deriva, ed al quale tutto ritorna, se non quella delle opere stesse da Lui create. E qual altro sapere infuse Iddio nella mente dell' uomo allorchè lo mise padrone dell'Eden?

Formatis igitur, Dominus Deus, de humo cunctis animantibus terrae, et universis volatilibus coeIi, adduxit ea ad Adam, ut videret, quid vocaret ea; omne enim, quod vocavit Adam animae vicentis, ipsum est nomen ejus.

Laonde non sarì mai ricordata a baslanza questa sentenza - Contemplatio Naturae praegustus est voluptatis coelestis, constans animi gaudium, perfectique ejus solatii initium, summusque felicitatis humanae apex; cum anima hujus particeps fuerit, et gravi quasi sopore excitala, in luce ambulat, sui ipsius obliviscens, in coelestis, ut ita dicam, terra, inque terrestricoelo, vitam degit.

Tali sono i principî che mi ànno costantemente guidato nella ricerca del vero: nè da altro interesse fui spinto giammai nell' intraprender fatiche, e nel renderne di pubblica ragione i risultati. Mettere a giorno le occulte e naturali riccheza del patrio 
suolo; incitare l'altrui amore per simili ricerche; coltivare lo spirito ed arricchir la mente di coloro che succedono; ecco lo spirito dal quale sono state inspirate le opere mie, e credo che vi tralucesse a bastanza. Ma la presente opericciuola, comunque tenuissima cosa, è perciò stesso la grande e più chiara manifestazione del mio pensiero.

L'opera viene in luce per Monografie generiche, accompagnate da tavole litografiche, 0 incise in rame, se così la natura de' soggetti richiede. Ciascuna Monografia sarà preceduta dalla storica esposizione del genere, se questo era già fondato; e se nuovo, verrà esposto analiticamente quanto concerne le convenienze, i rapporti, ed il nesso tra quanto si conosce e quel che succede. Nel quale sviluppo è mia mente far rilevare gli errori e gli equivoci ne' quali si è forse caduto, o quelli ne' quali cader si potrebbe, applicandoli al caso nostro: ed in ciò parmi consistere la filosolia della scienza. 


\section{CAPITOLO I.}

A NIMALI A R T I C OLA T I.

\section{MALACOSTRACI}

ORDINE DEGLI ARANEIFORMI

FAMIGITA DE'PICNOGONIDI.

E già decorso un secolo e più dacchè il sistematico naturalista svedese fondava il genere raLsNGio, per la sola specie a lui nota, quando scriveva la Fauna Suecica (1746). Era questa specie il Phalangium opilio sì comune in Europa; c lo comprese nella classe degl'Inselli senza ali o Atteri. Più tardi (1764), lo stesso immortale scrittore, nel suo Museo della $\boldsymbol{R}$. L. Ulrich, vi aggiunse il Phalangium caudatum delle Indie, ed il reniforme di America.

A queste tre specie linneane Stroemer associò altre duc, ad una delle quali diede nome di Phalangium littorale, ed all' altra di $P h$. marimum, comechè ricavate entrambe dal mare.

Al $\boldsymbol{P}$ h. littorale di Stroemer mutò il nome Fabricio, assegnandogli in vece l'addiellivo balaenarum, per essersi trovalo a vivere parassito sulle Balene: e Baster lo appellò perciò pure Pediculus Celi, inconsapevole forse di ciò che scritto se n'era dai suoi contemporanei. 
Nel 1764, mentre Linneo dava alla luce il Museo deLLa R. L. Ulnici, Brunnich, nelle sue tavole sistematicie di entomologia, stabiliva il genere Pychnogonum, per i due Falangi di Stroemer, distaccandoli dagli altri, tra quali impropriamente erano stati per lo innanzi inseriti : e Fabricio lo adottò nella sua Fatina groelandica, registrandovi le medesime specie, ma sotto lo specifico nome di grossipes e di litlorale (balaenarum), aggimgendovi una terza specie, che distinse con l'addiellivo spinosum.

Posteriormente il medesimo Fabricio fondò il genere Nymphum, rellificato indi in Nymphon, assumendo per tipo il suo Phalangium grossipes, ed associandovi l'hirtum (Entom. sistematica, 1794). Di là in poi, moltiplicate e sottoposte a migliore studio le specie, si crearono i generi Phoxichilus da Latreille, e Pallene da Leach; onde ne surse la Famiglia composta di cinque generi.

Tutti cotesti generi pertanto ondeggiarono per lungo tempo fra gl' Inselli succianti e gli Aracnidi; e sempre mescolati i terrestri con i marini, poichè non si ebbe per guida che la esterna forma ed il complesso delle parti di cui si compongono; senza metter cura all' importante diversità de' mezzi ne'quali vivono, ossia al diverso modo con cui la funzione della respirazione si compie. Ignoravasi prima, e non fu valutata di poi, la differenza essenziale di essa, riposta in ciò, che i primi respirano l'aria libera, ed i secondi ricavano l'ossigeno indirettamente dall' acqua. Ma quando l'oracolo della notomia comparata svelò questo doppio modo di respirare, e la differenza degli organi a questo uffizio dalla natura assegnati, i maLAcosrnaci vennero sottratti dalla classe degl' insetтI , perciocchè questi respirano per lo mezzo di trachee $\mathrm{e}$ quelli di branchie.

I Pienogonidi però, non appalesando nella loro ana- 
tomica composizione nè le une nè gli altri, chè, per la loro piccolezza e per i tegumenti duri del loro corpo, i mezzi che l'uomo possiede insufficienti riescono a poterli scoprire, furono registrati fra gli aracNIDI, tenendo in conto soltanto le analogie delle loro parti esterne, nella incertezza del modo come respirano.

Mentre degli aracidi si sa, che altri son forniti di trachee, altri di polmoni, e che perciò la loro respirazione è puramente aerea; i Picnogonidi per l'opposto, abitando abitualmente le acque, è da supporsi logicamente, o che provveduti fossero di branchie, o che la intera superficie del loro corpo ne compisse le funzioni: c perciò più convenevole è sembrato ai moderni classalori riporli fra i malacostraci, occupandone l' ultimo gradino.

Un tal confine pertanto trovasi naturalmente a contalto con la classe degli aracnidi per lo mezzo de' falangi, i quali, come è stato avvertito, tanto si somigliano ai picnogonid nelle loro esterne fattezze. Onde non a torto Linneo riguardò gli uni come gli altri di una stessa natura, e però congeneri. Molti ancora fra i dotti naturalisti teslè trapassati, come Lamark, Latreille, Savigny, Cuvier ed altri, ànno divisa la stessa opinione; lulli protestando però essere incerti su tale convenienza.

Nel 1838, pubblicando noi le due specie nostrali in allora di scoperte, e seguendo l'adotlato sistema di Cuvier, fummo costrelti fondare un nuovo genere, non trovando luogo da riporle in quelli già stabiliti : nè mancammo ancor dichiarare essere incerta la sede nella quale si riponevano questi viventi. Il nostro genere Fanodemo, di cui abbiamo due specie, ed un piloxiculus, erano in allora i soli rappresentanti deila famiglia de' Picnogonidi nella Fauna del regno.

Posteriormente (1840), il chiarissimo M. Edwards, 
faceva comparire la malacostracologia, come parte dellé Continuazioni di Buffon; nella quale opera, seguendo egli le orme tracciate da Johnston, distribuiva i Picnogonidi come segue:

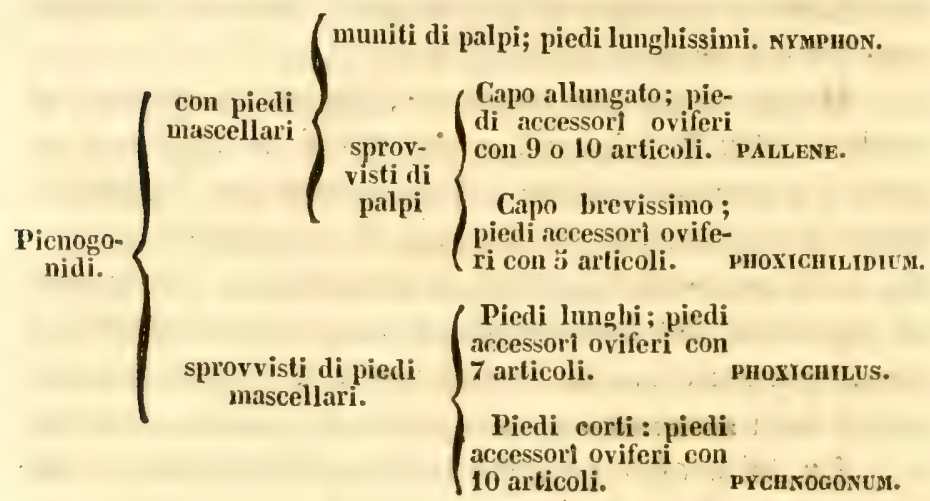

Malgrado l'oculatezza abiluale e la perizia di questo dotto zoologo non devesi occultare, che la distribuzione per lui elaborata si risente di qualche imperfezione: e ciò perchè talune delle specie tipiche non gli furono altrimenti note che per le descrizioni e figure de'predecessori ; nè sempre potè esaminare i due sessi di una medesima specie, onde assicurarsi del numero degli articoli de' piedi accessorî della femmina ${ }^{2}$. E qui ci permelterà l'illustre autore il notare, che questo carattere, mentre ci sembra di poco valore, mette ben di sovente in imbarazzo, sia per la mancanza della femmina, quando si avesse il solo maschio, sia per le anomalie, cui può esser soggello, ed il modo di contare gli articoli, chè il primo

- Cosi del Phoxichilidium non ebbe a sua disposizione che il'maschio; e sulla fede di Jonhston à registrata la femmina con 5 articoli ne' piedi accessorl oviferi; mentre che è questo il solo carattere su cui rijosa il genere, conyeuendo per ogni altro col Pallene, 
o basilare suol essere rudimentale, sia finalmente per mutilazioni non rare ad avvenire, spezialmente lorquando si è costretto svincolarli dalle uova che tengono strette fra loro.

Un' altra ambiguità occorre pur rilevare nello specchio sopraccennato, riposta nella presenza od assenza de'piedi mascellari e de'palpi. E dapprima noteremo, che quelle appendici, che vanno con tal nome designate, in molti casi, non potendone compiere l' uffizio, come vedremo nella descrizione delle specie, impropriamente si possono ritenere come piedi mascellari : e la loro assen$\mathrm{za}$, alternante ben spesso con quella de' palpi, mena in maggiore imbarazzo. Or di tali cose non essendosi occupati gli antichi nella loro disamina con quella stessa sottigliezza impiegata dai moderni, non avendone tenuto quindi gran conto nelle descrizioni, difficil cosa si rende il potere coordinare le specie, secondo i caratteri assunti per norma, senza riesaminare i soggetti in natura.

Poste le quali condizioni, non è strano se noi non possiamo rigorosamente riferire talune delle nostrali specie ai generi fin qui stabiliti, e registrarle convenevolmente nelto specchio riportato dall'Edwards; mentre siamo in lusinga di averle esaminate con quanta scrupolosita per noi si potesse, e col soccorso di non mediocri ollici stromenti. Che se altronde apportar si volesse la indispensabile riforma al proposto specchietto, sfuggir non potremmo noi stessi le medesime difficoltà incontrate dall' Edwards. Laonde, descrivendo le specie tratte dal Mediterraneo, con quella precisione che per noi si potrà, lasciamo al tempo ogni riforma del metodo; potendosi meglio ciò faro quando si avranno maggiori elementi e men dubbî.

Dieci sono tulte le spccie note fin qui della famiglia de' Picuogonidi, giusta la Monografia che n' esibisce l'Ed- 
wards, a cui erano ancora ignote le due nostrali specic del genere Fanodemo quando quello scriveva : sono esse ciò $=$

Nrmirnox, Leach -1 N. gracile. Delle coste dell'Oceano.

2 N. femoratum. Della Manica e della Norvegia.

3 N. carolinensis. Della Carolina del Nord.

4 . grossipes

$5 \mathrm{~N}$. hirtum

(Di patria indeterminata.

PALLENE,

Johnston - 6 P. Urevirostris. Della Seozia e della Groe landia.

7 P. chiragrus. Della Nuova Olanda.

phoxicnuluw, Johuston $-8 \mathrm{Pl}$. coccineum. Della Maniea e delle Isole britanniche.

pnoxicurcus, Latreille- 9 Ph. spinosus. Delle coste della Bretagna. (Ph.aculeatus. Giver. Icon. del regno animale.)

PYCINOGONUM,

-10 Pyc. litlorale. Parassito de' pesci e delle Ascidie.

Da questa enumerazione emerge, che niuna specie sia stata conosciuta come propria del Mediterraneo, o con questo mare comune, ad eccezione del Pychnogonum littorale, il quale ben s'intende potersi trovare ovunque siano Pesci ed Áscidie. Nondimeno, oltre le due specie del genere Fanodemo, e l'altra del genere Phoxichilus, il nostro Mediterraneo ne alberga più altre finora sconosciutc, e talune delle già note. E con ciò resta ancor per questa parte comprovato, che molte privative svaniscono quando meglio saranno ricercate, e più estesamente, le altre località, o fugacemente e per un solo visitate, o del tulto rimaste sconosciute, come in altro luogo si è delto. Non tulte però entrar potrebbero nella Fauna del regno, stando rigorosamente ai termini di una Fauna locale. Quelle rinvenute nei fondi coralligeni delle coste settentrionali dell' Affrica, ed in quelli dell' Isola di Sardegna appartengono al Mediterraneo in sencrale; c quindi me- 
ritamente debbono far parte della sua Microdoride. Gli altri, che per ora abbiamo come esclusivi delle coste del regno, sono già riportati nella propria Fauna.

$\mathrm{Ci}$ sarebbe piaciuto, e forse avremmo incontrato lo assentimento di molti, riunire tutte insieme le specie, ravvicinandole in guisa da far rilevare immediatamente tutte le differenti combinazioni, e le modificazioni de' piedi mascellari e de' palpi, tanto per la loro struttura, quanto per la loro inserzione e grandezza. Ma in tal caso, o avremmo dovuto sottrarre dalla Fauna del regno quelle specie che le appartengono, lasciandovi così una lacuna, o avremmo dovuto ripeterne qui la descrizione e le immagini. A conciliare questi due opposti pensieri riferiremo qui le cose, che a rigore non possono far parte della Fauna locale; e delle altre che spettano a questa daremo una breve notizia, talchè basti a farne discernere le specie: il resto potrà consultarsi nella Fauna del regno di Napoli, che oramai è troppo diffusa.

\section{Genere Ruinchothonax , Cos.}

$$
\text { Tav. 1, fig. } 1 \text { e } 2 .
$$

Capo ovato-oblungo, con l'estremità anteriore biloba (fig. 1, A).

Piedi mascellari (fig. C.) lunghi tanto da oltrepassare un poco la estremita del capo; composti di 4 articoli, il primo de'quali breve ed un poco tumido, il secondo più lungo di tulli e cilindraceo, il terzo brevissimo ed ovolare, il quarto alquanto più lungo del precedente, c terminato da delicala forcipola: sono essi inseriti nella inferior parte e ne' lati del capo.

Palpi (fig. D.) più lunghi c più gracili de picdi ma- 
scellari, composti di 8 articoli, i qualtro ultimi de' quali brevissimi, e guerniti di una forte spina dal lato interno; l'estremo avente una delicata unghietta.

Primo anello toracico prolungato in un rostro acuto (fig. 2, A), che libero si protende sul capo, di cui oltrepassa l' estremità; angoloso alla base, spinoso ne' lati, e scabro nella superficie, come tutta quella degli altri segmenti del corpo.

Occhi posti alla base del rostro.

Addome angusto e brevissimo, di 7 articoli.

Osservazioni. Dagli esposti caratteri risulta, che avendo questo nostro Pienogonide piedi mascellari guernili di palpi, entrar dovrebbe nel genere Nymphon. Ma a ciò si oppongono eminentemente tutti gli altri caratteri assegnati a questo genere, oltre l'abito intero che ne to allontana di troppo. La forma del capo, gli articoli del torace, la forma e composizione dell addome, e la proporzione de'piedi veri, sono tulti in opposizione con quelJi de' Nymphon. Per tutte coteste cose potreble accostarsi al Fossichilo ed al Pallene; ma del primo non à il picciol capo, mentre è provvisto di piedi mascellari; e la presenza de' palpi lo separa dal secondo. Infine l' addome non è qui un semplice lubo, che in forma di appendice atlaceasi sopra l'ultimo segmento del corpo, ma è organizzato come quello degli Ancaeus.

\section{Rilynchothonax meditentaneus, Cos.}

I quattro segmenti del corpo, più larghi che lunghi c ben saldali tra loro, costituiscono insieme uno scudo ellissoideo, compiendone la figura il capo, nel mezzo correndovi una larga e ben rilevata carena. Sul primo ed anteriore articolo è impiantato il rostro, dalla superior 
parle; c dalla parte inferiore, tra questo ed il capo, nei lati, stanno inseriti i piedi mascellari e i palpi. Agli altri 4. articoli si annetlono i piedi veri, il doppio più lunghi della Junghezza del corpo, quasimente uguali tra loro, e tulti composti di 7 articoli, con una unghielta terminale; l'ultimo e posteriore segmento è semicircolare, ed alla sua posterior parte, tra mezzo ai piedi, si attacca l' addomen Questo è poco men lungo di due segmenti toracici, ma molto angusto, depresso, composto di 7 articoli, che nei lati si terminano in un acume diretto alla parte posteriore, onde apparisce fatto a modo di sega; l'ultimo de'7 articoli è tridentato nel margine posteriore, tumido superiormente o quasi emisferico ( fig. $1, \boldsymbol{B}$.), semplice dalla parte inferiore (fig. $2, \boldsymbol{B}$.). Tutta la superficie del corpo, addome e piedi compresi, è scabra per minutissime punte elevate, come d'ispidi e corti peli ; così pure gli articoli de'palpi e de'piedi mascellari.

Lunghezza del corpo, capo ed addome compreso $=1,6$ mill.

Abita le coste seltentrionali dell'Affrica, sulle rocce coralligene, tra fuchi, vermeti, e serpole - Trovasi nella collezione speciale della Microdoride, nel mio Museo. II solo maschio.

Genere Platychelus, Cos.

Tav. I A, fig. 1.

Capo quasi conico, rigonfiato verso la base.

Piedi mascellari brevissimi, forcipati, inseriti nella superior parte del capo, tra questo ed il primo ancllo toracico; ove direbbesi il collo.

Palpi lunghi quanto il capo, composti di 3 articoli. 
Occhi inseriti ne' lati di un prolungamento rostriforme del primo anello toracico, disteso sul capo, e fianclieggiato dai piedi mascellari, coi quali si adequa in lunghezza.

Torace costituito da quattro segmenti poco distinti, massimamente $\mathrm{i}$ due posteriori.

Addome allungato, cilindraceo, con oscuri segni di segmentazione.

Osservazioni. Ritenendo i soli due primi caratteri, sopra de'quali l'Edwards stabilisce le sue generiche divisioni, questo altro Picnogonide esser dovrebbe considerato come congenere del precedente. Tuttavia i piedi mascellari ed i palpi sono in perfetto antagonismo con la loro deputazione genericamente considerata. Primieramente i piedi mascellari, inseriti, come si è detto, sulla nuca del collo, non raggiungono l'apertura boccale : e però esser non possono organi destinati a prendere gli alimenti. I palpi ancor essi, seguendo la posizione de piedi mascellari, si trovano dalla faccia suprema, beschè lateralmente al capo. Gli occhi finalmente, in luogo di essere inseriti sopra un tubercolo eretto, stanno ne' lati di quella specie di rostro a punta acuta, e sono al numero di due, e non di 4, quanti d'ordinario se ne vogliono far esistcre in tutte le specie della intera famiglia. Non è da tacersi però, che presso gli angoli laterali del primo segmento toracico si trova una macchia nera, la quale potrebbe esser anche un occhio; ma mentre di ciò non siamo certi, sarebbe ancora un fatto singolare, proprio per altro alla massima parte de' Malacostraci, spezialmente de' decapodi. 
Peatychelus sardonicus, Cos.

Capo piriforme, lungo più de' quattro articoli toracici presi insieme, ed anche di questi più largo, nella sua estremità aprendosi la bocca; c questa munita di un lobo mediano, quasi labbro superiore; un solco delicatissimo corre da questo per tutta la lunghezza del capo nel mezzo. Nella sua parte suprema e posteriore sono inseriti i piedi mascellari, piatti, non articolati, con un dito mobile alla parte esteriore, come le chele o tanaglie del Porcellana.

Dai lati de' piedi mascellari sorgono i palpi, lunghi quanto il capo stesso, sicchẻ la loro estremità giunge a toccare precisamente l' apertura boccale. Essi sono composti di 4 articoli poco diversi tra loro in lunghezza e grossezza, decresceudo verso la estremità, terminata da una papilla pelacciuta. Tra mezzo ai due piedi mascellari trovasi un prolungamento in forma di rostro, ancor esso stiacciato, terminato anteriormente da punta acuta, a lati paralleli; ove comincia a restringersi per formare l'acume sono inseriti i due occhi (fig. A.). Il primo anello toracico è lungo e largo ugualmente; il secondo e terzo, saldati intimamente fra loro, adeguano il primo; il quarto è angustissimo, e si prolunga postcrịormente, per dare altacco all'addome, che appena lo supera in larghezza e nella lunghezza. Questo è quasi cilindraceo, apparentemente di un sol pezzo, con un articolo terminale molto. più stretto e brevissimo.

I piedi veri sono lunghi per modo che gli anteriori superano di una metà la lunghezza del corpo, capo ed addome compresi ; ed i due posteriori l'oltrepassano appena, essendo tutti cosi gradatamente decrescenti. Si compongono di 8 articoli, ed una unghiella terminale. Tulti scabri e rivestiti d'ispidi peli. 
Lunghezza del corpo, dalla estremita del rostro a quella dell' addome $=$ un millimetro.

Lunghezza de' piedi, come essi si trovano $=4$ millimetri ( nella figura si trovano un poco più corti di quello che realmente in proporzione sono).

Unico esemplare maschio, ottenuto dai fondi coralligeni dell' Isola di Sardegna.

\section{Genere Alcinous 1, Cos.}

Tav. II, fig. 1 e 2.

Capo grosso, ovato allungato.

Piedi mascellari inseriti nella superiore e posterior parte di esso, terminati da un piccolissimo articolo pelacciuto.

Palpi lunghi alquanto più del capo, inseriti ai lati de' piedi mascellari, e composti di 8 articoli. toracico.

Occhi posti sopra una prominenza del primo ancllo

Piedi accessori oviferi di 8 articoli.

Osservaziom. Quando le divisioni generiche dovessero regolarsi dalla sol a presenza de' piedi mascellari e de'palpi, anche questo altro Picnogonide entrar dovrebbe coi precedenti nel genere $N y m p h o n$. Ma se i due primi si scostano da quello, per le cose già rilevalé; questo massimamente se ne dilunga, per la forma del sto torace, la quale lo distacca eziandio dai generi di sopra descritti Rhynchothorax e Platychelus. E volendo tenere in conto it numero degli articoli, di cui si compongono i palpi, accostasi più al genere Pallene, senza poterne far parte, sia per non essere porfellamente lo stesso il numero degli ar-

Alcinoo Re della Feacia, nell'Isola di Corcira, oggi Corfủ. 
ticoli, sia per la grandezza del capo, e massimamente poi per esser munito di palpi.

Qui entrar dobbiamo ora in quella discussione importante relativa ai piedi mascellari. Se fin qui la loro struttura autorizzava a riguardar questi organi come addetti a prendere gli alimenti, e porgerli all' apertura boccale, od agevolarne lo avvicinamento, quantunque nel genere Platychelus a questa funzione fossero disadatti, per la posizione loro e per la brevita; nel genere presente mancano per fino di tale struttura da potersi considerare come organi deputati all' uffizio di prendimento. Non è dunque che per analogia che si considerano come piedi nascellari, senza poterne compiere l'ufficio. La natura di fatti sa dispensarsene fino a farne mancare del tutto i rappresentanti, siccome ciò avviene ne' generi Phoxichilus e Pychnogonum. Similmente, migliorando poscia la condizione de' piedi mascellari, siccome trovasi ne' generi Pallene e Phoxichilidium, dismelle del tutto la presenza de' palpi. In tal guisa piacesi di variare alternando tino a distruggere. Da tali fatti, d'inperscrutabile significato , risulta la grandissima difficolta di ben ordinare le generiche divisioni, come quelle delle famiglie e degli ordini; chè la natura nelle sue moltiplici variazioni non ha confini. E questo è ciò che dimostrar voleva Buffon contra Linneo.

1. Alcynous vulgaris, Cos.

Tav. I A, fig. 1.

Il capo è lungo più de' quattro anelli toracici insieme presi. Dalla sua posterior parte, tra esso ed il primo anelto toracico, partono i piedi mascellari? parallelamente distesi sopra di esso, e men lunghi della sua metà. Essi 
però constano di 3 soli articoli; il primo basilare dritto, lungo, cilindrico, dilatato e quasi clavato, e terminato da una lunga spina laterale; il secondo è ovale, brevissimo; il terzo è minutissimo, quasi fosse una semplice papilla ( fig. $C$ ). Ai lati del capo sono inseriti i palpi, alquanto più lunghi del capo, composti di 7 articoli; $i$ due primi quasi ugualmente lunghi, gli altri cinque brevissimi, ed uguali fra loro, eccetto l'ultimo ch'è men grosso degli altri ( fig. $D$ ).

Due altri occhi sono sopra i lati del primo segmento toracico.

Larghezza, co'piedi come si trovano distesi, 6 mill. Lunghezza del corpo $=2,4$ millim.

2. Alcinous megacephalus, Cos. Tav. II, fig. 1, 3, 4, 5 .

Il capo, probosidato, è lungo più de' segmenti toracici presi insieme, di figura ovato-allungata, terminato dall'apertura orale.

Piedi accessorî composti di 9 articoli, de'quali i primi cinque gradatamente crescenti in lunghezza, ed inversamente decrescenti in grossezza; $\mathrm{i}$ qualtro ultimi assai corti e quasi uguali fra loro.

Occhi posti sopra una prominenza di figura esagona ( fig. 3 ), estuberante presso il margine anteriore del primo segmento toracico, ch'è pur esso stesso alquanto rilevato, e terminato in punta acuta, tanto nel mezzo che nei lati, similmente che i rimanenti.

Piedi mascellari meno lunghi della metà del capo, composti di 3 articoli cilindracei, i due primi quasi uguali fra loro, ed il terzo brevissimo, troncato obbliquamente dal lato esterno, ed armato di minuta unghielta articolata da questo medesimo lato. 
Palpi lunghi tanto da oltrepassare la estremità del capo, composti di 9 articoli ; il primo o basilare de'quali brevissimo e gracile; il $2^{0}$ maggiore di tutti, cilindraceo, alquanto tumido nella sua parte anteriore; i successivi tre quasi uguali; e gli altri sensibilmente decrescenti; l'ultimo armato da unghielta ben distinta, archeggiata ed aguzza.

Piedi veri lunghi tre volte quanto il torace, composti di 8 articoli ; i tre primi brevissimi, quasi uguali tra loro, ed inversamente conici; gli altri crescenti gradatamente in lunghezza, e quasi uguali in grossezza; l' ultimo delicato, falciforme, ed armato di valida unghietta, con due appendici filiformi, ed una spina brevissima allo esterno (fig. 4).

Torace di 4 segmenti, riuniti e saldati tra loro in guisa, che rimangono appena due tracce delicatissime delle loro divisioni nel solo mezzo, sicchè meglio direbbesi composto di tre soli segmenti, il medio de' quali angustissimo; il suo perimetro si termina con 10 angoli aculi, sporgenti a modo di spina, uno cioè antcriore sul capo, qualtro da ciascun lato, interposti ai piedi veri, ed un altro posteriore e mediano, che prolungasi a modo di coda, lunga alquanto meno del torace stesso.

La femmina porta le uova sul dorso, ossia sul torace. Trovasi frequente nel golfo di Napoli, fra le radici della Zosiera e della Posidonia.

Nella Tav I, A, fig. 2, vien rappresentata una mostruosità di questa specie, nella quale il capo è tumido , irregolarmente estuberante, ed irsuto.

Il tubercolo addominale è rilevato obbliquamente.

In esso la lunghezza del corpo, tutto compreso $=$ 2 1/2 millimetri.

Larghezza, coi piedi come si trovano distesi $=7 \mathrm{mill}$. 


\section{SPIEGAZIONE DELLE TAVOLE.}

TAv. I, Fig. 1. Rhynchothorax Mediterraneus, ingrandito al microscopio.

$\boldsymbol{A}$, estremità anteriore del capo, con le due unghie. de' sottoposti piedi mascellari.

$\boldsymbol{R}$, l'addome dalla parte superiore.

D, uno de'suoi palpi.

$\boldsymbol{C}$, uno de'suoi piedi mascellari.

Fig. 2, lo stesso veduto dalla inferior parte.

$\boldsymbol{A}$, il rostro maggiormente ingrandito.

$\boldsymbol{B}$, l'addome veduto dalla parte inferiore.

TAv. I A, Fig. 1, Alcinous vulgaris, ingrandito.

$\boldsymbol{A}$, tubercolo oculifero con le due forcipole, o piedi mascellari.

$C$, uno de' suoi piedi mascellari.

Fig. 2. Mostruosità dell' Alcinous megacophalus.

$\boldsymbol{A}$, il capo veduto dalla inferior parte.

$\boldsymbol{B}$, lo stesso veduto di lato.

$C$, piede mascellare ingrandito.

$D$, uno de'palpi laterali.

$\boldsymbol{E}$, piede accessorio della femmina, composto di 8 art.

TAv. II. Fig. 1. Alcinous megacephalus, ingrandito; veduto dalla superior parte.

3 , tubercolo oculifero del medesimo.

4, estremità de' piedi, con la propria unghietta.

5 , uno de' suoi palpi.

Fig. 2, Varietà del medesimo, veduta dalla inferior parte. 


\section{ANELUIDI}

Nella Fauna del regno di Napoli, al corrispondente articolo si è premessa una compendiata notizia intorno allo stato progressivo della scienza relativamente agli Anellidi : e noi rimandiamo i lettori a quel luogo, ove fos. sero vaghi conoscere l'importanza di 'ogni altra specialità che alle già note cose congiungesi. Quì ci limiteremo perciò ad esibire la descrizione di due specie dell' ordine degli errantr; e di talune spoglie calcari spettanti a quello dei SEDENTARî o tuBicol, intorno ai quali occorre premettere alcune osservazioni, come faremo a suo luogo. Tutto però è limitato a specialità minutissime, se non microscopiche, giusta i limiti prescritti per questo lavoro.

\section{ORDINE DEGLI ERRANTI}

\section{IAGIGIIA DE' NERIDXI.}

Genere Monocerina, Cos.

CApo grosso,; occhi apparenti (2-2). Una sola antenna grossa, lunga e dritla, inserita superiormente, fra i due lobi cefalici. Palpi della medesima struttura. Conpo composto di molti anelli tulti simili. PIEDI con un lungo cirro addominale. Setole di due sorta.

monocerina diaphana, Cos.

Tav. IV.

Corpo composto di 60 anelli, quasi di ugual larghezza, cccctlo gli ultimi 4 codali, che sensibilmente restrin- 
gonsi. Il capo è corto, anteriormente terminato in duc lobi, da mezzo ai quali e dalla posterior parte spicca una antenna, lunga, dritta, grossa, composta di 10 articoli, tutti uguali, e simile nell' organamento interno a quello de' palpi e de' cirri ; l'articolo estremo quasi ovale ed un poco più grosso degli altri ; il primo o basilare cilindraceo e più lungo.

I quattro palpi inferiori composti similmente di articoli, come i precedenti. La loro origine ed inserzione indiscernibile, ma i due primi oltrepassano appena in lunghezza i lobi cefalici; i due secondi, o posteriori li sorpassano di più. Siccome essi nascono dalla inferior parle, e l'esser tulto diafano non lascia ben distinguere la loro inserzione; così di essi non può vedersi che la parte sporgente fuori del corpo : quindi gli anteriori ci lasciano contare 12 articoli, ed i posteriori 18.

In ciascuno anello vi è un cirro ventrale simile, come si è delto, in quanto a struttura, all' antenna ed ai palpi, ma decrescenti gradatamente in lunghezza dal primo all'ultimo; sicchè nel primo e ne' sei succéssivi si contano 11 articoli; nell'ottaro 10 , e nell' ultimo 6 solamente; ma questi alquanto pì̀ grossi; l'articolo ultimo e terminale à figura ovata, alquanto appuntita allo estremo; gli articoli sono vesicolosi.

Dalla parte dorsale a ciascun cirro corrisponde un lobo brevissimo, dentro del quale un fascetto di setole, delle quali si contano sei per ciascuno degli anteriori fin dove giunge il pacco de'visceri gastrici, o fino all' undecimo pajo inclusivo. In ciascuno degli altri vi sono due setole forcute in cima, fig. 5 , più grosse e più corte delle precedenti. L'ultimo articolo à due lunghe appendici, simili ai cirri, ma più lunghe degli ultimi di questi.

Quattr' occhi, de'quali due più piccoli presso la con- 
giunzione de' lobi cefalici col primo articolo, e due maggiori sul margine anteriore del medesimo primo articolo, anche un poco più distanti tra loro che i precedenti.

Questo primo articolo, che direbbesi toraco-cefalico sembra quasi suddiviso per una linea trasversale poco sensibile; e dalla inferior parte di questa partono i due primi ed anteriori palpi; dalla cui metà posteriore sorge il primo pajo di cirri, ed il lobo dorsale col suo fascelto di setole. Il secondo articolo presta l' attacco al secondo pajo di palpi dalla inferior parte; e dalla laterale sorge il cirro; dalla parte dorsale il corrispondente lobo col fascetto di sctole, come all' ordinario.

\section{PARTI INTERNE.}

Internamente dal medesimo primo segmento comincia ad apparire il canale degli alimenti, il quale si estende fino all' undecimo inclusivo. Questo cunale è cilindraceo, alquanto più ristretto nella posterior parte fino al termine del $7^{\circ}$ articolo. Quivi s'immerge in un grosso e cilindracea gomitolo, triplo in diametro ed occupante ire interi arícoli $(8,9,10)$, più una porzione brevissima dell'articolo sticecssive, ove si arresta bruscamente, come se fosse tronzato. Da çuesto punto non ò potato scorgervi alcuna continuazicne, nè di canale alimentizio, nè di vasi circolatorî; ma solo un tessuto cellulare uniforme, diafano, e scoloratc, come la figura lo rappreserta. $\mathbf{E}$ quì soggiungerò che l'animaie è stato per me osservato in piena vita, poscia morio, ma tultora nell'acqua marina, e finalmente disseccato sopra vetro. Nitina differenza ho potuio scorgere nel stio interno organismo in alcuno di questi tre stati.

Sul cominciamento del canale alimentare trovasi la 
rescichetta del cuore; la quale à figura ovale, anteriormente terminata da una specie di collo da una parte, e dall' altra da un tronco-vascolare, che si ramifica ben tosto, dando vasellini per due branche a tutta la parte anteriore cefalica. Un grosso vaso forma un anello, che sembra circondare l'apertura esofagea; e dai lati di questo scendono due canali a sangue fosco o livido, che fiancheggiano, il canale degli alimenti. Questi due canali sanguigni, immersi insieme al tubo alimentare medesimo nel gomitolo gastrico, scompariscono affatto ancor essi.

Il gomitolo di cui si è discorso rassomiglia a quello che in pari modo si trova nelle Difie e nelle Salpe.

I fascetti di setole sono tanto contratti, che giungono proprio nel mezzo del corpo, sporgendo appena allo esterno; e molti sono interamente occultati allo interno, mostrandone appena qualche punta in mezzo al lobo. Se l'animale li distendesse più di quello che in taluno de' fascetti si mostra, e come noi gli abbiamo tutti rappresentati, non sapremmo affermarlo, nè contrastarlo.

La lunghezza reale dell'animale uguaglia un centimetro, e la sua maggiore larghezza, eccetto i cirri, quattro decimi di millimetro.

L' insieme dell' animale ingrandito, qual si vede nella fig. 1, mostra falso lo aver detto, che la larghezza si mantiene quasi la stessa per tutta la lunghezza del corpo, tranne gli ultimi 6 o 7 anelli codali, che bruscamente restringonsi. Ma quest' apparenza risulta dallo abbreviamento de' cirri ventrali, i quali, colla piccola reale differenza di larghezza degli anelli, rendono insiememente molto più sensibile allo sguardo la diversità graduata di larghezza. 
Il cuore consiste in una vescichetta di forma ovale, anteriormente terminata in due colli o prolungamenti vascolari. Uno di essi, ed è il destro, è più largo, e proprio fatto a modo di collo d' una bottiglia, o di un matraccio a collo stretto; siccome il canale nel quale deve prolungarsi è vuoto, così sembra esso interrotto. Da ciò pure scmbra potersi conchiudere, ch' esso spetta alla vena cava. L'altro si ramifica dapprima in due grossi tronchi, i quali biforcandosi tosto, col maggiore, formano un circolo che abbraccia l'esofago, il minore si protende innanzi.

Osservazione. Niente più naturale quanto il sospettare, che questo minutissimo Anellide fosse il primo stato di specie di maggior dimensione. Tale lo fa supporre la mollezza e trasparenza di tutto il suo corpo. Niun genere però di quelli noti finora fra questi viventi ci porge una simigliante composizione di parti esterne, e spezialmente quel cirro mediano cefalico, omogeneo ai laterali . Potrebbesi ancor sospettare, che tali cose si mutassero nel completo sviluppo dell' animale. Ove ciò si avverasse, alJorchẻ sarà conosciuto colesto stato perfetto, noi avremmo offerto alla scienza un fatto, che concerne a renderne completa la naturale sua storia.

\section{Genere Cinemonotus, Cos. 1}

Capo piccolo el inerme. Branciue a modo di cirri sporgenti dalla parte anteriore ed inferiore de piedi. PIEpi con un solo ramo di setole. Un fascetto di aculei adunchi a modo di chele sull'ottavo segmento del corpo.

Da Xsıpos, manus; e voros, dorsum: 
CHERoñtus IIEXadactYlus, Cos.

Tav. III. fig. 1.

Corpo cilindracco, depresso, composto di 30 anelli quasi uguali, la cui superior parte è quasi cornea, più clevata nel mezzo, e declive ne'lati.

Il capo è piccolo, ed estensivo, chè l'animale lo ritira e nasconde quasi per intero nel primo anello; la bocca si apre anteriormente, avendo una brevissima proboscide incrme. Niuna sorta di appendice sul capo.

I primi otto anelli o segmenti del corpo costituiscono una spezic di torace, il cui ottavo ancllo posteriore, più Jargo degli anteriori, ed anche un poco più lungo, porta sul dorso, da ciascun lato, un fascio di aculei grossi, adunchi in cima, alquanto più grossi nel mezzo ed un poco inarcati, con l'estremo radicale un poco bifido e bulboso; sono essi di color succineo, e trasparenti. Questi aculei sono riuniti a ventaglio, e l'insieme loro paragonar non si può che alle ali di uno Pleroforo, per disposizione e figura. Da mezzo a questi aculei partono alcune appendici molli, forse anche membranose, bianche, trasparentissime, di figura per lo più lanceolata, un poco variabile; e la prima, o anteriore di esse è filiforme, incurvata c terminata con una dilatazione inversamente conica. Queste appendici sorgono dagl' intervalli degli aculei, e dalla loro parte inferiore risguardante il corpo. L'animale irritato vibra quei grossi aculei come fan l'Istrice e le Afrodite; della qual cosa mi sono accorto mentre tenevalo in osservazione sotto al microscopio, quando istäntaneamente uno ne scacciava, ed il maggiore, spingendolo al di lì del corpo per entro all' elemento nativo nel quale giaceva.

I segmenti che succedono all'ottavo sono alquanto 
più stretti dapprima, e mano a mano si vanno dilatando fino a pareggiare gli anteriori; indi si dilatano ancor più nella posterior parte, sicchè ben potrebbe dirsi essere in tre regioni divise, l'anteriore o toracica, terminata da quell' armatura a guisa di alette; la media, o dorsale; e la estrema posteriore 0 addominale, la quale è la più dilatata, molle, e facile a distaccarsi dal corpo, o dalla parte media.

Tutti i segmenti sono muniti di piedi, ma questi non tutti uguali. Nei primi, o anteriori sono più corti, ne' posteriori più lunghi, gradatamente crescenti. Tutti portano un fascetto di setole semplici, curve, acutissime; ma di

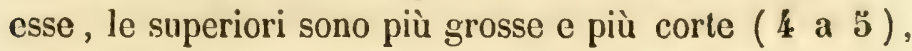
le inferiori delicatissime, molto più lunghe, e più incurvate ( da 4 a 6 ); le prime un poco colorate di gialliccio, le seconde bianche, nitide e trasparenti.

Alla base di ciascun piede, e dalla parte anteriore vi è un lobo vescicoloso; e da questo sorge un cirro branchiale; quello de' primi piedi anteriori è corto, uscendo appena fuori del contorno del proprio segmento; quello dell' ultimo, ai lati della coda, più lungo; e gl' intermedi gradatamente crescenti.

L'ultimo segmento codale è largo, e terminato nella sua posterior parte con un prolungamento breve ma bilobo, senza appendici di sorta.

Il colore è generalmente di arancia ; tale essendo pur quello dell' interna sostanza de' visceri e dei fluidi, che traspariscono a traverso di un derme fatto a squame. Un tal colore nei lati va cancellandosi, essendo questi più delicati, e l'orlo esterno trasparente. Sull' anterior parte e nel mezzo del primo segmento vi è una macchia nera; forse gruppo di occhi.

Lunghezza totale 0,001 -larghezza $0,001 / 2$. 


\section{SPIEGAZIONE DELLA TAVOLA III.}

La figura prima rappresenta l'animale ingrandito.

La fig. 2 rappresenta l' ottavo segmento, maggiormente ingrandito, con la sua armatura dorsale e le sue appendici; la struttura del derme, e le ramificazioni vascolari.

La fig. 3 è quella dell' aculeo maggiore vibrato, c quindi isolato.

La fig. L è di uno de'piedi, col suo lobo, il cirro branchiale, ed il fascetto di setole dolle due sorta. 
OR D INE DE' SEDENTARI.

TuBxcorx.

Pria che l'Adanson si fosse avveduto non esser lo stesso l'animale ospitante in tulti quei tubi calcari marini, vermiformi, dritti, od in varie guise attorcigliati o contorti, lisci, nodosi, od ornati di creste, di espansioni, lacinic, ed altre tali appendici ; tutti cotesti tubi furono considerati della stessa natura dai naturalisti che lo precedettero; ed il loro nome appellativo da tempo in tempo vedesi mutato a seconda de' diversi scrittori.

L'Aldrovando non diede loro altro nome che quello semplicissimo e naturale di Tuboli, registrandoli fra $\mathrm{i}$ suoi animali esangui ${ }^{1}$ : e con lo stesso nome li ritenne Bonanni ${ }^{2}$, e Klein ${ }^{3}$.

Jonston gli appellò Serpole, mercecchè i più sono contorti a modo di serpentelli; ed avendo riguardo all'animale loro abitatore e costruttore insieme, ben si avvisava dicendogli animali fatti a modo di pennello ${ }^{4}$. Come tali furono indi considerati e denominati da tutti $\mathrm{i}$ naturalisti francesi fino a Lamarck, cioè Pinceau de $\mathrm{mer}$. Nè mancò chi considerati gli avesse come spoglie analoghe a quelle di certi cost detti multivalvi.

Lister vide in taluno la forma di un pene, e li denominò tulti Phallus testaceus.

Tubuli alii in quibus vermes delilescunt : 1. c. pag. 561 .

2 Tubuli vermiculares saxis adhaerentes caeterarumque ostrearum testis adnati. ut serpentes sine reyula, et innumeris pene modis circumflexi, ut plurimum soli, figura rotunda et laevigata. Recreat. pag. 92, Clas. I, n. 20, A. $D$.

3 Penicillus - Exang. Tab. 17.

4 Penicilla, Carolo Langiò, Methodus testaceorum ecc. 
Linneo, nella sua Fauna Suecica, confuse alcuni di cotesti tubi con quelli del genere Dentalium; sicchè la sua Serpula lumbricalis del Systema Naturae, trovasi colà registrata con questo nome: Dentalium testa cylindrica inaequali, flexuosa, contorta. I. c. pag. 380 , n. 1328 ? (sic in Adanson). Nel Systema Naturae poi considerò tutti cotesti tubi quali Serpole.

Adanson, come da principio fu detto, avvedutosi che altri di tali tubi sono abitati da un animale, avente nell'anterior parte le branchie distese ed in fascetto, simile a pennello, siccome erano stati per lo innanzi e per molti visti e ben definiti : ed altri al contrario rassomiglianti all' animale delle lumache (ad un gasteropede cioè); diede all animale ed al suo guscio il nome di Vermetus, da Vermet, come gli abitanti del Senegal gli appellano ${ }^{1}$.

Persuaso Lamarck che l'animale del Vermet di Adanson sia un Mollusco, sebbene non identico a quello delle lumache; ne costitui il suo genere Vermetus, così definito:

Testa temuis, tubulosa, laxe spirata, spira per apicom adhaerente. Apertura orbicularis; marginibus comexis. Operculum.

La quale definizione, essendo stata tratla dall'unica specie ch' egli per tale riconosceva ${ }^{2}$, non può ora ritenersi, perchè non abbraccia tutte le altre specie congeneri per l' animale costruttore di lali spoglie. Di ciò sarà delto in seguito.

Posteriormente però, vista la giusta separazione fatta da questo dotto naturalista francese, essendosi posta mente all' organismo dell' animale, in vece di arrestarsi

Senegal, pag. 160, Tab. II, fig. 1. Paris, 17:77 ( un secolo dietro appunto). Histoire Naturelle du Senegal.

$\checkmark$ Vermetus lumbricalis. 
alla sola forma apparente delle sue spoglie, le Serpole linneane sono state meglio esaminate; ed altre si sono lasciate nella classe propria degli Anellidi, altre si sono riposte fra' molluschi; ritenendo i generici nomi di Serpole per i primi, e di Vermeti per i secondi.

E però notava il sullodato e giudizioso Lamarck , che Daudin descritto aveva altre sei specie solto la generica denominazione di Vermelus; ma ch'egli non acconsentiva punto che tali fossero tutti. Perchè, dic egli, in luogo di essere altaccati per la estremità spirale, come il Vermeto, lo sono lateralmente, e rampicanti, sia sopra le pietre, sia sopra valvole di pettini, di ostriche ecc. Questa sola condizione però non è bastevole per assodare il concolto del dotto uomo. Il carattere fendamentale riposa sopra l'organismo del vivente, non sopra le forme della spoglia, o nei costumi.

Egli pertanto creava il genere Vermilia, per comprendervi talune altre specie del genere Serpula di Linneo, riponendole nella classe degli anellidi. Vol. V. pagy. 368 ; descrivendone egli stesso altre due come nuove.

Serpula triquetra Linn. - Vermilia triquetra Linck.

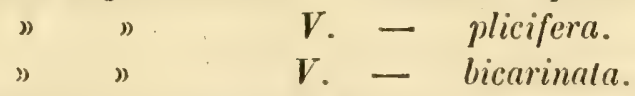

Conservò poi nel gencre Serpola le seguenti specie: Serpula vermicularis;

- glomerala; riconosciuta per un Verineto, come la seguente specic.

- contortoplicala; idem.

- filograna.

- echinata.

La differenza essenziale fra questi tre generi, Vermelus, Vermilia e Serpula, è riposta in ciò, che l'anima- 
Ic dei Vermeti è un Gasteropede, munito di un opercolo corneo.

L'animale delle Vermilic non differisce essenzialmente da quello delle Serpole; ma à solo la forma dell'opercolo, e la disposizione delle branchie diverse.

Quello delle Serpole è un Anellide, le cui branchie sono per lo più riunite in un fascetto, alla guisa d'un pennello, o di pennacchio, che spiegasi a modo di ventaglio, inscrito nell' anterior parte del capo, ch' è pure indistinto, e privo di occhi, di antenne, di proboscide e di mascelle.

Benissimo si possono distinguere in tal guisa le specie de'tre generi suddetti, quando si ha l' animale in piena vita. Ma trattandosi delle sole loro spoglie calcari, quando cioè l'animale è morto, o manca affatto; non più i caratteri dell' animale possono soccorrere la mente per la determinazione del genere, cui questa o quella spoglia appartiene. In tal caso si desiderano caratteri proprì delle spoglie, valevoli a servire di criterio per poterle distinguere. Ecco un problema di difficile soluzione.

La Zoologia manca di un lavoro completo su questo ramo, tale da polersi senza ambiguità separare le Serpole dai Vermeti, per registrare le prime fra gli Anellidi, ed i secondi fra i Gasteropedi. Lo stato della scienza lo reclama. Quello ch' essa possiede non abbraccia che le specie più comuni della Fauna atluale; e che sono cadute più facilmente solto gli occhi, tanto degli studiosi, che degl'investigatori. Una folla di minutissime specie giace affatto sconosciuta, se n' eccettui taluna fossile con incertezza clossificata.

Scendendo ora ai particolari, e separando dalle generalità le specialità che ci riguardano; discorreremo quì de Vermeti. Sono stati riconosciuti per tali i seguenti, pro- 
prî de'nostri mari, ad eccezione del Vermetus lumbricalis, tipo del genere, e proprio dell' Affrica.

Vermetus gigas, (il gigante delle specie congeneri nostrali ) - subcancellatus - triqueter (vermilia triquetra Lmrk) - glomeratus (Serpula glomerata Lmrk).

Philippi riportava queste quattro specie nel suo Enumeratio Molluscorum Siciliae, tutte con la denominazione del Bivona, aggiungendo a talune alcuni sinonimi. Nella Fauna Molluscorum indi, riproducendole, protestava che, meglio considerate le cose, aveva trascurato i sinonimi linneani, perchè non si erano ancor chiariti tutti i dubbî che in quelli si racchiudono, poichè abbracciano dispare cose ( vedi pag. 143 in nota).

Le Serpole quindi pel contrario, avrebbero il guscio tutto strisciante ed aderente su qualche altro corpo.

Il fatto ci dimostra altronde, che la Serpula protensa, la infundibulum, la fascicularis, sono aderenti in origine, e si rilevano a misura che crescono. Quindi un tale carattere non può valere per distingucre le specie de' duc generi.

Tralasciamo di ragionare quì de' due altri generi fondati da Lamarck a spese delle Serpole, Spirorbis e Galeo laria, comechè del tutto artificiali, fondati sopra la semplice spoglia calcare, e con caratteri vacillanti. Oramai sono cotesti generi ripudiati dalla parte più sana de'Zoologi.

Or se tante dubbiezze ancor regnano scpra specie che cadono facilmente alle mani, e che ben si possono studiare per dileguarle, sendo che trattasi di animali visibilissimi anche ad occhio nudo, e con la vista ordinaria: come non incontrarne poi in quelle, delle quali andiamo a discorrere, e forse anche più gravi? Trattasi non solo di spoglie così piccole da doversi esplorare col soccorso di ollici stromenti, ma che, essendo nascoste fra cripte o 
forami profondi, tra cavita tortuose, ed anfratti vorticosi ; e provenendo da profondità enormi del mare; fino a che non si raggiungono tali minute spoglie, il loro abitatore e costruttore è già morto e disfatto. Come assicurarsi allora della struttura organica dell'animale?

In tal condizione di cose, il solo criterio di cui possiamo far uso è quello che proviene dai caratteri intimi della conchiglia o spoglie calcari tubolose.

Lamarck, attenendosi strettamente al dettato di Adanson, ed all' esempio della specie tipo, il vermelus lumbricalis, da per fermo, che le conchiglie de' vermeti si attaccano a corpi duri per la sola estremilà spirale, rizzandosi in alto col rimanente.

Pretende altronde Philippi che le conchiglie costituite da una sostanza più consistente, ed allo interno maggiormente vetrosa, spellassero a Vermeti; e che tutte quelle pretese Serpole di sostanza vetrosa e quasi pellucida debbano appartenere perciò a questo genere. Vero è che il Vermeto tipo à la conchiglia delicata, diafana e quasi cornea; ma di tal natura è pure la spoglia della Marphisa tubicola, e non pertanto è indubitatamente un anellice.

In tale stato d'incertezza noi descriveremo tutte le diverse forme di tubi calcari chie abbiamo effigiate nelle tre tavole V, VI e VII, riferenỏo le une al genere Serpula, le altre al genere Vermetus, secondo che talune anaJogie con le specie note di questi due generi ci persuadono; senza con ciò esibirle come inảubitatamente tali, anzi con tutta la riservatezza. Spetta all avvenire la soluzione del problema, quando quălche genio soigerà, dotato di amore per la scienza e di longanimità, sorprenderà con destrezza la gelosa natura.

Linneo commise è vero un grave errore, confondendo con le Serpole i Vermeti ed i Dentali; ma questo che 
apparisce tale nello stato presente della zoologia, non poteva manifestarsi lorquando si tenevan presenti le spoglie inani. Nullameno, il progresso scientifico del giorno non à del tutto dileguati $\mathrm{i}$ dubbi. Altronde la scoperta di Berkley, per rapporto all' animale del Dentalium subulatum, dimostrato grià essere un Anellide, verrebbe indirellamente, e per questa sola eccezione, a giustificare il concelto del Naturalista Svedese.

Anche l'attuale Caecum trachea apparve come un Dentalium, indi si tenne come un genere affine, ma diverso ; ed ora è riposto in prossimità de Vermeti. Così la scienza claudicando si raddrizza ed emenda.

1. Serpula cribrata. Cos.

Tav. VII, fig. 1. $a A, B, C$.

S. testa triquetra, adhaerente, subtus planulata, supra carinata, carina oblusa; lateribus duplici serie foraminum cribrala.

Il tubo calcare di questa serpola à forma di prisma triangolare; aderendo sul piano per una delle sue facce la più larga, alla quale si oppone uno spigolo rilevato, che costituisce una carena scorrente nel mezzo della superior parte o dorsale; nelle due facce laterali vi è una doppia serie di forami, coniugati tra loro per un solco profondo, a simiglianza di quelli degli ambulacri degli echini. Ciascuno di tali forami immelte ad una cavità generata negli spigoli; i superiori cioè conducono a quella della carena mediana, e gl'inferiori a quelle degli spigoli laterali. Questi si avvertono dalla faccia inferiore, dove rimangono aperti, perchè la delicata loro superficie, con la quale aderiscono o rimane su quella del piano, o distrutta affatto nel divellersi tutto il guscio. 
$20^{\circ}$ sempula labiata, Cos.

Tav. VII fig. 2.

Esaminando attentamente lo accrescimento successivo di questa specie, non lo si trova in fondo diverso da quello della Serpula infundibulum; se nonchè, l'espansioni successivamente ingenerate non sono nè così larghe e disgiunte, nè così regolarmente circolari come nella infundibulum. Esse si dilatano invece maggiormente dalla parte ventrale, formando un lungo ed acuto labbro, o linguetta: e sul dorso altra simile espansione s'ingenera. Tulto il rimanente del lubo è rugoso senza simmetria.

Osservazione - La presenza di quell' appendice spatolata, o linguetta, farebbe credere esser questa una $G a-$ leolaria; ma essa non à poi null'altro di ciò che a tal genere si addice.

\section{Serpula frondicuiata, Cos.}

Tav. VII, fig. 4 a $A, B$.

Tubo suernito dalla parte dorsale di $\ddot{b}$ carene delicate, alte e laciniate; le lacinie rilevano sul piano del tubo in suisa da superare il diametro del tubo stesso; es se sono semplici e spiniformi in sulle prime, indi bifide, e successivamente trifide e multifide, sempre rivoltate indietro, simiglianti quasi a foglia di Acanto, come si trovano in parechi Murici le proprie varici. Esse s'interrompono ne' diversi periodi di vila dell' animale, e si riproducono sempre al modo stesso, crescendo però più rapidamente nell' anterior parte, ossia nell' avanzare di età. E pero, nello escmplare efligiato, avvertesi una interruzione nella vila dell'animale; c quindi, nel riprendere le 
sine funzioni, riproducendo il tabo, la cresta dal lato inicrno o sinistro prosegue come la parte antecedente a dividersi in lacinie; ma la carena media e la destra si com. portano come quelle della Serpula crenata. Nel lato ventrale si grenera una espansione a modo di labbro, come si rappresenta dalla fig. $C$, che ne mostra l'apertura di fronte.

\section{Serpula sulcosa, Cos.}

Tav. VII, fig. $5 \mathcal{A}, b$.

Tubo aderente, circolarmente attorcigliato, sicchò le due estremità si congiungono, sovrapponendosi l'anteriore alla posteriore. Cinque solchi longitudinali molto profondi generano sci risalti o creste, bellamente crenati dall uno e l'altro lato; quello del lato concavo o interno si diffonde sul piano a modo di frangia; gli altri a mano a mano divengono più grossetti, e meno rugosi. L' intero cerchio à un diametro di ä millimetri; ma il diametro del tubo non oltrepassa un millimetro.

\section{Serpula crevata, Cos.}

Tav. VII, fig. $3 a, \Lambda$.

Ponendo mente al carattere che distingue questa dalla precedente specie, siamo disposti a credere l'una essere varielì dell' allra. In queșta i cinque solchi sono meno profondi, e le sei creste si țovano più slargate o distanti tra loro, e piegate a zig-zag, in luogo di generare delle minute grinze, come nella sulcosa. Lo intiero tubo rivolgesi ancora circolarmente, ma con minore regolarita, e dopo aver raggiunto l'estremo posteriore, od esordio suo, 
si protende ancora alcun poco quasi in linea retta. Il diametro del tubo è alquanto minore di quello della sulcosa; ma la lunghezza essendo maggiore compensativamente si adeguano.

Tutte queste specie provengono dai fondi coralligeni, tanto dell'Affrica che dell' Isola di Sardegna; nè sono rare. Le loro grandezze naturali sono quali si veggono espresse nella Tavola, solto la lettera a della rispettiva figura. La lettera $C$ ne rappresenta di fronte il taglio trasversale ingrandito, come il rimanente.

Ossercazione. Fin quì abbiamo deseritte come specie, con cinque diversi nomi, le cinque forme diverse, co rispettivi incidenti che adornamo il tubo. Ma ben ponderando il caraltere organico loro, to si trova essenzialmente comune; c quindi potrebbero ritenersi tulte quali semplici ed accidentali modifiche, e però varietà l'una dall' altra. In tutto si trovano cinque creste longitudinali ben pronunziate, ed una sesta or più or meno sensibile. Coteste creste nella $S$. cribraia sono più semplici e più distinte sul dorso, confuse e slargate in ambi i lati; sicchè un taglio trasversale ci porge l'immagine di un triangolo scaleno, con un cerchio inscritto che ne rappresenta la cavitì (fig. 1, C) - Nolla S. Sulcosa le medesime creste sono delicate, e proporzionalmente più clevate ed approssimate tra loro; sicchè il taglio trasversale ci rappresenta un cerchio, con cinque lunghe digitazioni a modo di raggi, ed una sesta brevissima o rudimentale ( fig. B, $b$ ) - Nella $S$. crenata le medesime cinque a sei creste sono meglio distinte, e piegate a zig-zag, in luogo di essere più o meno grinze, come nelle due precedenti (fig. 3 ) - Nella $S$. frondiculata le cinque creste ingenerano di tratto in tratto, ed a dislanze quasi uguali, tranne le piccole differenze proporzionali allo accrescimento suceessivo del diametro, ale uni 
prolungamenti ramosi, come veggonsi meglio nella fig. 4 in $b$, che ne rappresenta il taglio trasversale dell' apertura. $\mathbf{E}$ quì anzi troviamo espresso un fatto, che viene in appoggio alla nostra conghieltura. Verso il termine del suo accrescimento, due o tre delle creste del lato esterno non danno più l'espansioni frondicolari come le altre, ma si ripiegano in guisa da vedervi la medesima fondamentale struttura di quella della $S$. sulcosa, e della crenata. La porzione così organata è lo effetto di una interruzione nella vita dell' animale, e quindi una modifica sofferta nel suo pallio. Finalmente, nella $S$. labiata, fig. 2, tulto ì alterato in guisa da farvi ravvisare una mostruositả. Le carene qui sono confuse, congiunte, lasciando ne' loro intervalli una cavilà, come si vede nella fig. $b$, che ne rappresenta il taglio trasversale; dal lato concavo pel contrario l' espansione concentrata prolungasi in una spezie di linguetta o labbro, siccome nclla stessa fig. $b$ di fronte è rappresentato.

Tulte tali cose convengono con la Serpula cristata, carinata e triquetra viventi ne'nostri mari : ed è sa questi dati positivi che mi sono determinato piutlosto a riporre coteste specie nel genere Serpola, e non fra i Vermeti. 


\section{MOLLUSCHI GASTEROPEDI}

\section{OLOSTOMATI}

\section{FAMIGIIA DE' TURRITEIITT.}

Genere Vermetus, Adans.

Contrariamente a quello che ci à consigliati a riporre nel generc Serpula le specic precedentemente deserille, alcuni dati, congiunti ancora a qualche esempio, oi guidano ora a riferire al genore Vermetus le segueati specio.

Si trova in esse tutte un tubo solido, cilindrico, liscio, ornato soltanto di tratto in tratto di certe espansioni, che si modellano sollo forma di tazza, di sfera, o di cilindro, ma ora chiusi del tutto, ora aperti anteriormente, ma sempre cavi allo interno.

Domina nelle stesse per lo più quella disposizione, cle si pretende caratteristica de'Vermeti; l'essere cioè aderenti ed attorcigliati spiralmente in origine, ed indi eretti. Nondimeno troviamo un esempio tale, che mentre tutto il tubo è completamente aderente e strisciante su qualcho corpo solido, ci presenta allo esterno quelli stessi nodi, ne'quali a poco a poco si convertono l'espansioni superiormente indicale; come è lieve cosa avvertirsenc, dando uno sguardo alle figure comprese nella Tav. V, ove abbiamo disposti ed avvicinati tutti i mutamenti per noi ragunati. Cosi la natura si piace oscillando passare dall' uno all'altro tipo, senza legge, o con quella legge che non concede ai nostri occhi avvertire, o concepir dalla mente! 
1. Vermetus annulates, Cos.

Tav. V, fig. 1 a 6 , ed 8 .

Tubo delicalo, cilindrico, liscio, semplice in origihe, e nel suo maggiorc sviluppo cinto da espansioni in forma di anelli più o meno distinti, talvolta confusi, spesso irregolari: in origine aderente, indi isolato ed cretto.

Trovasi ancor di sovente intieramente prostrato, ed aderente; nel qual caso l' espansioni anellari si spianano dalla faccia inferiore, e si slargano ne' lati, come lo si vede nella fig. $6 a, A$. In tal caso, talvolta, la porzione rilevata degli anclli restringesi in modo da rappresentaro nodi o tuberboli clie adornano la superior parte del tubo.

Specie non rara nelle rocce coralligene.

La grossezza del tubo non ofirepassa un millimetro ed il diametro degli anelli che lo cingono è il doppio.

Il Goldfus ci rappresenta una specie fossile soito il nome di Serpula angrslata. Munster (Goldf. Tab. LXIX, fig.4), con la quale potrebbesi ben confondere il nostro $\boldsymbol{V}$. anmulatus, rappresentato nella Tav. $\mathbf{V}$, fig. 6 . Se non che gli anelli o cingoli di quella sono più delicati, più distinti e discosti fra loro, c regrolarmente disposti; mentre nel nostro Vermeio sono grossolani, approssimati, spesso confusi, e senza ordine di successione. Le quali cose, se all'occhio fan distinguere l'una dall'altra specie, la mente vi riconosce l'identità di organismo.

Similmente, il medesimo autore, nella sua Tav. LXX, fig. 14 b, ci rende l'immagine di un frammento del tutto simile ai nostri esemplari (eccettuato quella della fig. 6), e propriamente si stringe coi due de' numeri 3 e 8. Egli ce la esibisce col nome di Serpula Noggera 
thii assegnatoli da Munster; ed afferma essere un moncone anteriore di quella, che solto lo stesso numero viene effigiata in $a$; la quale parte posteriore manca affatto di anelli, ed invece il tubo è soltilmente striato a traverso, ed attorcigliato a modo di spira, con la quale parte estrema aderisce. Tale sarebbe il tubo dell esemplare effigiato da noi solto il numero 7, tranne la mancanza di spira. Ne differirebbe solo per le dimensioni, sendo che quella rappresentata dal Goldfus pareggia ed avanza la grandezza de' nostri esemplari, quali si trovano effigiati; ma questi sono immensamente ingranditi, non avendo gli originali più di \&’ millimetri di lungo, ed il diametro değli anelli uguale ad 1 millimetro. L'A. non ci avverte, se la sua figura esprimesse la grandezza reale del soggetto, come d'ordinario lo dice; percui devesi ritenere quella immagine come la vera espressione del suo originale.

Dalle citate figure della nostra Tav. V, agevolmente si scorge a quante variazioni è soggella questa specic; nè son tutte quelle che possediamo, le quali ò creduto superfluo rappresentare. Quella della fig. $̈$ partecipa molto della $S$. angulata, ma c̀ desso un moncone, mancante del suo esordio e del suo compimento.

La fig. 9 rappresenta anche un esordio della medesima specie. La figura 10 è quella di un altro, il cui anello o cingolo è molto gonfio, e quasi sferoidale, con un altro anteriormente esordito appena, il quale solto il numero 10 lo abbiamo rappresentato aperto per meta, onde dimostrarne le cavità de' nodi. 
2. ${ }^{\circ}$ Vermetus calyculatus, Cos.

Tav. V, fig. 7 .

Il tubo è irregolare in origine per effelto delle impressioni ricavate dal corpo sul quale aderiva. Eretlosi quindi e liberato dagli altacchi, cresce regolarmente cilindrico, generando di tratto in tratto un calicetto, aperto anteriormente, come vien rappresentato dalla figura 7, ingrandito. Questi calici sono talvolta convessi in giù, o in forma di tazzetta, come il posteriore della figura citata; tal altra cilindrici, appianati nel fondo, come nella stessa figura trovasi l'anteriore.

Ortoceras minims, Gualtieri, Index, Tab. 19 fig. RR. S.

La quale differisce in ciò solo, che i nodi, o cavità circostanti al tubo mediano (sifone, secondo l'A.) sono assai più distanti tra loro, e come si trovano in quel piccolo moncone con le sole cavilà, rappresentato nella Tav. V, figura 7 .

Specie tutte reperibili nc' medesimi fondi coralligeni con le precedenti, e provenienti dai mari medesimi.

3. Vermetus mutabilis, Cos.

Tav. VI, fig. tutte.

Tubo or liscio e semplice, ora guernito di $\ddot{3}$ a $7 \mathrm{co}$ stole longitudinali, più o meno distinte, e talvolta convertite in spigoli, cinto ad intervalli da una espansione ordinariamente angolosa, laciniata, intiera o spinosa; non 
di rado questa espansione stessa ripiegasi anteriormente formando una specie di tazza, e chiudendosi pure piï al raro, costituendo una spezic di barile: sempre però serbando variabilmente i marchi delle costole o degli spigoli. Si dà pure il raro caso che il tubo si presentasse corrugato a modo di trachea; come lo si vede nella posterior parte del numero $\mathrm{g}$.

Non è possibile esprimere tutli gl'incidenti che ci à offerti questa elegante specie. Nella citata Tav. VI se ne sono rappresentate 13 , per dimostrare la più parte dei suoi diversi incidenti; ma molte altre ne avanzano, le quali in sostanza scrbano in fondo gli stessi caratteri. Tulte sono ugualmente ingrandite; ma le dimensioni naturali sono limitate fra i tre ai cinque decimi di millimetro.

La figura $5^{\prime}$ ed $S^{\prime}$ rappresentano di fronte la tazzelta terminale delle corrispondenti varieta $\ddot{b}$ ed 8 . Nella prima di esse $5^{\prime}$, le sette costole sormontano il labbro e si ripiegano allo interno come altrettanti cordoni : nella seconda s' si convertono in altrettanti petali le sei lacinie.

La figura 13 esprime una di quelle chiuse a modo di barilotto; e l'altra 133 una di tali espansioni chiuse, ma guernita di costole, come si veggono ancora sull' esemplare rappresentato al num. 3. L'interna cavilà è però sempre rolonda c liscia. 


\section{$-41-$}

\section{FORAMINIFERI 0 RIZOPODI}

\section{Genere Linguliva d'Orb.}

Il Sig. D'Orbigny, fondatore di questo genere, nella classe de' suoi foraninifer ne enumeravà "ủ specie fossili, c due viventi. Di queste due ultime, una dice egli vivere ugualmente nell'Adriatico, nelle Isole Canarie e nelle Antille, la Lingulina carinata cioé; la quale specie si trova pur fossile nelle terre Senesi, e ne' nostri terreni terziarî, come risulta da quanto se n' è detto nella nostra Palcontologia del reame di Napoli.

Dell' altra vivente l'A. non c'istruisce a bastanza ; onde poterci pronunziare.

Tre delle 3 fossili egli ripone esclusivamente ne'terreni terziarî dell'Austria. Nondimeno due di esse son pure frequenti fra noi, nelle marne terziarie, e spezialmente la $L$. costata.

Nulla si sa pertanto della ubicazione e della maniera di vivere di questa grenia di animali: ed è questa una lacuna importante che si vienc ora a colmare. Pérocehè io trovo costantemente la Lingulina polymorpha, di cui verremo descrivendo tutte le svariate forme e grandezze, dentro le roccie coralligene, racchiusa in lunghi, profondi e tortuosi cunicoli, poco o niente più larghi del proprio diametro.

E quì sorger potrebbé il sospetto, che tali cunicoli fossero per l'animale stesso scavati. Ma parecchie altre condizioni, e talune osservazioni oppostamente dimostrano, non esser l'animale menomamente trivellante; simiSliando in ciò alle Gasirochene, alle Petricole e simili ; e senza avere alcun che di comune co' Litodomi. La con- 
chiglia i rivestita di epidermide, e questa spesse fiate annerita, o altrimenti alterata, come se fosse altaccata da qualche acido. I cunicoli sono irregolari allo interno, e spesse fiate consistono essi in crepacci ingenerati nella formazione della medesima roccia, che, come si sa, è concrezionata. Si trovano pure infarciti costantemente di melma indurita e frapposta tra la conchiglia e le pareli del cunicolo; la qual cosa prova che non vi è immediato contalto tra l'una e le altre. Mentre tulto questo nulla racchute in favore del potere trivellante della conchiglia; vi si oppone d'altra parte direttamente la stessa natura dell'animale che l'abita. Mercecchè à desso un sacco membranoso, che investe l' anterior parte ed esterna dell'ultima cavila, attaccandosi col lembo suo posteriore un poco innanzi della sutura precedente; sul quale sito trovasi l'esordio della nuova cavita in costruzione, ogni qualvolta la conchiglia non è completa. Anzi, nello stato d'infanzia, questo sacco è più crasso e più tumido nella sua anterior parte, come se fosse una escrescenza carnosa, ma molle. Nè altro l'animale presenta nel suo organico complesso; essendo ciò pure quel tanto che ò potuto scorgere nelle Triloculine ed in qualche Anomalina, che ò trovate vivere sopra la Zostera, e sopra alcuni polipi a polipario flessibile. Mi è occorso pure trovare alcune di tali Lingoline frapposte a certi lubercoli o escrescenze prodolle da incrostazioni calcari, senza che queste si mostrassero punto alterate o tocche dalla presenza di tale ospite. Finalmente non è mancato il caso di trovarne taluna attaccata a fuchi, come già nella mia collezione conservo una di tali Lingoline col frammento del Fuco, qual si trovò normalmente attaccata.

Del resto, qualunque fosse l'importanza di queste mic osservazioni, conviene ch' esse fossero confermate 
per più altre, ed anche più chiare prove, affinchè trar sc ne possano meno incerte doltrine. Sarebbe anzi da studiarsi a trovar modo, onde sorprendere la natura ; osservando le Lingoline appena estratte dal mare, mentre sono in piena vita; la qual cosa è a me negata eseguire per le gravi sofferenze che patisco nel mare.

Quello che poi non lascia punto a dubitare è la mutabilità di forma cui va soggetta la Lingulina, della quale anderò ad esibire la descrizione. Perocchè numerosi sono gl'individui che ne ò raccolti, dai primi suoi rudimenti fino al massimo sviluppo, e tra questi di rado due se ne incontrano, che perfettamente simiglino tra loro. Regrolarissima la conchiglia ne' suoi primordi, si difforma poscia col crescere, ripiegando in varie guise, e talvolta incurvandosi sopra uno de lati, tal da mentire la forma di una Marginolina; come per lo appunto è quella effigiata al n. 7 .

La sua costante dimora dunque permetterà considerarla essenzialmente cunicularia, senza esser con ciò terebrante, nel vero senso della parola. Ed in quanto a tale quistione mi riporto a quello, che sarà detto nel genere Echinocyamus, in questa medesima opera.

Il generico nome di Lingulina ricorda le Lingole fra gli Brachiopodi; ed è distinto da Ligola genere di verme.

In quanto alla specie che si va a descrivere bisogna convenire, che ne'suoi primordî, o nella sua infanzia, quando essa non consta che di 3 a 4 cavilà, presenta la Lingulina carinata descritta dal D'Orbigny; ma neggli adulti niuno si avviserebbe riconoscere la stessa specie. Sorgono quindi da ciò i seguenti problemi :

$1^{\circ}$ E veramente identica questa specie, che noi designiamo col nome di Lingulina polymorpha, alla carinala? $2^{0}$ Nell' affermativa, perchè mai non si rinvenne fun 
gui dal prelodato autore, nè per altri, nelle condizioni stesse in cui noi la troviamo, e così abbondevolmente per entro le roccie coralligene?

$3^{\circ}$ Perchè mai nelto stato fossiłe la Lingulina carime si trova composta di 2 a 4 cavitì, e non già con concamerazioni tanto moltiplicate, come nelle attuali viventi ?

$4^{0} \mathbf{E}$ forse che questa genia di animali fosse in via di progressivo sviluppo nell'epoca attuale della vita organica? essendo che, neppure tra i fossili si è ancor trovato un solo individuo con caviti cotanto moltiplicate, che spesso se ne contano fino a 40.

In sulle prime, allorchè mi si offerse quella rappresentata dalla figura I, mi parve ben da ogni altra distinta; ed opinava insignirla coll' aggeltivo ampullacea, a causa della sua figura ovale, un poco cordiforme, trasparente come il vetro ece. Ma quando, moltiplicati a centinaja gli esemplari, ò potuto ravvisarvi quasi tutti i passaggi, tutte le gradazioni, e tante svariate forme, mi sono persuaso che questa altro non fosse che un primordio della polimorpha, e di una delte tante sue varielà. Ecco una delle sorgenti di errori, per i quali si moltiplicano spesso le specic; quando cioè si ottengono isolatamente certi individui, i quali, mostrandosi di figura, struttura e grandezza molto tra loro diversi, e spezialmente se provenissero da località diverse, niuno esiterebbe a considerarki come distinte specie.

Cosi pure, se star si volesse alle diverse forme che assume la nostra Lingulina, precipuamente trattandosi di individui di diversa ela, statura, ed incremento; si sareble guidato a formarne una ricca monografia. Ma quando si esamina la quistione, tenendo solto gli occhi la numerosa serie d' individui, il concello comincia a vacillare 
appena che si comincia a ravvisare il passaggio senza verun limite dall' uno all' altro individuo. Forse si durerà pena ad ammettere, che quelle due rappresentate solto i numeri 3 e 4 fossero semplicissime variola; ma nondimeno, quando si cerca in esse un carattere distintivo organico, si finisce col confessare non esservene alcuno. Nella difficile posizione di esibire di tutte, o di una gran parte la immagine, ci siamo limitati ad ollo solamente, scelte nella serie da tratto in tratto. E ciò basta pure a persuadere, che niuna fra esse può distaccarsi come specie, ad eccezione della sola segnata con la cifra $7 \boldsymbol{B}$; nella quale, come vedremo, si trovano tratti potenti di specialità, che non permettono confonderla con le rimanenti, quando anche essa partisse originariamente dal medesimo tipo. Almeno mancherebbero i mezzi ed i modi di persuadercene.

\section{Lingulina ampullacea, Cos.}

\section{Tav. VIII, fig. 1. - ingrandila.}

Conchiglia di forma ovale, alquanlo cordata, compressa, con una delicata carena ne' lati, quasi cultrata, levigatissima; composta di 5 cavità, la prima delle quali alquanto acuta nel suo estremo posteriore, le altre, successivamente crescendo in larghezza, sono quasi uguali in lunghezza ; l'ultima è poco men grande delle precedenti prese insieme, è tondeggiante, ed anteriormente terminata da una elevatezza a foggia di labbro, tra le quali la rima od apertura generica, come all'ordinario. La sua sostanza è vitrea, trasparente in guisa che lascia intravedere gli interni scompartimenti a traverso delle sue pareți. 
Lunghezza 1 mill.

Specie reperibile con le seguenti, essendo però molto rara.

Osservazione. Si è fatto rilevare nelle generalità, che questa, la quale si affaccia come specie ben dalle altre distinta, sta nell' animo mio altro non essere che il primordio della stessa polymorpha che anderò a descrivere: e me ne persuade la sua grandezza uguale precisamente a taluni inizî, che su certi individui maggiori mi è riuscito osservare. Tultavolta si è descritta come specic, per quella prima impressione che può fare all' occhio della maggioranza; lasciando in arbitrio di tulti lo ammettere oppur no il mio giudizio.

\section{Linguidis polymorpia Cos.}

Tav. VIII, fig. 2-6, ed 8.

Conchiglia allungata, molto compressa, di un numero variabile di cavità, le quali crescono ancora svarialamente, per lo più senza legge; flessuosa, o per lo meno alquanto inarcata; levigatissima, un poco trasparente, ma non di rado opaca; la prima cavità è un poco rotondata allo estremo, e poco men lunga della seconda; le successive, crescendo pochissimo in diametro, sono appena tumide; tutte distinte da sutura poco impressa , ma non sempre uguale; ai lati corre uno spigolo acuto, o coltrato; l'ultima cavità si termina, come nella precedente specie, in una eminenza, nel cui mezzo è la rima, 0 apertura.

Non può darsi esatta dimensione di questa specie, variando ceme le sue forme: nè manca qualche individuo mostruoso. I limiti sono però fra i 2 ed i 4 mill. 
3. Lingulisa mediternanea Cos.

Tav. VIII, fig. 7 .

Conchiglia straordinariamente allungata, tortuosa, c composta di cospicuo numero di cavità, 18 a 24 , l'ullima delle quali si prolunga obliquamente come nelle Dentaline. Essa à l'apparenza di una Marginulina; nè dalle specie di questo genere altrimenti distinguesi, che per la sua caratteristica apertura.

Osservazione. Chi si arrestasse ad una semplice comparazione di figure, non esiterebbe punto a riconoseere in questa nostra specic la Marginulina clongata del D'Orbigny ( Foram. foss. di Parigi, Tav. I, fig. 22) . Ma quando allentamente si esamina l'una come l'altra, oltrel'esser la nostra quasi doppia in grandezza ( 5 mill. e $1 / 2$ ). ed aver l'abito e la sostanza identica alle altre Linguline polimorfe, con le quali coabita, è poi molto compressa come questa, mentre quella vuol essere pressochè cilindrica, ed à l'apertura allungata nel senso stesso della compressione delle sue cavilà. Egli è vero che l'apertura non è così angusta come la si vuole e qual'è realmente nol tipo generico, essendo in vece un poco allargata; ma ò questa una delle tante eccezioni, le quali s' incontrano nei successivi passaggi da uno ad altro genere, da questa a quella famiglia, e così sempre.

Vivono tulte le suddette specie nello Jonio e nel Mediterraneo, presso l'Isola di Sardegna, c le coste settentrionali dell'Afrrica. Trovasi costantemente, come si ì detto, annidata fra le cripte delle roccic coralligene. 
4. Lingulina gracillima Cos.

Tav. VIII, fig. 7 B.

Conchiglıa molto allungata, gracilissima, quasi rettilinca, molto compressa, e quasi laminare, spezialmente nella sua parte anteriore, ore dilatasi alquanto più, e nella stessa ragione si comprime; composta di 8 cavita quasi di uguale lunghezza, poco diverse in larghezza; la prima brevissima e più angusta di tutte, ma ugualmente alquanto tumida; le suture sono spianate; la superficie levigatissima; la sostanza trasparente e vitrea.

Lunghezza 1 1/2 millimetro.

Delle coste del Tirreno; trovata nella sabbia presso Cuma. Sarebloc quindi la sola specie spettante meritamente alla Fauna Napolitana.

\section{SPIEGAZIONE DELLA TAVOLA VIII.}

Fig. 1. Lingulina ampullacea - ingrandita.

2. „ " varietà della medesima - similmente ingrandita in proporzione.

3,6 ed 8 L. polymorpha; come sopra.

$S A$, apertura caratteristica delle specie di tal genere.

7 L. Mediterranea.

7 B, L. gracillima.

9 Marginulina clalrata.

9 A, la sua apertura caratteristica, molto ingrandita.

10 Merginulina flexuosa; Cos.

11 Buccinulina afra.

$12 B$. irregularis. 
Genere Marginulina, d'Orb.

\section{(Nautilus, Lin. - Orthocera, Lamk.)}

Il signor d' Orbigny, meltendo una grande importanza nell'apertura estrema de'suoi Foraminiferi, ne valutava la forma e la posizione, in rapporto all'andamento generale della conchiglia, ed a tulti gli altri accidenti delle cavilà. Quindi separava dalle Dentaline le Marginoline, perchè in queste l'apertura si trova corrispondente al lato convesso della conchiglia, laddove nelle Dentaline si trova sul lato concavo. Le separava poi dalle Vaginoline, per la forma convessa dell' ultima cavilà, pel prolungamento della stessa, al cui estremo si trova l'apertura, e per lo inarcamento in senso opposto, tendente a rivolgersi in foggia di spira.

E stato notato in più luoghi, tanto nei Foraminiferi viventi della nostra Fauna, quanto nei fossili della slessa nostra Paleontologia, la instabilita di tali principî, e gli equivoci ne'quali facilmente si può cadere. La natura non à prescritlo confini a se stessa: e non mai passa bruscamante dall' una all' altra forma; come si suol concepire e supporre nelle generiche divisioni sistematiche: a prescindere dalle abberrazioni od anomalie, che non sono infrequenti; e tanto più, per quanto maggiormente si scende nella scala dell'organismo, e per quanto la frequenza degl' individui è magggiore.

Se tulto questo è facile incontrarsi in ogni genere , nelle Marginoline non manca, seppure non è più frequente. Esse si ligano da un lato con le Cristellarie per l'andamento delle cavità, e per la posizione del forame; poichè le Cristellaric ancor esse dal proprio lato passano 
dalla forma inticramente spirale a quella allungata delle Marginoline, raddrizzandosi a poco a poco dopo l'esordio spirale. Or di tutti questi passaggi successivi, e di tal progressivo cammino della natura, noi troviamo esempî eclatanti nella presente Microdoride, come altri ne abbiamo riportati nelle due sopracitate opere, la Fauna e la Paleontologia.

Lo stesso d'Orbigny non manca dichiarare nei suoi Furaminiferi fossili del bacino di Vienna, pag. 66, esservi delle Marginoline siffattamente rivoltate in spirale, che se fosse possibile di stabilire una catena continua, un lal genere verrebbe a piazzarsi immediatamente accosto delle Cristellarie. E parlando delle Cristellarie dichiara " non potersi negare, che tra le meno altorcigliate Cristellarie, c le più spirali Marginoline, vi sia un passaggio evidente. 'Avrebbe però detto megrlio esservi uno strettissimo legame. Nonpertanto, mentre il d'Orbigny alternativamente confessa l'esistenza degl'intimi rapporti tra le Marginoline e le Cristellarie, ed il passaggio che fanno le une nelle altre; non solo le separa genericamente, ma le ripone in due ordini diversi ; fra gli Stigostegi le prime, e fra gli Elicostegi le seconde !

Ma, dimanderemmo al prelodato scrittore, chi vieta lo stabilire una tale successione o legame? La Natura? No certamente; che anzi molti opinano, che questa catena esista; ed io confesso dividere la stessa loro opinione: e si è altrove pur dichiarato, che le interruzioni dipendono dalle lacune che lasciano le nostre conoscenze. Perocchè la vastità del creato è tale, che possono riguardarsi come frammenti le nozioni raccolte in tanti secoli di ricerche, e per tanti uomini laboriosi e diligenti. Un esempio luminoso ce lo porge quest'opera medesima, come lo è stato annunziato di grià nel preliminare. Per altro lato, 
le separazioni sistematiche sono concelti del nostro intendimento; e n'è alta riprova il continuo variare de'sistemi, secondo il modo di pensare degl'individui, ed a misura che avanzano le conoscenze nostre.

Dicesi che attualmente le Marginoline abitano l'Adriatico, il Mediterraneo e le Isole Canarie. Ma quali altre località sono state così ben esplorate per dar questo gitudizio comparativo? Controprova di tale asserto n'è il numero delle specie da noi discoperte nel Mediterraneo, descritte nella Fauna del Regno, e quelle che qui riportiamo; mentre pochissime ne abbiam potute ottencre dalie coste dell Adriatico. $\mathbf{E}$ ciò viene in sostegno della nostra convinzione medesima, che queste eifre corrispondono sempre alla moltiplicita ed assiduita delle ricerche, non meno che alla intelligenza e diligenza con la quale le ricerche medesime si compiono.

Rimontando ai caratteri generici, le due specic offigiate nella Tav. VIII, fig. 11 e 12 , vengono in dimostrazione di quello che noi stiperiormente abbiamo dichiarato. In esse l'apertura, lungi dal trovarsi sul lato dorsale o convesso, sta nel bel mezzo: c nella figura $1 \mathrm{l}$ inoltre si trova allo estremo di un prolungamento tuboloso, col peristoma dilatato, contro la ordinaria manicra degli Stigostegi.

Quindi, volendo stare al rigore del metodo stabilito dal d'Orbigny, queste due specie non possono entrare nel genere Marginulina; e però ò creduto per esse proporre il nuovo genere Buccinina, nome che viene esprimendo la forma dell'apertura. 
1. Marginulina claturata, Cos.

Tav. VIII , fig. 9.

Conchiglia composta di tre sole cavità, tumidette, compresse, guernite di 14 costole, ben rilevate, longitudinali, i cui intervalli sono ornati di punti impressi trasversali, per i quali la parte rilevata che resta intorno ad essi costituisce altrettante linee trasversali, che si uniscono alle costole, e formano una spezie di reticolo. La prima cavità, nel suo estremo posteriore, à una punta allungata, nella quale convengono le costole e si confondono; l'ultima e anteriore si prolunga obbliquamente ed in opposto senso dell' apice posteriore; le costole si arrestano sul perimetro, sicchè il prolungamento è levigatissimo, ed al suo termine sta l' apertura normale. Così di fronte la rappresenta la fig. $9 \mathrm{~A}$.

Lunghezza - un millim.

Abita i fondi coralligeni delle coste di Affrica.

\section{Marginulina flexuosa, Cos.}

\section{Tav. VIII, figura 10.}

Conchiglia ben distinta dalla precedente, per la disposizione delle sue cavità, pel minor numero di costole, e per la sua compressione. Ha dessa tre sole cavità, la media delle quali brevissima, le altre due con una sensibile depressione nel mezzo, e lutte guernite di cinque sole costole per lato, oltre la marginale. La cavita posteriore è compressissima e quasi coltrata nel suo estremo, ch'è pure rotondo; l'anteriore prolungasi alquanto a mo- 
do di tubo, diretto in senso opposto della curvatura della cavità posteriore. L' apertura è generica come nella precedente.

Lunghezza - tre decimi di millim.

Abita con la precedente.

\section{Genere Buccinina, Cos.}

Osservazione. Non è già cli' io fossi persuaso esser veramente di un genere distinto le due conchiglie, che sotto questa generica denominazione vengo qui registrando; ma sol perchè tanto è richiesto dal sistema artifizioso che si è costretto seguire, fino a che non sarà fondamentalmente rifatto co'principii di una sana filosofia, e dalla natura stessa dettati.

In fatti, le due conchiglie che si fanno servire di tipo pel genere Buccinina, non differiscono punto dalle Marginoline e dalle Dentaline; ma cadrei nella censura dei sistematici se nell' uno o nell'altro di tali generi osassi riporle. Perocchè, non avendo esse l'apertura laterale $\mathrm{c}$ dal lato concavo, come si richiede nelle Marginoline; e neppure nella direzione del lato convesso, siccome nelle Dentaline; ma sibbene dritto nel mezzo, non saprei come giustificarmi se altrimenti avvisato mi fossi. Per la medesima ragione non può tenersi come Cristellaria la specie effigiata sotto il numero 12, mentre è presumibile che realmente altro non fosse, che una specie mostruosa di tal genere.

Oltre a ciò, l'apertura delle Buccinine è larga, rotonda ed allo estremo di un sensibile prolungamento a modo di tubo.

La specie rappresentata solto il numero $12 \mathrm{si}$ accosterebbe anche di più alle Vaginoline; ma la sua aper- 
tura mediana e prolungata ne la separa, sendochì nelle Vayinoline vuol essere marginale, e nell' angolo ascendente della cavita. Inoltre una sensibile tendenza alla spirale ne l'allontana vieppiù.

Ricorderemo qui pure il già detto, che la natura non à confini rigorosamente prescritti, ma passa per gradi dall'uno all altro genere, come da questa a quella specie, le quali cose tutte sono per to più nostri concetti.

1. Buccinina subrecta, Cos.

Tav. VIII, figura 11.

Conchiglia di forma quasi conica, un poco inarcata, cl alquanto compressa; composta di 8 cavita, tutte liscie, con le suture spianate e poco profonde. La prima caviti (juasi sferica, la seconda brevissima, e le altre successivamente e gradatamente in ogni senso crescenti. Li ultima anteriormente uniforme, prolungasi alquanto formando un tubolino rotondo, aperto in cima.

Lunghezza - 1 millim. e 2 decimi.

Vive sulle coste del Tirreno. Raccolta presso Cuma. Ben rara.

\section{Buccinina recunva, Cos.}

Tav. VIII, figura 12.

Conchiglia liscia, molto incurvata in sulle prime, raddrizzandosi con le due ultime cavilà; le prime 8 cavila sono compresse, ristrelte dal lato concavo, tumidette dall'opposto convesso; le suture successivamente più sensibili; la nona cavità è tumida, più larga che lunga, e 
maggiore di tutte; l'ultima è allungata, quasi ovale, anteriormente prolungata in tulo dritto e rotondo, com'è l'apertura. Vive con la precedente.

\section{MOLLUSCHI GASTEROPEDI}

\section{PROSOBRANCHIATI}

\section{FAMIGIIA DE' MURICIDI.}

Si sono distaccati da quest' ordine i Vermeli per avvicinarli alle Serpole, a causa delle loro spoglie difficili a distinguersi da quelle, lorchè son prive del proprio abitatore e costruttore.

Genere Trocius.

1. Trochus elegantissinus, Cos.

Tav. IX, figura 1. ( figura inesatta )

Conchiglia torreggiante, conica, svelta ; composta di ¿ giri di spira ben distinti per una delicatissima ma profonda sutura. Ciascun giro à tre cingoli ben tra loro diversi, essendo il medio molto più elevato e più grosso degli altri due, distinti da un solco profondo, e trasversalmente increspati, rugosi, sicchè talvolta sembrano guerniti di tubercoli. L' apertura è ampia, quasi che rotonda, col labro esterno un poco disteso, e quasi dentellato per la sporgenza de' cingoli; dalla parte interna è flessuoso; il labro interno è angusto e dritto, distendendosi sulla colonnetla, ch'è dritta, e senza ombellico.

Altezza - millimetri $51 / 2$.

Diam, della base - 2 unillim. 3/10. 


\section{Trocnus monninus, Cos.}

Tav. IX, figura $6, a, b, c$.

Conchiglia ovale allungata, quasi conica, composta di 4 giri di spira; il primo apicale liscio, il successivo trasversalmente rugoso, le cui rughe si vanno facendo a mano a mano più sensibili; nel terzo si convertono in varici o costole molto elevate, al numero di 20 a 24 ; nel quarto ed ultimo giro di spira tutlo si fa più sensibile, e gucsto vien per lo lungo solcato, ed i solchi si protendono fino alla estremilà della coda, la quale è brevissima; l'apertura, con la coda, è uguale all'altezza della spira. Il labro è liscio allo interno; l'apertura stretta ed alJungata.

Tal è questo Trocolo nella sua infanzia; ma negli adulti, scomparendo quasi le punte, restano i cingoli trasversali, e le rughe longitudinali meglio distinti, onde il grande ed ultimo giro della spira è bellamente cancellato. In questo stato raggiunge essa la dimensione di $\ddot{3}$ mill. in altezza, e tre di diametro. I piccoli non oltrepassano i due millimetri.

\section{Genere Murex.}

1. Munex spinulosus, Cos.

Tav. IX, fig. 2, $a, b$.

Conchiglia di forma simigliante a quella del $\boldsymbol{M}$. $t$ run . culus, di cui dir si potrebbe essere il pullo (1). Essa è

(1) Le minute conchiglie, allorchè non àmmo qualche carattere eminentemente capace a farsi distinguere dalle specie affini, lasciano sempre 
però naturalmente sì piccola, e nondimeno completa e bene sviluppata. Si compone di 4. giri di spira, il primo de' quali liscio e ritondato; gli altri ornati da 3 grosse pieghe trasversali, e da 8 grosse varici longitudinali, le quali nella superior parte si prolungano in una grorsa ed acuta spina quasi verticale ed un poco incurvata verso il centro della spira; le quali spine constituiscono una corona molto rilevante e caratteristica. Apertura triangolare; labro esterno angoloso ; canale un poco curvo.

\section{Altezza - 4. millimetri.}

Diametro - 4 millimetri.

\section{Murex Rugulosus, Cos.}

$$
\text { Tav. IX, fig. } 4, a, b \text {. }
$$

Conchiglia quasi globosa, appena conica, con quattro giri di spira molto convessi ; i primi tre divisi da sutura profonda, trasversalmente cinti da varici squamose ed erte; il quarto solcato per lo lungo ed a traverso con frequenti interruzioni, per effetto de' successivi incrementi ; questi divisi e prolungati in acute lacinie che ne rendono ispida tutta la superficie; la parte inferiore fortemente e concentricamente striata. L'ombellico è chiuso dal ripiegamento del labro interno, che genera una colonnetta dritta, mezzanamente elevata, e troncata quasi nella base. L'apertura è ovale, obliqua. Colore bianco sudicio.

\section{Altezza - 3 mill. \\ Diametro - 2 mill.}

a sospettare ch' esser potessero la prima età di qualche specie maggiore $\mathbf{e}$ già conosciuta. $\mathbf{E}$ veramente è questo un sospetto che ben di sovente si sveglia e ripete. Tuttavia, ponendo mente alla condizione peculiare degli individui pulli, e comparandole co primordi de' loro adulti, si può ben pervenire alla positiva loro ricognizione, od alla possibilità di appartenere ad altra specie nota come suo pullo. 
Genere Solarium.

1. Solarium calcar, Cos.

Tavola IX, figura $5, a, b, c$.

Questo minutissimo Solario à il suo analogo nella Delphinula calcorala, fossile in Taranto: e forse si direbbe esso il piccolo di quella; ma i caratteri generici sono assai chiari per non potersi confondere.

Simigliantissimo è pure al Cirrus calcar del d' Orbigny, fossile di Fontana Etoupefour, talchè potrebbesi credere il suo rappresentante della Fauna vivente così ammiserito, mentre il suo tipo è grande e si riferisce al Lias. Ma ne' Cirri veri vuol essere il labro esterno scisso, come nelle Pleurotomaric, e tutto il corrispondente perimetro gucrnito di tubi aperti in cima, siano o no prolungati. Nei nostri escmplari non si scorge traccia di scissura, nè alcuno di quei prolungamenti spiniformi è menomamente aperto in cima. Tal è pure la condizione del Cirrus calcar, per la qual cosa io credo, che dovendosi stare ai caratteri stabiliti per contradistinguere un genere, mal siasi avvisato il d'Orbigny di riporre tra i Cirri la sua specie.

Meglio ancora dir si potrebbe, che il nostro Solario fosse il primordio del Turbo rugosus, nel quale i giri della spira sono sempre spinosi; ma contro questo sospetto basta la sola grande apertura ombellicale per persuadercene.

Egli è vero che le spine periferiche del nostro Solcrio sono inpervie nella sommità; ma è vero altresì che esse sono cave, e la cavità loro è in continuazione di quella dello stesso giro di spira, come lo dimostra la spina 
che sla sul labro esterno, e che si è rappresentata di fronte in $c$, la quale è incompleta. Non è così nel Turbo rugosus, le cui spine sono solide, compresse, c derivano dal cingolo esterno. Per opposto nel nostro Solario è il labro stesso che forma quei tre o quattro ripiegamenti, il supremo de' quali si prolunga siffattamente da formare un' angolosità tanto acuta.

Anche con le Bifronzic anderebbe esso congiunto; ma è questo genere eziandio alquanto ambiguo. Ricordiamo dunque la premessa sentenza, che la natura non à confini prescritti, e lasciamo il giudizio ad altrui.

La conchiglia è piana quasi perfettamente al di sopra, ove le suture lasciano appena distinguere i quattro giri di spira di cui si compone, e questi sono lisci ; alla faccia inferiore ed opposta à un amplissimo ombellico, quale per lo appunto si trova nelle migliori specie di tal genere; ed il margine interno dogli anfratti è bastevolmente increspato.

Diametro - 2 millim.

Abita con le precedenti specie i fondi coralligeni dell' Alfrica.

\section{Genere Murcuisonia.}

Riferisco a tal genere la conchiglia effigiata sotto il numero 3 della Tav. IX, sol perchè l'abito suo tale l'addimostra. Nondimeno manca in essa la scissura o fenditura del labro esterno, nella quale propriamente risiede l'altro carattere essenziale del genere. $\mathbf{E}$ però la ritengo come tale con dubbio, in altenzione di ottenerne altri individui di età maggiore e completi.

La conchiglia è molto allungata, e non à che 4.05 giri di spira, svariali un poco, e bene scanalati, l'ultimo de' quali con due cingoli ben rilevati nel mezzo, ed un 
terzo che segna la linea della sutura. L'apertura è larga, un poco allungata, col labro esterno sormontato dalle tre angolosità prodolte da' cingoli ; il labro interno è liscio, semplice ed intiero.

La sua altezza è di un millimetro e quattro decimi. assai rara.

Abita con le specic precedenti ne' fondi coralligeni;

\section{Genere ScissurkiLa, d' Orbigny.}

\section{(Anatomus Montf.)}

Anche in tal genere la nostra microdoride aggiunge due altre specie alle già note. Le Scissurelle generalmente minute, quelle che dalle profondità maggiori del Mediterraneo si estraggono sono minutissime: esse si distinsuono per la loro forma prossima a quella de' Sigareti, la cui spira più o meno depressa, e dalla parte opposta ombillicate; e sopratutto le contrassegna una rima o fessura nel labro esterno, come nella pleurotornarie e ne fori. Non se ne conobbero che 4 sole specie fino al 1838; e non già due, come pretende d'Orbigny. Mercecchè, nel 1836 Philippi ne descrisse una sotto nome di Scissurella plicata, la quale, aggiunta alle due cognite all'A, ed all'altra per me precedentemente descritta nella Fauna del regno, solto il nome di Padollus d' Orbigny (Scissurella d'Orbigny), compiono le quattro specie.

Più tardi poscia il medesimo d'Orbigny dava conoscenza ai Cocchiologi di due altre specie, dell' Isola di Cuba l'una, e delle Isole Maloccine l'altra. Il Philippi dal canto suo ne aggiungeva ancor altra della Penisola di Magnisi, nelle coste meridionali della Sicilia: e quindi si à la somma totale di 7 . 
A niuna di tali specie può riferirsi alcuna delle due, delle quali qui discorreremo. Solo quella rappresentata nella Tav. X, fig. $2 \boldsymbol{B}$ si accosta alla nostra Scissurella d'Orbigny.

\section{Scissurella decipiens, Cos.}

\section{Tav. X, fig. 1, $A, D$.}

Conchiglia quasi appianata, i cui giri, al numero di 3, sono mezzanamente convessi nella superior parte, e molto ben distinti; trasversalmente e finamente increspati; e presso l'orlo del terzo ed ultimo giro corre un duplice cordone, il quale comincia semplice sulla metà del giro, ed a poco a poco si manifesta diviso in due per un solco profondo che nel mezzo s'ingenera; sul termine del labro pare si volesse ingenerar la scissura, senza però realizzarsi; il labro si inflette alquanto ver dentro in guisa che l'apertura si rende un poco più angusta, come la si vede nella fig. $C$, che la rappresenta di fronte. La qual cosa imporrebbe doversi escludere dal genere scissurella. Ma i suoi stretti rapporti con la seguente, nella quale la presenza della scissura è evidente e lunga, persuadono a crederla un passaggio positivo, per modo che potrebbe essere riguardata come una varietà sua.

Diametro maggiore -1 millimetro.

2. Scissurelua cingulata, Cos.

Tav. XII, fig. $9, \boldsymbol{A} \boldsymbol{B}$.

Conchiglia mediocremente depressa, con 3 giri di spira, tutti regolarmente ornati a traverso di cordoni ben 
limitati e distinti, al numero di 11 a 12 per ciascun giro della spira. Sul terzo ed ulcimo giro si genera un rilievo in parte dorsale e presso il labro esterno, nel cui mezzo apresi la rima o scissura. Nella faccia inferiore evvi un largo ombellico, ed il labro columellare od interno distendesi a traverso in linea retta. L'apertura è quindi semiovale.

Diam. maggiore mill. $0,7 / 10$

Proviene, come la precedente, dai fondi coralligeni dell' Isola di Sardegna.

3. Scissurella affinis, Cos.

Tav. X, fig. 2. B.

Come poco innanzi si è dichiarato, questa Scissurclla non dissimiglia dalla Se. de Orbigmy per i suoi tratti generali. Nondimeno, oltre l'essere di quelli più piccola, stando tutte le altre cose uguali, è poi molto piì appianata al di sopra, lo spigolo periferico meglio pronunziato, e lutta la superficie ornata di strie trasversali, delicatissime, e spesse: e mentre così è appianata la spira, dalla inferior parte gli anfratti si clevano, c l'apertura è ristretta. E perciò solo che credo non dorersi assolutamente con quella confondere, mentre non disconvengo essere cose possibilmente variabili sopra diversi individui di una medesima specie.

Trovo di falli qualche esemplare, in cui lo spigolo dilatasi in modo da costituire una lamina, e le strie trasversali si protendono sul contorno esterno ingenerando alcuni dentelli.

Diametro maggiore -1 millim. $7 / 10$

Dalle coste di Affrica. 


\section{Genere Helicielia, Cos.}

Malgrado tutta l'austerità di creare nuovi generi, e d'introdurre nella scienza nomi nuovi, per non accrescerne maggiormente la serie, ed aggravare la mente de'cultori di essa; sono costretto ciò fare, per iscansare l'erroneat collocazione di specie solto nomi generici già conosciuti, e fra quali non possono giacere senza gravissimo errore.

\section{Heliciella costellata, Cos.}

Tav. X, fig. $3, A, B, C$.

Conchiglia rotondata, con la spira appianata, molto convessa dalla inferior parte; composta di 3 giri di spira, il terzo de'quali si aggira tutto quasi addossandosi alla inferior parte del precellente, sopra del quale perciò rileva, come la si vede in $C$, che la rappresenta di profilo, avendo l'apertura di prospetto. I giri della spira sono ornati di cordoni ben rilevati nella faccia suprema fino al perimetro, ove si convertono in angolosita acute; dalla faccia inferiore insensibilmente si vanno cancellando fino a scomparire del tutto presso l'ombellico ; questo vien chiuso in parte dalla espansione del labro della conchiglia. L'apertura è quasi ovale; il labro è scmplice, ma quando es. so si termina col ripiegramento che ingenera i cordoni trasversali, mostrasi incrassato o dilatato.

Diametro trasversale - 1 millimetro.

Proviene dalle medesime profondità coralligene delle coste di Affrica - Rara. 
2. Heliciella mutabilis, Cos.

Tavola $\mathrm{X}$, figure 4 e $5, A, B, C$.

Conchiglia quasi globosa, con la spira ben rilevata, acuminata; composta di 3 a 4 giri di spira ben regolari, e tutti ornati di strie finissime trasversali; gli anfratti sono rotondati, discreti per delle suture profonde; l'apertura varia sovente, dilatandosi in diverso senso, come dalle due effigiate si vede.

Potrebbe ciò dipendere dalla diversa età, dall' esse re cioè più o meno complete; ma pare che questa differenza andasse pure associata ad una maggiore o minore elevazione della spira. Si trovano delle condizioni ancíe intermedie alle due che si sono effigiate.

Specie non molto rara, proveniente dalla medesima località.

Diametro - 1 millimetro.

\section{Genere SpIrolidivi, Cos.}

Ecco un altro luminoso esempio che viene in conferma di quanto fu esposto sotto il genere Ammonitina.

Trovasi in natura un mollusco cefalopede, il quale abila, o gencra una conchiglia spirale, i cui giri non sono punto in contatto, e la cavilà è scompartita in più altre, tulte simili, e comunicanti fra loro per un forame aperto nel mezzo de' sepimenti, a traverso del quale scorre un sifone. Di tali conchiglie il loro scopritore Peron fece il genere Spriola, nome che n'esprime nitidamente la forma; ed alla specie fiu data poscia il nome di lui, Spirola Peronii. 
V'à tra Foraminiferi anche una microscopica conchiglia così spiralmente attorcigliata e scompartita allo interno; ma senza forame di comunicazione, nè sepimenti, nè i giri della spira sono disgiunti; in vece, dopo due o tre giri spirali, la cavità tubolosa si protende tangentalmente ín linea relia, o presso a poco così, e l'ultimo scompartimento si chiude per una lamina cribrata da più forami rotondi. A tali microscopiche conchiglie è stato dato il generico nome di Spirulina, ricordando con ciò la forma analoga a quella della Spirula Peronii; e col diminutivo esprimendone la picciolezza inerente alla diversilà di struttura.

Del tutto simili a queste ultime discopriamo ora una altra "conchiglia, che per la forma esteriore, e per la sua picciolezza è siffaltamente simigliante alla Spirulina, che non sapresti punto distinguerle. Nullameno, per quanto ci à permesso vedere la sua esteriorità, mancano affátlo gl' interni scompartimenti, ond'è di una sola e semplice cavita, ed il suo estreme è aperto del tutto. Mostra alquanto dietro del peristoma qualche leggiero indizio di lamina, con grande apertura nel mezzo, e due forami in giù. Le quali cose potrebbero anche dipendere da propria innormalità; ma questo non è che un dubbio lontano.

Or è di tale conchiglia che necessariamente conviene costituire un genere, al quale ben sarebbe convenuto il nome di Spirulina. Ma essendo stato questo impiegato in doppio modo, come si è esposto, una logica convenzione vieta adibirlo. Laonde, ricordandone le analogie, propongo per essa il nome di Spirolidium.

Qual'è pertanto l'animale che l'abita, o che la produsse? $\mathbf{E}$ un desiderio cui un fortunato aecidente potrì soddisfare. Ma quando, e per chi non si può prevedere.

Dorendoci quindi accontentare di conoscerne la spo- 
glia, è sopra essa che il genere si fonda; la cui definizione va formolata così:

Conchiglia libera, regolare, simmetrica, spirale in sulle prime, per due o tre giri, $i$ quali si toccano ed in parte lo esterno abbraccia il precedente; indi si prolunga in linea quasi retta, assumendo la forma di pastorale; aperta all'estremità, con apertura semplice; internamente di una sola cavità continua, e senza veruno scompartimento di sorta.

1. Spinolidum Mediternayeum, Cos.

$$
\text { Tav. Xl. fig. } 2 \text { e } 4 .
$$

Trasparente come il vetro, bianca, liscia, con qualche oscuro segno di strangolamento nella parte prolungata. Lamina aperta nel mezzo, dietro del peristoma, con due forami piccolissimi, uno per lato ad una spezie di linguetta, che, partendo dal lato concavo, si protende fino all' apertura centrale, come viene rappresentata in $b$ della figura citata.

Si ànno di tale specie due varietà. La prima è di statura minore e meno gracile, fiỳ. $a$. La seconda è più delicata, più prolungata, ed il prolungamento un poco imbutiforme; di maggiore statura, come vien rappresentata dalla figura trasversalmente soltoposta alla precedente.

Lunghezza della prima $=1$ mill.

$$
\text { della seconda }=2 / 10 \text { mill. }
$$

Abita le rocce coralligene del Mediterraneo delle coste di Affrica e di quelle di Sardegna.

Osservazione. Woodvard, nella Tav. $\mathbf{I X}$, fig. $b$, del suo Nanuale rappresenta una conchiglia identica a queste nostre, riferendola al genere Cuecum di Flemming; lo 
stesso che il Corniculum di Münster, lo Brochüs di Bronn : e l'Odontidium di Philippi; e crede essere il giovine dello stesso Caecum trachea. Con permesso di lui, e di quanti altri ànno opinato allo stesso modo, affermar debbo , esser queste due conchiglie intieramente diverse, quando anche considerar si volesse l'una come il primordio caduco dell'altra. La forma, l'andamento, la struttura, e sopratutto l' apertura col suo diaframma, ne la dipartono del tutto. Io posseggo esemplari minimi, lisci, e trasparentissimi del Caecum trachea, che ben si potrebbero considerare come i polli di quello; ma essi non dissomigliano dal tipo se non per la mancanza delle rughe trasversali: in ogni altra cosa completamente convengono.

\section{-Genere A muonicenina, Cos.}

Frequenti sono i casi in natura, in cui, o sotto spoglie simili, almeno in apparenza, si racchiudono animali per organica composizione diversi, e più o meno lontani tra loro; o sotto spoglie dissimili l'animale è affinissimo e. di un ordine stesso.

E tale è la condizione de primi, che, mentre si è certo della differenza somma che regna tra l'organizzazione dell'uno e quella dell' altro; non sapresti trovar poi un solo segno caralteristico ben espresso ed importante ne' rispettivi nicchi, onde poterli per esso contrassegnare, e separarli. Esempi ne porgono i Dentali e la Ditrupa, Je Serpole ed i Vermeti, i Planorbi e le Bifronzie ecc.

Cosi parimenti in altri casi non si saprebbe sospettare, che gusci o nicchi diversissimi nelle loro forme este-. riori, ed anche nella sostanza, polessero racchindere animali della stessa famiglia, od almeno della stessa clas-. se. Tal' è il caso, a modo di escmpio, delle Teredini e le: 
Foladi, de Concolepi e le Porpore, i Balani e le Tubicinelle, ecc.

Dalle quali due condizioni proseguita, ch' essendo cadute sotto l'occhio de'naturalisti coteste spoglie, prive del loro abitatore, ancorchè peritissimi per la maggioranza de casi, sono state diversamente per ciascuno di loro definite, e per ordinario l'uno oppostamente all' altro le à giudicate. Alle quali diverse sentenze ànno pure influi to i tempi e le condizioni in cui si sono trovati i soggetli e gli autori.

Da ciò ànno avuto origine quei tanti sinonimi, di cui si trovano soverchiamente caricate certe specie; da ciò la diversa denominazione generica, e non di rado ancora la posizione svariata e lontana nel metodo. Gli esempi ridondano negli antichi, sono cresciuti ne'moderni, ed avanzeranno nella posterità; perocchè le cagioni si accrescono siccome aumenta il numero degli scrittori, la loro distanza, e la celerità della stampa.

Non è da farsi le maraviglie perciò, se di sovente si pone piede in errori, sia nella novita, e sia con la falsa generica determinazione-Molti sono gli esempî che addur si possono in comprova di tali verità. Mi limito non pertanto a porne una in mezzo, bastevole ed immediata al caso nostro, senza dilungarmi di troppo.

La conchiglia effigiata nella tavola XII, sotto il numero 1, a primo sguardo direbbesi un Ammonite; per tale annunziandola la sua forma spirale, avendo la spira ugualmente depressa ed ombelicata d'ambe le facce, i cui givi, gradatamente crescendo in diametro, sono guerniti di cordoni trasversali, e questi con una eminenza acuta nel mezzo sì dall' una che dall' altra faccia; sicchè si à una conchiglia completamente simmetrica. Nondimeno, non essendo essa allo interno concamerata, ma unicavi- 
taria, e senza vestigio di sepimento di sorta, entrar non può nella classe de' cefalopedi. L' apertura è quasi rotonda, con oscura tendenza al quadrilatero; peristoma esternamente angoloso, internamente liscio, levigato, ed a margine ottuso e spesso.

Una conchiglia di simil natura, se fosse terrestre , non esitereste a crederla del genere Planorbis; considerandola solamente quale specie ben distinta da quante altre se ne conoscono, spezialmente per la sua picciolezza. Ma poichè è dessa marina, quindi il suo abitatore non polmonato; non può con le specie di quel genere essere associala.

Restringendola dunque ad analoghe abitatrici del mare, e però fra le spoglie di molluschi branchiati, essa si trova fra mezzo ad una folla di generi, si poco distinti, che vià pure chi, riunendoli insieme, gli à, con poca avve. dutezza, ricondotti ad un solo, perchè primitivo, il genere Strapasolus Monf., ma che però non merita per altro riguardo la preferenza. Conciossiachè questo gencre, come gli altri del medesimo autore, è stato fondato sopra una specie sola, nel modo che da principio abbiamo dichiarato.

Conviene ora dunque passare in rassegna brevemente i generi affini, onde riconoscere se ve ne fosse uno, al quale possa più convenevolmente riferirsi.

Solarium. Non à come questi la spira da un lato, ed ombelico scavato dall'altro con forame nel mezzo.

Rotella. In tal genere la spira è spianata e l'ombelico chiuso e calloso.

Delpunvea; affinissima ai Solari, si distingue da quelli per l'apertura rotonda; val quanto dire, che i giri della spira son tutti tali, mentre ne' solari sono trigoni piu o meno; e più per la mancanza di ombelico scavato, con forame centrale nella spira. Con le delfinole quindi 
conviene la nostra conchiglia per la sola integrita de'giri della spira, e perciò ancora dell'apertura; ogni altra cosa è diversa.

Bifnontia. Il nome parrebbe condurla dritto a tal genere, essendo nella nostra conchiglietta realmente due $\mathbf{c}$ quasi uguali le facce; ma ciò non è che approssimativamente vero nelle conchiglie registrate sotto tal nome. Conciossiachè in esse da un lato vi è un ombelico larghissimo col margine carenato, e l'apertura angolosa (trigona o tetragona); e per questo solo essenzialmente diverse dalle Delfinole. La nostra specie manca affatto di ombelico propriamente detto; siccome non à menoma differenza nelle due facce spirali, in entrambe essendo la spira ugualmente depressa.

Orbs - Lea à fondato questo genere per una conchiglia analoga , i cui caratteri convengono completamente con quelli della nostra specie, tranne solo quello dell'apertura: eccone la frase :

Conchiglia orbicolare, discoidale, ombelicata, apertura quadrangolare; ombelico largo, spirale, tutto ugualmente visibile d'ambi i lati. Senza colonnetta.

Planania, Brown (Melurile? Leseur).

Conchiglia discoidale, compressa, sopra e sotto ugualmente piana, splendente, e diafana; sostanza di questa conchiglia molto delicata e fragile; tre intieri giri convessi; apertura lunata; labbro superiore riflesso.

Poste dunque tutti questi, ed altri simili confronti che far potremmo, ma soverchiamente; risulta indispensabile il creare per questo nostro tipo un nuovo genere Ma solto qual nome?

Ecco un secondo imbarazzo, nel quale tuttodi ci troviamo. I radicali greci non somministrano più voci capaci di esprimere i nostri concelti; essi sono esauriti. E 
poichè una legge di convenienza inibisce adoperare lo stesso nome impiegato già per altro genere della medesima classe, ed anche se fosse in una stessa grande divisione di un solo regno naturale; cosi il nome di $\boldsymbol{S}_{\text {pirorbis, }}$ che ben gli sarebbe convenuto non può adottarsi (1). Non Planorbis, per la stessa ragione, che si confonderebbe con quello usato per altre conchiglie, sebbene di ordine diverso. Tenendo perciò presente l'apparente forma e struttura degli Ammoniti, e la sua somma picciolezza, ò creduto assegnarle il nome di Ammonicerina, o piccolo corno di Ammone.

Caratteri deL Genere.

Il genere Ammonicerina à dunque una Conchiglia ormbicolare, discoidale, depressa nel mezzo d'ambe le parti; giri della spira non abbraccianti, ma un poco coerenti ; apertura quasi rotonda ; peristoma semplice, talvolta ingrassato per l'esterna ruga, o espansione.

1. ammonicerina pulchella, Cos.

Tav. XII, fig. 1. $a, b$.

Conchiglia quasi ombelicata d'ambe le facce; composta di quattro giri di spira, rotondi, separati da sucura profonda; ornati da cordoni trasversali, i quali sul mezzo dell'una come dell altra faccia si elevano a foggia di spina, non molto acuta, laminare, dritta ; apertura rolonda, col peristoma delicato, acuto, dritto; tulta di color rosso vivace quasi sanguigno.

(1) Questo nome è stato impiegato da Heininger per' Conchiylia, meцfre già lo era per Anellide. 
Diametro $=\gamma_{10}$ di millimetro.

Specie rarissima, ospitante nelle rocce coralligene delle coste settentrionali dell' Affrica, insiene a molte altre specie di genere diverso, e di Foraminiferi. Nef mio Museo.

2. Amimonicenita paucicostata, Cos:

Tav. XI, fig. 1. $a, b$.

Soli 9 grossi cordoni per ogni giro di spira; apertura internamente anguslata, e come se vi fosse un diaframma, o strangolamento analogo a quello del genere Prolomedea.

Diametro trasvers. $6 / 10$ di millim.

3. Ammonicerina SImplex, Cos.

$$
\text { Tav. XI, fig. } 3, a, b \text {. }
$$

Simile alla precedente, però senza verun segno di cingoli, nè di rughe, ma solo guernita di strie finissime trasversali.

4. Amionicerina mutabilis, cos.

$$
\text { Tav. XII, fig. 2, } a, b \text {. }
$$

Conchiglia composta di 3 giri di spira, alquanto piit larghi che alli, lisci e semplici dapprima, l'ultimo peró verso il suo termine incrassato e guernito di grosse rughtue trasversali, con sei carene longitudinali.

Diametro $3 / 10$ di mill. 


\section{$-73-$}

Tutte tre queste specie provengono da fondi coralligeni della Sardegna.

Genere Protomedea, Cos. (1)

Tav. XI, fig. 5 e 6.

Le conchiglie che formano il soggetto del nuovo genere che quì si propone ànno strelli rapporti con quelle dell' Atlanta, e spezialmente dell'A. Cheraudrenii. Come quelle ànno la spira d'ambe le parti depressa, benchè inegualmente, gli anfratli si accollano sulle prime, indi si separano gradatamente, ma non ànno carena laminare sul dorso; e quale più quale meno si allarga trasversalmente, sicchè in taluna l'apertura è più dilatata che alta, come la si vede nella fig. 5 in $c$; inoltre, essendo più compressa, si allunga più che si dilata, come nella figura 6 in $c$.

Variano esse eziandio per la obbliquità con la quale si attorcigliano, volgendosi ora dalla destra alla sinistra , come quella della fig. 5 , ed ora in senso contrario, come vedesi nella fig. 6 .

Per tutte siffatte differenze, e perchè non ànno esse alcun tipo, cui si potessero riferire senza arbitrio, mi è paruto giustissimo proporle a tipo di un genere distinto ; il quale piacemi insignire col nome di una delle $50 \mathrm{Ne}-$ reidi, figlie di Nettuno e di Doride, seguendo il pensiero di Esiodo.

(1) Nome mitologico di una delle Nereidi 5 secoudo Esiodo. 
2. Protomedea elata, Cos.

Tav. XI, fig. $5 a, b, c$.

Conchiglia molto obbliquamente rivoltata in spira dal destro al sinistro lato, avente 3 giri di spira, alquanto abbraccianti ; apertura dilatata trasversalmente; superficie liscia.

Diametro maggiore $6 / 10$ di mill.

2. Protomedea ornata, Cos.

Tav. XI, fig. $6, a, b, c$.

Conchiglia compressa, rivolta in spirale da sinistra a destra obbliquamente; composta di 3 giri di spira, alquanto abbraccianti sulle prime, sensibilmente discreti in fine; apertura ovale, più lunga che larga, labbro scisso dalla parte dorsale. I primi due anfratti oscuramente striati per lo lungo nella faccia sinistra, lisci nella destra ; indi un marchio molto sensibile di accrescimento, come un cordone, al quale altro simile ne succede meno rilevato, e dalla opposta parte cancellati affatto.

Diametro magg. 1 mill. $\mathrm{e}^{7 / 10}$.

Abitano entrambe nelle stesse località delle precedenti - Rare. 


\section{$-75-$}

\section{CLASSE DE' CIRROPEDI}

\section{ORDINE I. IIBEEX.}

\section{Genere Tritone; Triton, Lim.}

Omero, volendo descrivere le orrende sventure di quanti, valicando per lo stretto Zancleo, vengono dai marosi furenti spinti fra gl'ispidi scogli di Scilla, personificava tal luogo, e gli dava per madre Cratei.

Favoleggiando in simil guisa i posteriori poeti, ed imitando quella classica ed originale epopeja, vollero dargli anche un padre; ed a questo imposero nome Tritone. Questo stesso nome, secondo Pausania, è proprio di un fume, da cui nacque Tritonia.

Linneo, cui tanto piacque improntare dalla favola i nomi per insignirne gli animali e le piante, e congiunger così i concelti della mente coi fatti della natura, assunse il nome di Triton per darlo ad uno degli abitanti del mare. Figura esso dapprima nel Museo di Ludovico Ulrich, pag. 466,1754 , ove Tritone viene appellato l'animale ospitante quei nicchi testacei del suo medesimo genere Lepas. Il quale genere, smembrato dai moderni zoologi, à dato origine ai generi Tubicinella, Coronula Balanus, Acasta, Creusia, Pyrgoma, Anatifa, Pollicipes, Cineras, Otion ed Alepas.

Ripose egli in seguito il genere Triton fra vermi molluschi, facendolo succedere alle Oloturie e seguir dalle Seppie (1).

(1) Lin. Syst. Nat. Edit. 10, reformata - Holmiae 1758. Pag. 6j9, gerı. 261 .

In origine però lo aveva collocato fra le Neduse - Vedi Edit. 5."2 Paris. 
Egli lo definì nei seguenti termini.-

Truton - Corpus oblongum -- Os lingua involuta, spirali. Tentacula XVI (1): utrinque 6: posticis cheliferis.

E non vi riportò che la sola specie seguente:

1. Triton littoreus - Habitat in foraminibus rupiunb subinarinorum.

Niuna descrizione illustrativa, non citazione di figura, non indicazione di patria. Ma lo aver indicato il domicilio suo ne'forami de'scogli coperti, fa sospettare, che davvero vi avesse trovato un mollusco nudo così costituito, o ch' ebbe così a concepire l'abitatore de'balani.

11 Tritone linneano però era stato effigiato e descritto negli Atti Anglicani ( 50 , vol. $2^{\circ}$, pag. 847, tav. 34, fig. A), e da Leouwenoech (Arcana Naturae, pag. 463, figura 7. 1697.)

Nè altra notizia sembra ne avesse avuta Linneo, eccello questa citata.

Nella edizione duodecima però, alle cose di sopra esposte ed ivi ripetute (2), soggiunge la descrizione seguente. -

Corpus quale in Lepadibus occurrit. Tentacula sex parium, bipartita, articulata, introrsum ciliata, involuta; harum paria tria posica chelata. Lingua inter extrema tentacula. Os ad basin tentaculorum. Figura similis.

Dalle quali cose si rileva aver egli veduto un animale nudo, simile a quello che abita le Anatife, i Balanidi ec.; siccome ben lo dichiara quel figura similis, ec. Laonde nello istituire il genere Lepas, tra i molluschi testacei, ei

(1) Forse per errore tipografico, poichè siegue a dire esserrene sci per lato: e XII ne assegna nella edizione di Vienna.

(2) Linn. Syst. Nat. edit. XII, Vindob. 17.... (pag. 1092 : gen. 292 ubi - Triton tentacula XII). 
ne indica l'abitatore col medesimo nome generico - Ani. mal Trilon.

Non essendo pervenuto giammai nelle mani de'zoologi alcuno esemplare di tal fatta , o poco presso di sinil forma, si è giudicato che Linneo avesse solainente supposto potere esistere in natura il mollusco senza la sua conchiglia (1).

In tale stato si trovan le cose per quanto spetta alla storia; ma nel fatto la natura ne porge oggi un documento, dal quale apparisce, che il naturalista Svedese non sognava, e non suppose, comunque possan le cose apparire alquanto diverse.

All' unica specie impose nome di littoreus, comechè abita i scogli coperti dal mare; e soggiunse esser lo stesso che sì frequente si trova nelle Lepadi. Per meglio chiarirne l'esterna organica composizione vi aggiunse: Tentaculorum arliculatorum involutorum introrsum ciliatorun paribus sex, posterioribus tribus cheliferis, ad basin tentaculorum os; inter extrema proboscis.

Nel 1783, Barbut, pubblicando il suo Genera Vermium (vol. unico, in $4^{\circ}$ ), alla pag. 63 riporta il genere Triton, con le stesse linneane parole; aggiungendo solo esser quasi la metà sì grande che la Seppia comune, e vivere sulle coste del Mediterraneo. In fine ne porge la figura nella Tav. VII, fig. 2.

Nella XIII edizione del Systema Naturae lo Gemlin ripete esaltamente le cose superiormente nolate, senza altro dire.

D'altra parte, Laurenti impiegò il medesimo nome Triton per un genere di Rettile anfibio della famiglia delle Salamandre, o della $5^{a}$ divisione delle Lucertole di Linneo.

(1) Cuy. Regn, auim. III, p. 361. 
Muller costitui il genere Triton.

Poli ci diede l'anatomia di quello ch'è l'abitatore dei Lepas;

Lamarck impiegò pure il nome Triton per un genere di testacei, di cui è tipo il Murex tritonis di Linneo.

I naturalisti più recenti, a contar da Cuvier, ànno cancellato dall'albo degli animali il primitivo genere Triton; conservando solo quel di Lamarck nei Testacei e quel di Laurenti per i Batrachi. In vero non poteva reggere il doppio impiego d'un medesimo nome in una medesima classe di viventi. Ma questo doppio impiego non è che apparente. Perciocchè uno era il tipo generico dell'animale, il quale aveva per affinissimo l' abitatore del genere Lepas. Ma siccome il Trilone tipo non è stato uiteriormente incontrato in natura, e sembra a me pure, che qual ce lo indica Barbut non sia vero; così non è da cancellarsi.

Cercavasi nondimeno questo animale isolato, qual ci venne descritto da Leowenoechio e da Barbut; ma era rimasto problematico: e ciò solo poleva giustificarne la scomparsa dalle opere di Zoologia sistematica. Io non so se realmente esistesse in natura il tritone sì grande qual lo descrisse Barbut; ma piccolo è un falto, che per ben due fiate sopra 4 individui identici ò potuto constatare: ed è quello che forma il subietto della presente descrizione. 
TAYOLA XII, fig. 3-6.

$a$ grandezza naturale,

$A$ lo stesso ingrandito e veduto di lato; ove $c, d$ sono i sei cirri di uno de'lali, ai quali corrispondono altrettanti dal lato opposto,

$\boldsymbol{B}$ è lo stesso animale veduto di prospetto, i cui cirri si sono divaricati dall'una e dall' altra parte, a fine di lasciar vedere liberamente il mezzo del corpo dell' animale; dal quale sorge la probosvide $a$, che parte dal centro $b$. Dal medesimo sorge ancora un sifone, che, ripiegato sul corpo, e racchiuso fra le due espansioni laterali del corpo stesso, si adatla fra mezzo, come trovasi rappresentato in $c$. Costituisce esso una cresta, siccome meglio si vede in $b, c$, della figura prima.

La Fig. 3. è quella di uno de'cirri, ne quali $a c$ è un canale, per entro al quale scorrono le uova? xxxx; e sul margine anteriore si prolungano i cirri secondarì $b$, i quali sono coperti di villi vibratili.

Anche i cirri primarî sono guerniti di villi vibratili.

Il colore de' cirri è di un rosso vivace, alternante col bianco nitido, occupando ciascuno spazio uguale: c questa alternativa vien regolata dagli articoli della rachide di ciascuno de' cirri primarì o maggiori, siccome la figura li rappresenta.

Vive questo Tritone nel fondo melmoso de' Golfo di Napoli; e viene pescato dalle cosi detle Tartanelle, in marzo ed aprile.

Nel 184.2 (ai 14 marzo) ricevei i due primi individui, i quali erane attaccati ad una Sinapta pellucida, n. 
ed ai 17 dello stesso mese ne ricevei altri due assai più grandi de' primi.

Ai 22 gennajo 1850 , ricevei una spoglia di questo tritone, appartenente ad individuo quasi doppio di quello rappresentato. Dal quale risulta che questo animale muta la sua spoglia crescendo.

N. B. Nella Enciclopedia Metodica, Pl. 83̈, fig. 6, vien rappresentato è vero questo animale denudato, come lo à fatto Poli; ma ciò non è lo stato normale, bensì qual si riduce spogliato del pallio o mantello, a fine di mostrarne la sua interna organizzazione. 
T.I.A

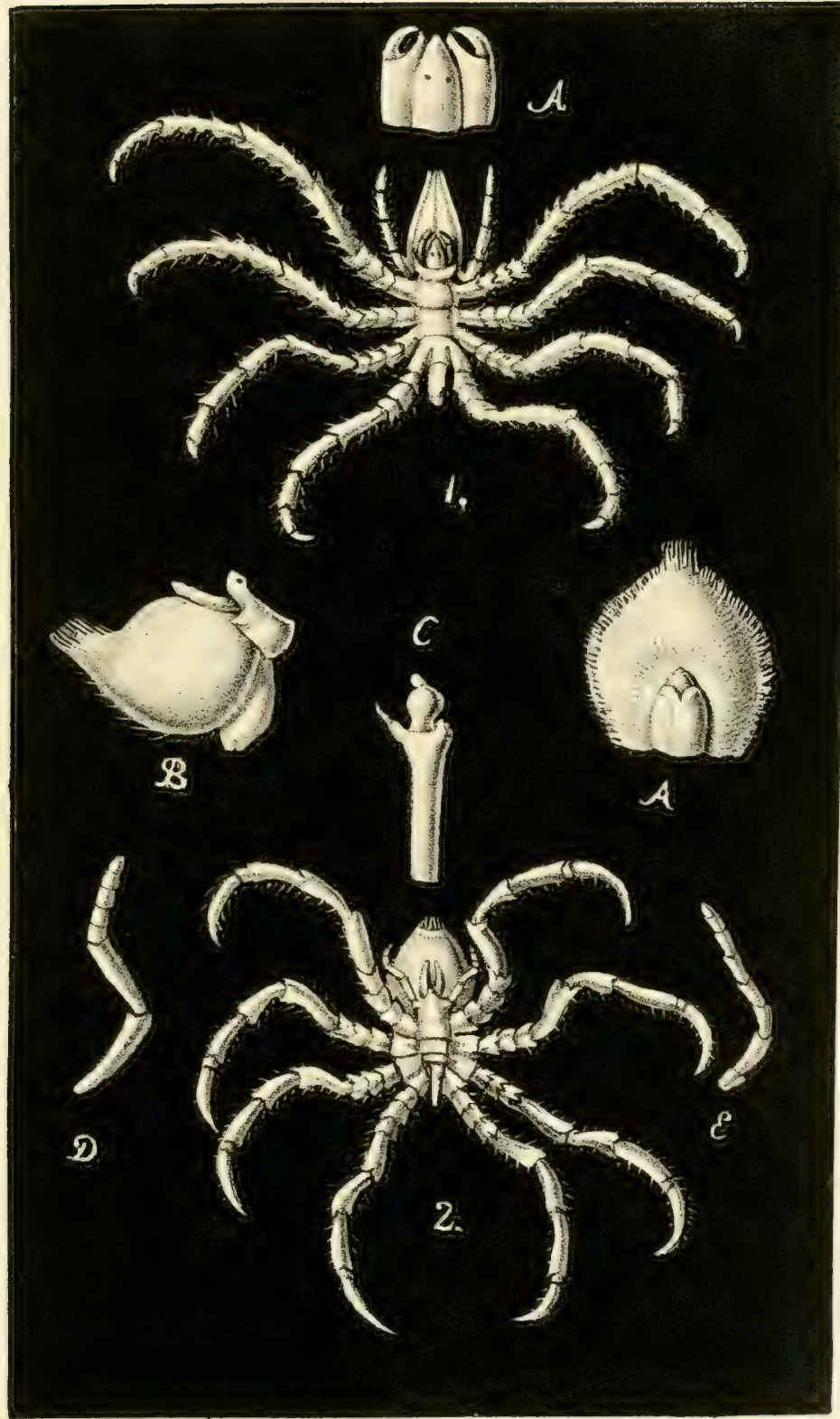

S.Galyo dis.

Dolfino Liz. 


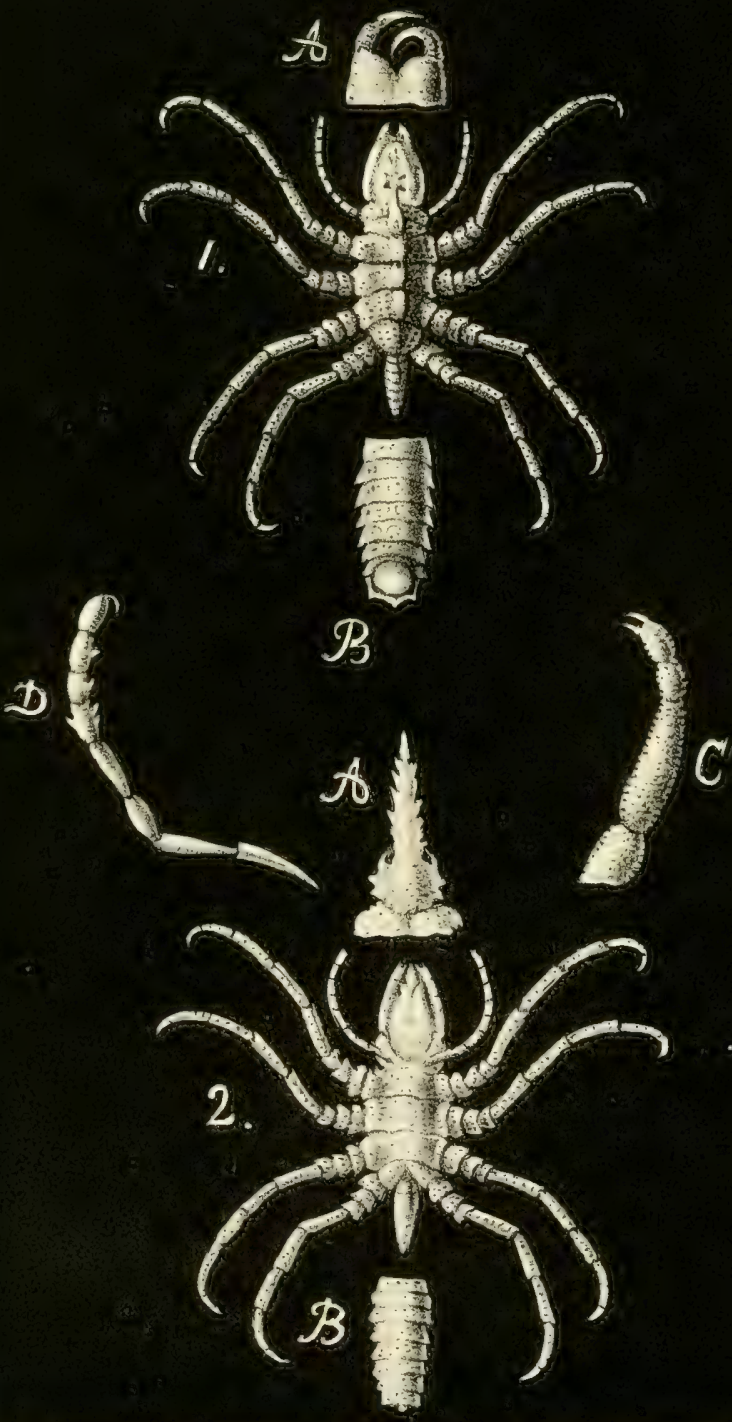



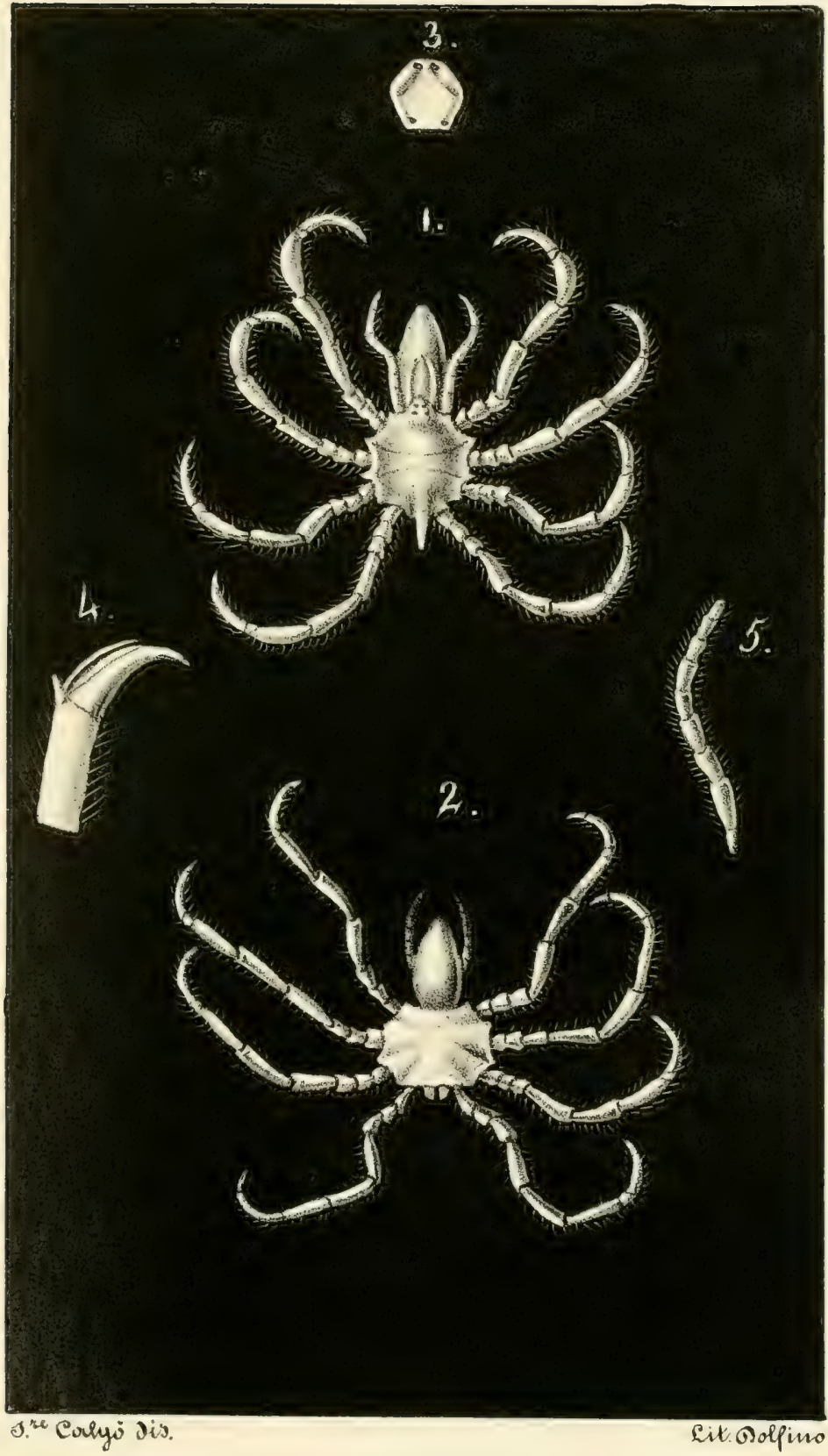





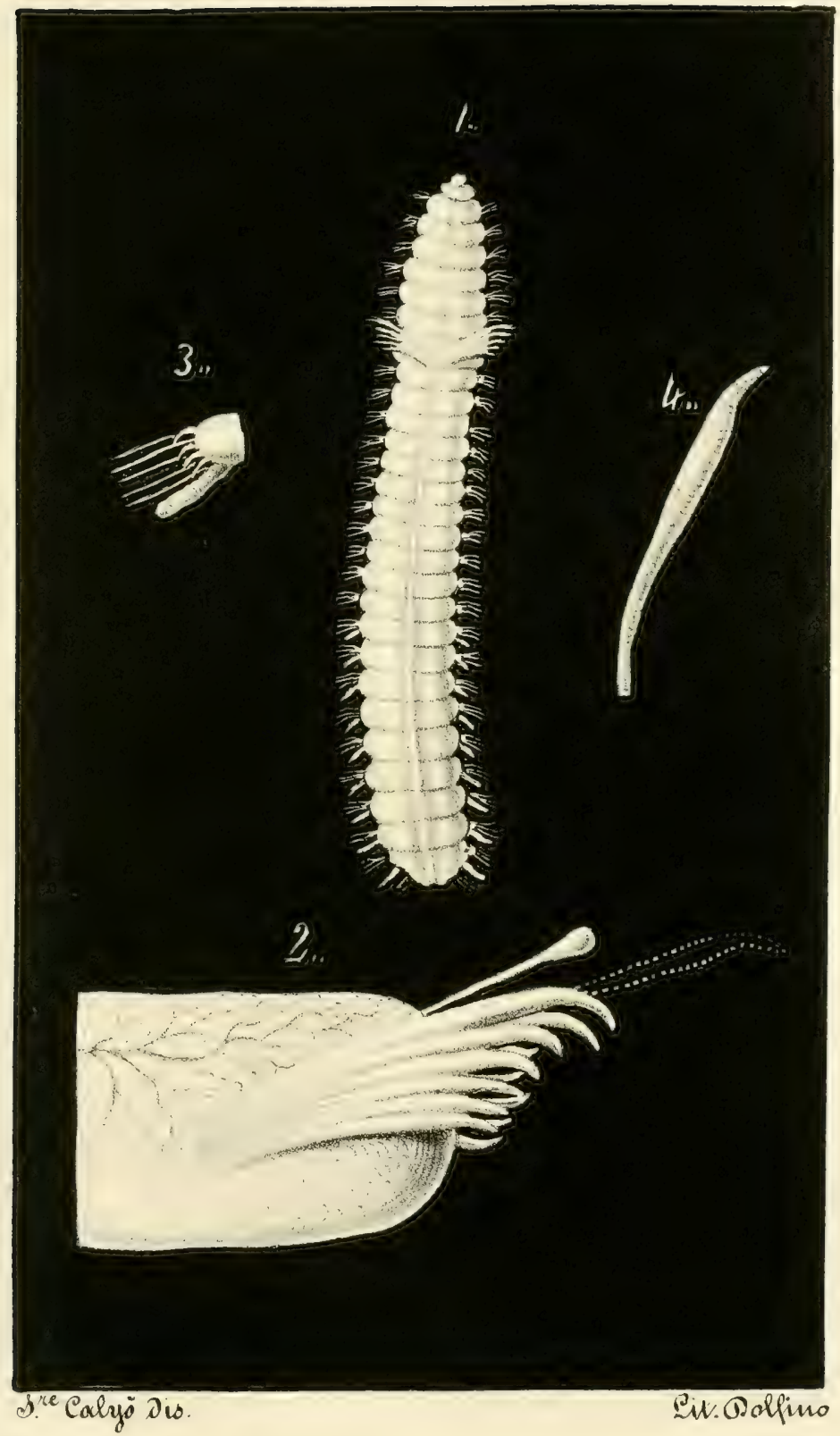



T. I.

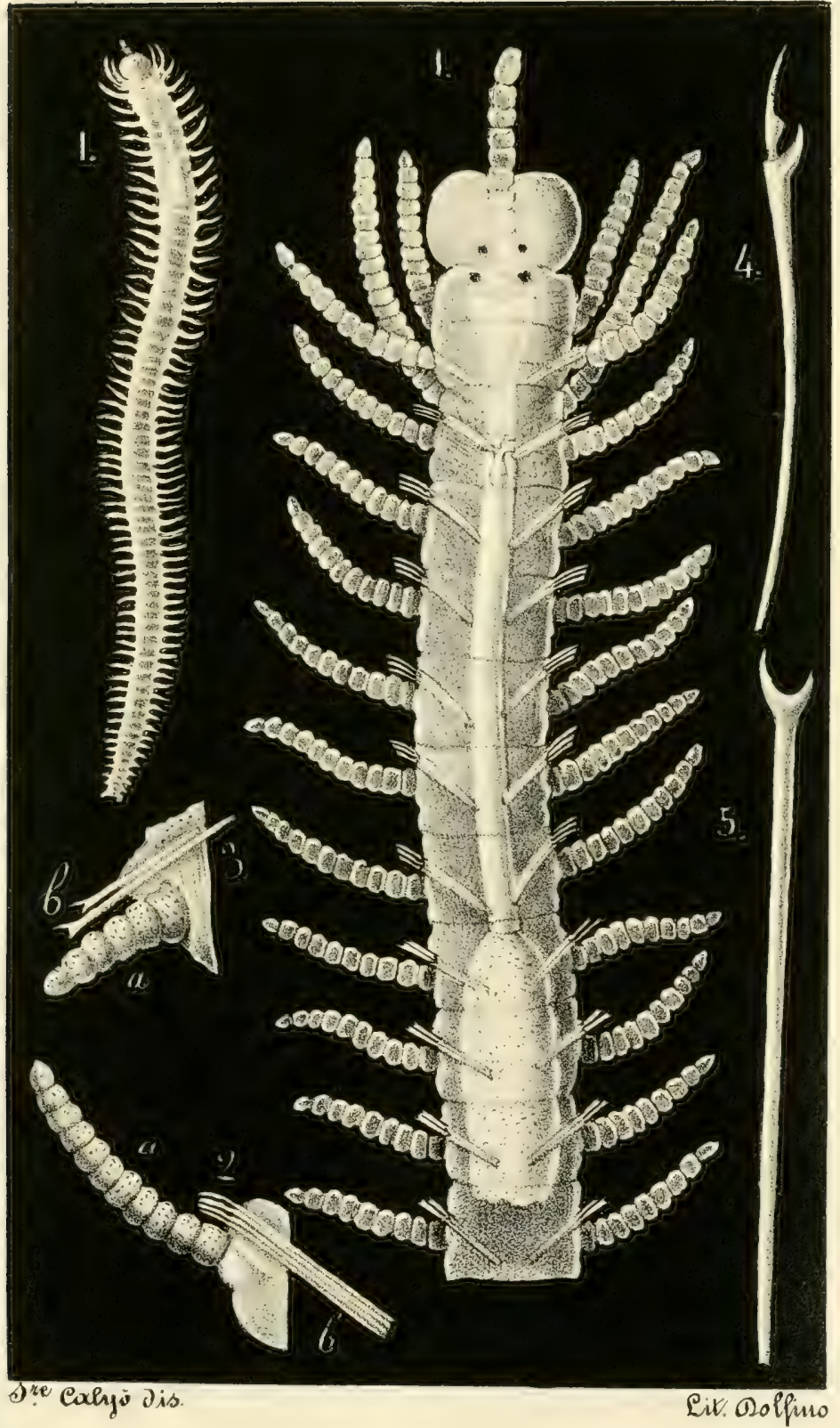





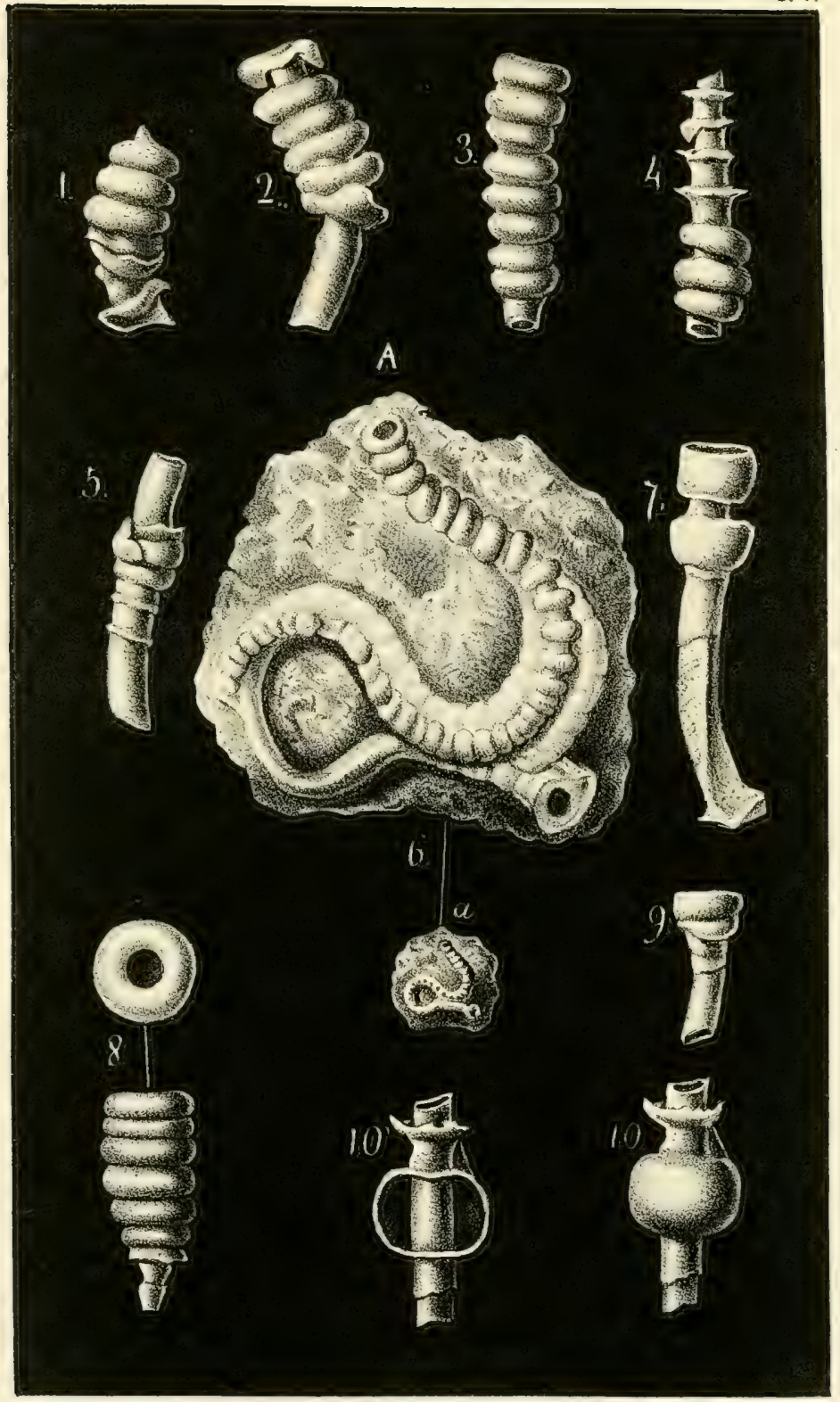

d." Colyou Jis. 



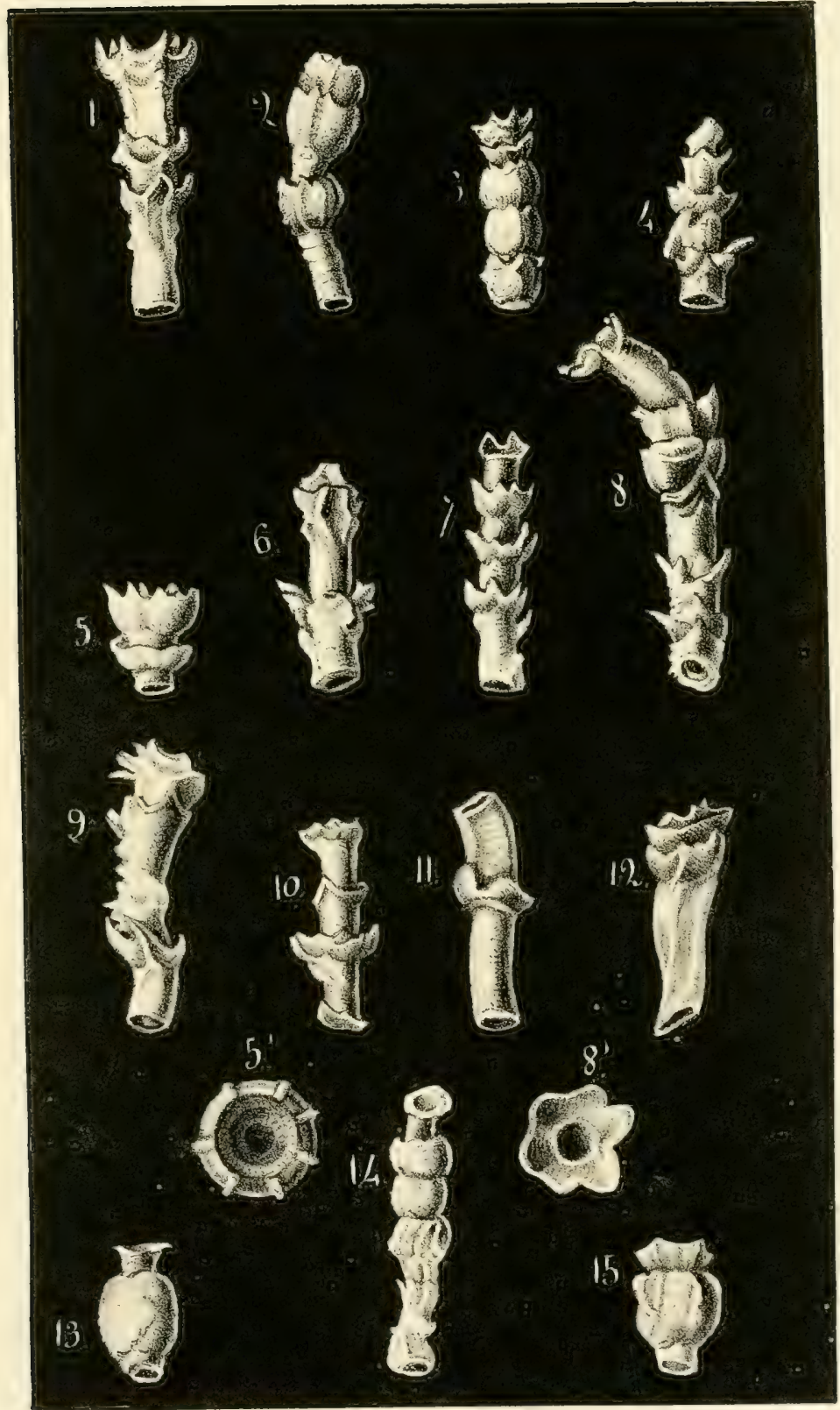





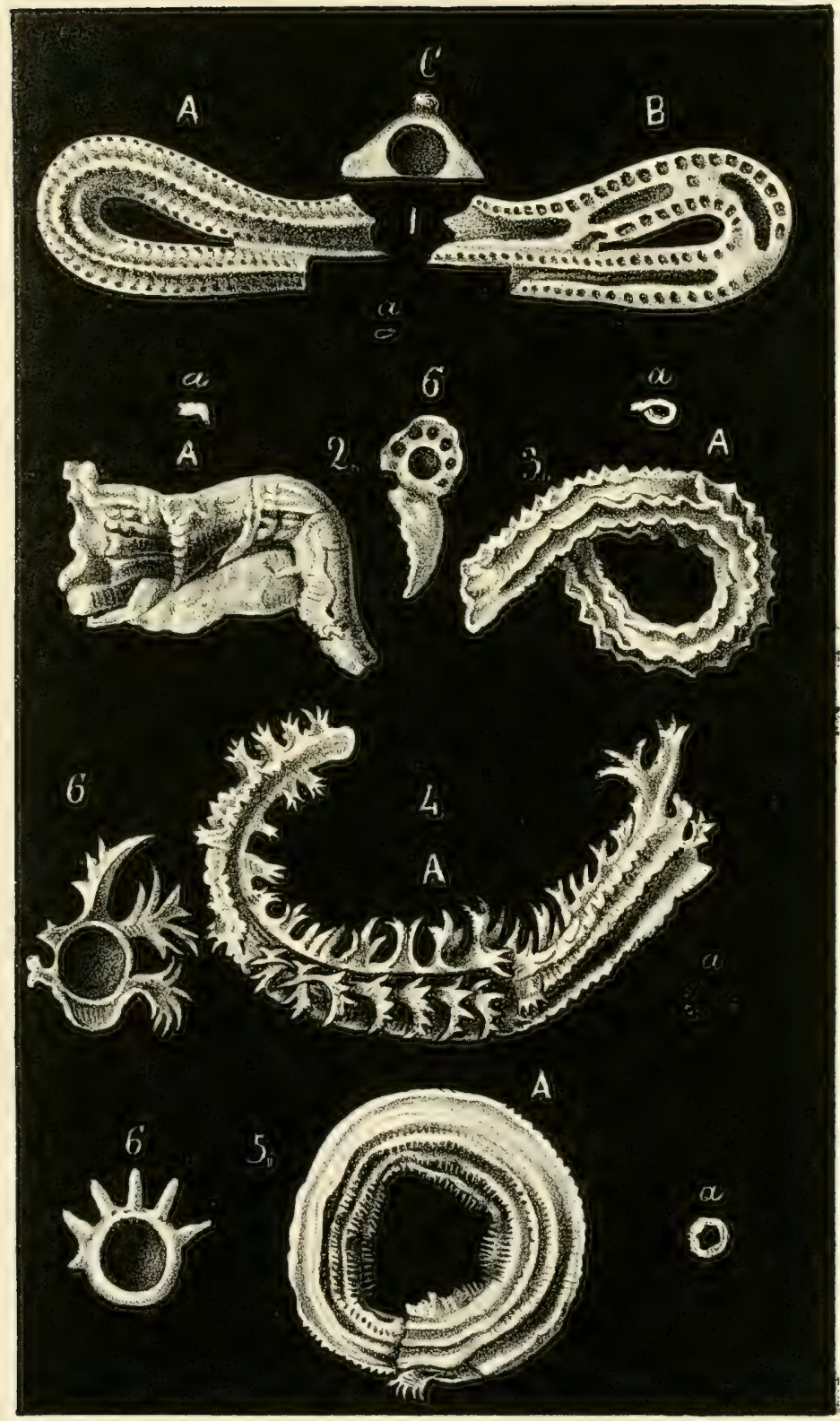

dec Gallyò Nis.

sil O? 



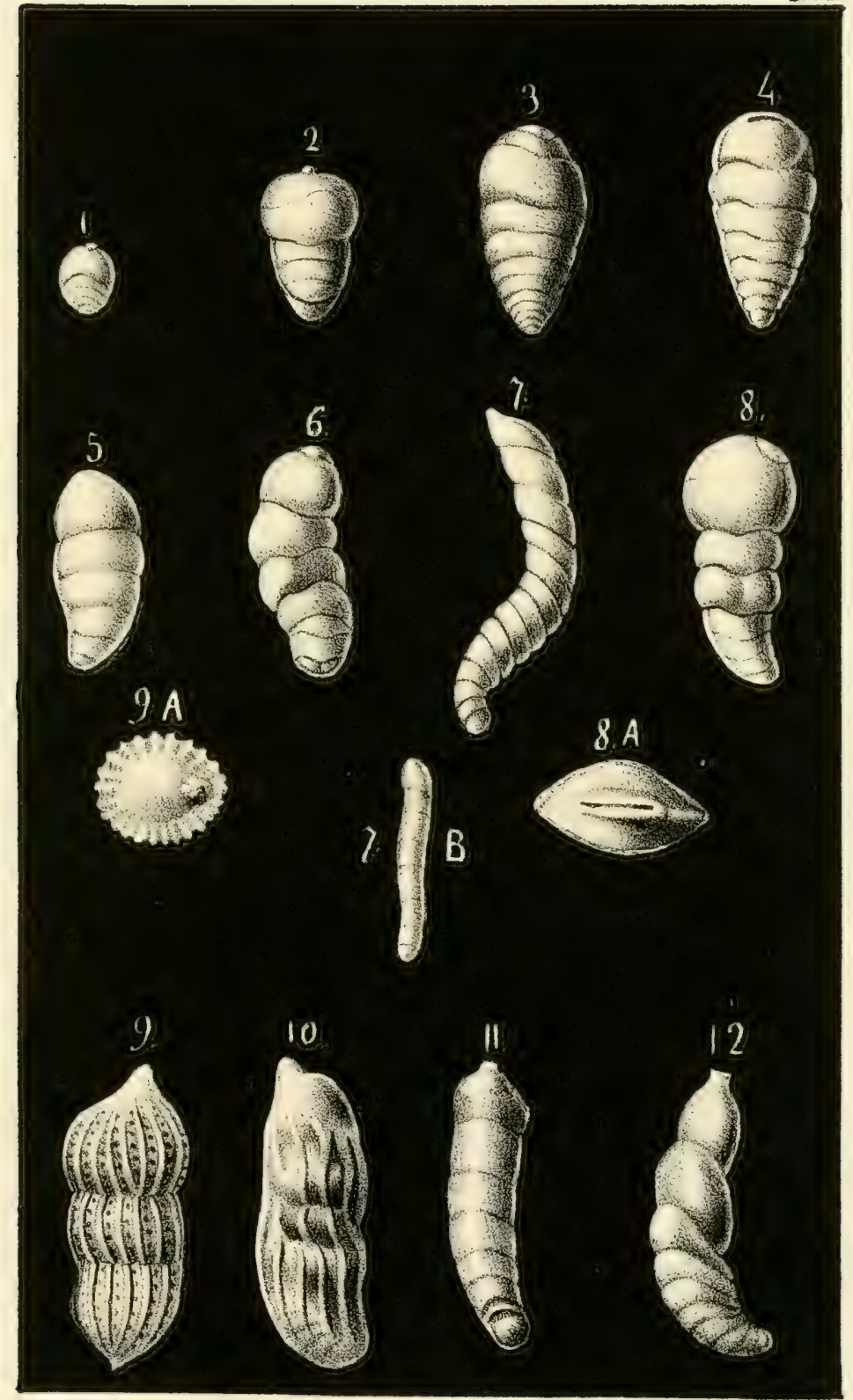

jis Conlyo Dis. 

Plate Ix

1. Trochus elegantisisnus, alt. $5.5 \mathrm{~mm}$.

$$
\text { p.5s, }
$$

2.a-b. murex spinulosas, alt. 4 mon. p. 36.

3. Murchisonia ap. alt. $1.4 \mathrm{mmo}$, p.59.

4. a-b. Murex zuguladek, all. 3 mme. p. 57.

5. a-c. Solarium calcas, diam. $2 \mathrm{~mm}$, p. 58 ,

6. a-c. Yrochue horrideu, nle. $5 \mathrm{~mm}, p, 56$ 



Plate $x$,

1. A.B. Ucesterselta decipiens diam, I min. p. 61 .

$\therefore$ H. Sciesurella affinis, diain. I.fnum, 62,

3. A-C. Heliciella coshellata diann, limm, p.63.

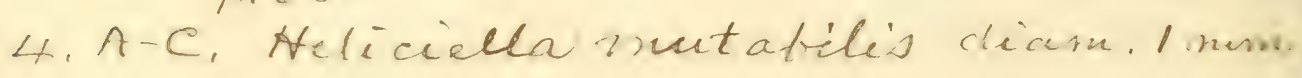
p.64.

5, A-C. H, mutrabiles tras, diann, 1 mone, p.64, 


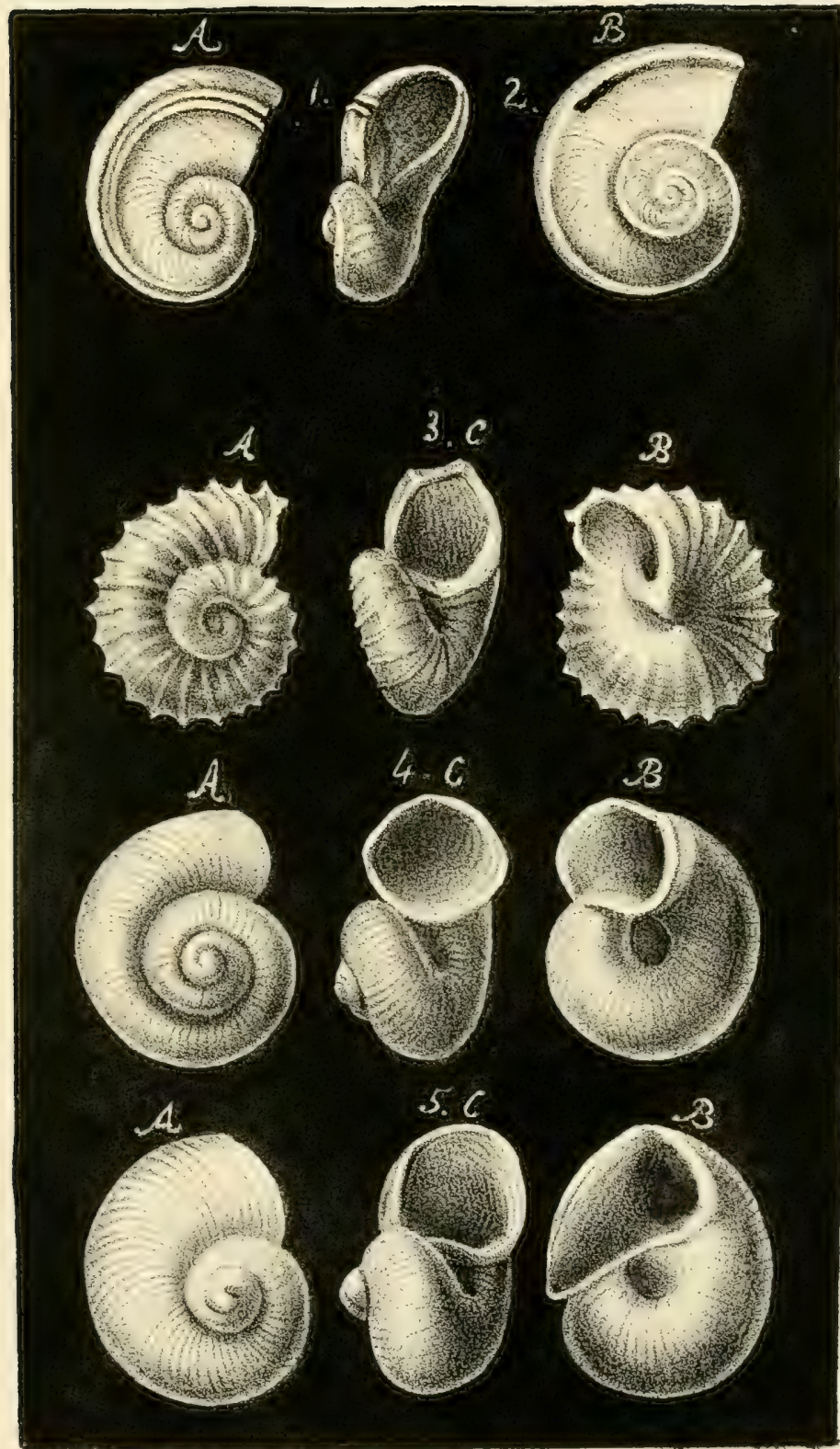

S. Galyo dis.

Dolfino Lit 


Plate $\times 1$.

1.a-b. Ammonicerina parcicastatas, diam $0.6 \mathrm{~mm}, p .72$.

2,4, Spinolidicano meditersanen m, lon. (2) 1 nsm, (4) $0.2 \mathrm{~mm}, p .71$.

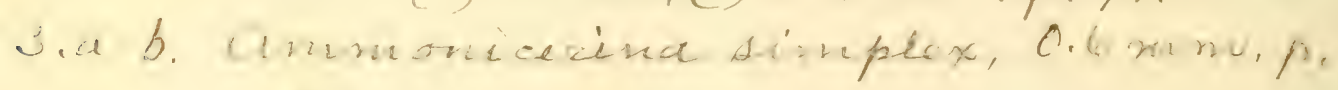
42.

5.n-c.l. Pretomede a clata, diam, $0.6 \mathrm{~mm} / \mathrm{se}$ 74.

6,a-c. Photomedcalomata, dia $\mathrm{m} .1 . \mathrm{tm}$ we $p$. 广世, 
$1 \% 1$.

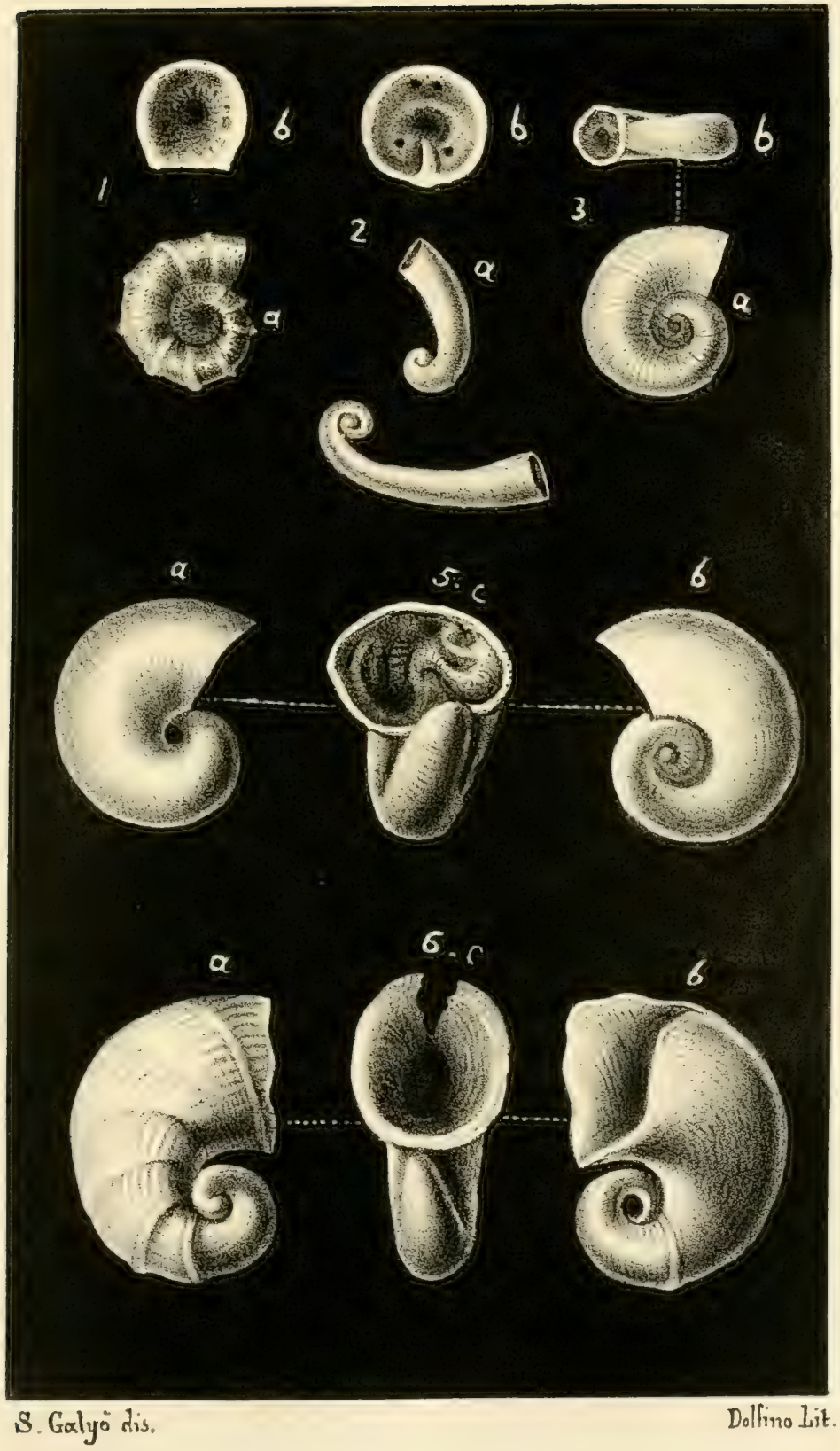


<smiles></smiles> 

Plate XII,

1,ab, Cunnomicenina pulchelln, dirm. 0.7 mm, p. 71 .

2. $a-b$, Aunveniceina mutabilis, diam 0.3 mm . p. 72 .

3-7. Balarices ap, p. 79 .

f, $a-b$. Acisurella ip. p.?

9, $a-b$, deiaderella cingulata, diam. C. $p .61$.

10. not refesred to in text. 


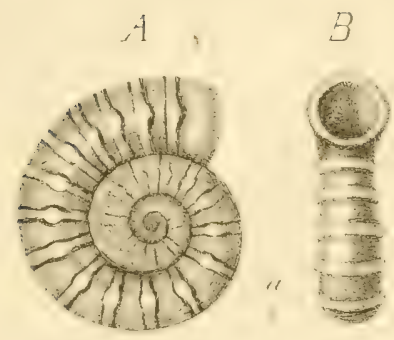

.4

B
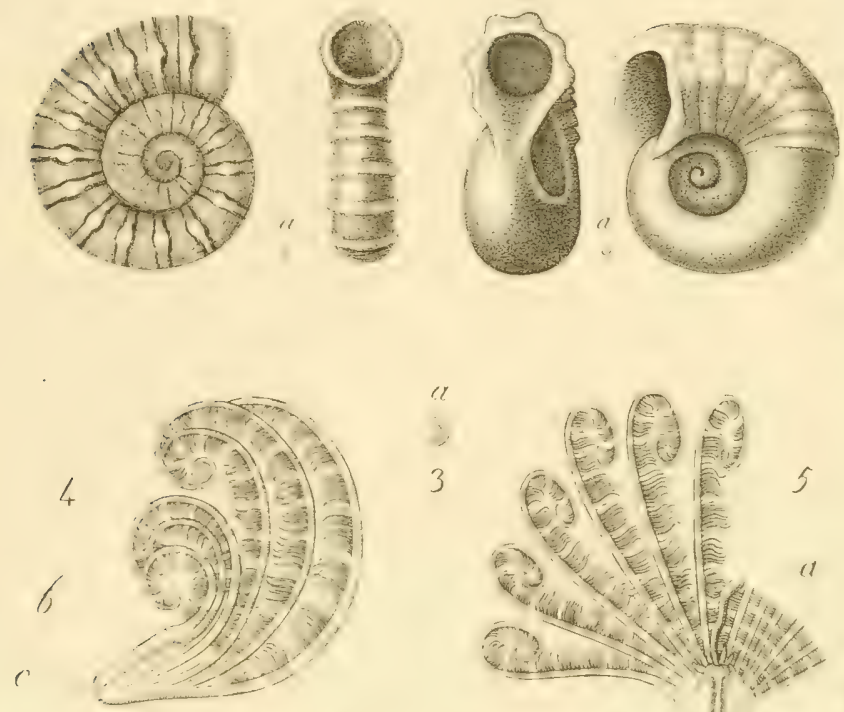

II

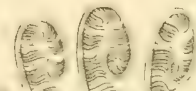
3 5 5 E $6,1<1$ ह Fo

$8 . \mathrm{A}$
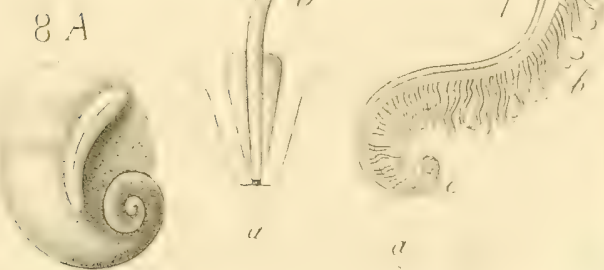

$3 B$
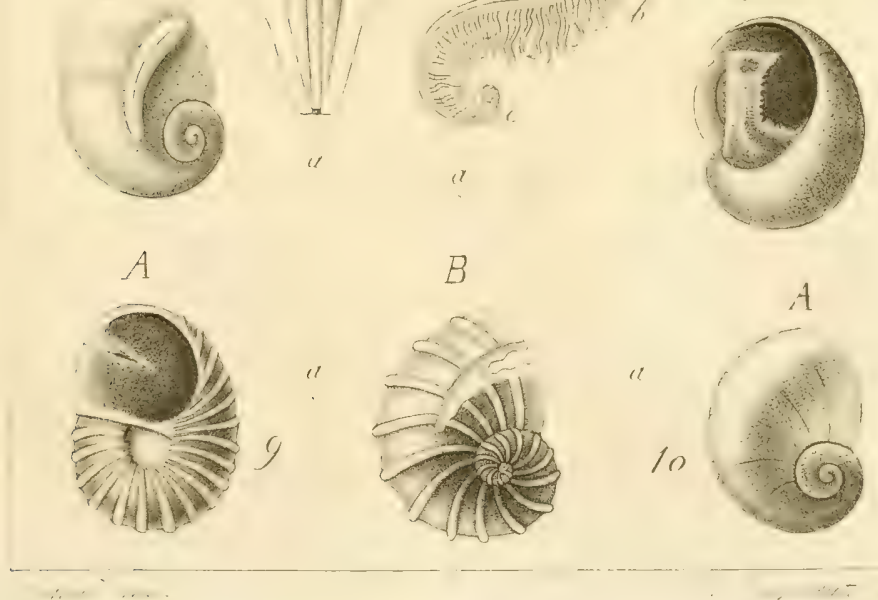












\section{$\leq \mathrm{K}^{2} \mathrm{k} k \mathrm{k}$}

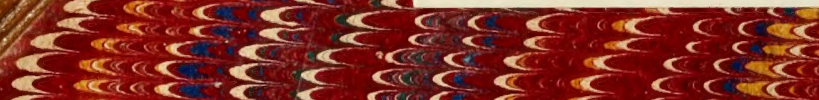

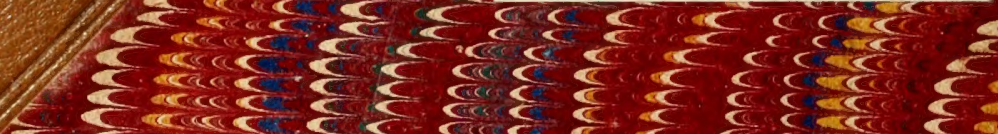

accose का

$\operatorname{sic} \frac{1}{2} \cdot \frac{1}{2}$

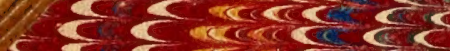

है है बला रे है

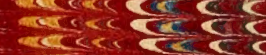

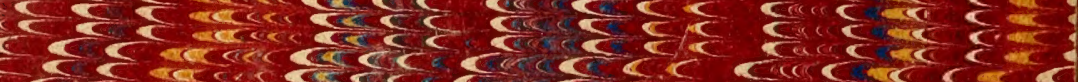

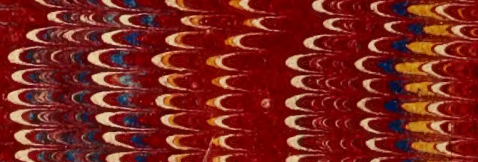

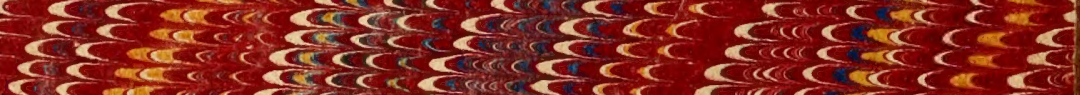

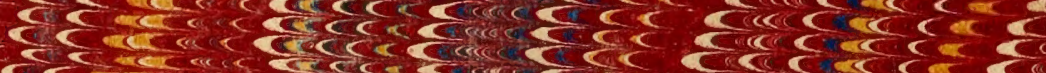

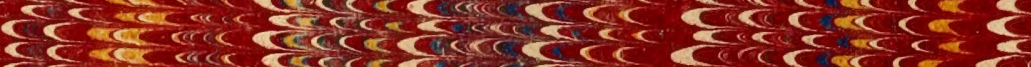

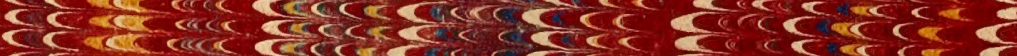

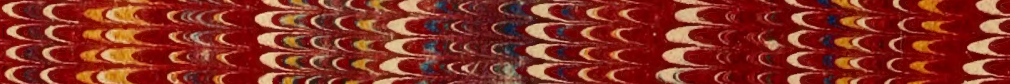

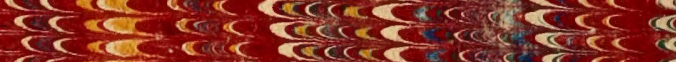

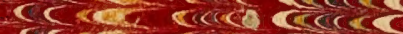

परen ank लnke

cese mos बares

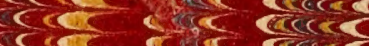

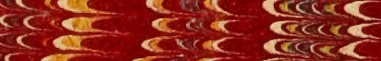

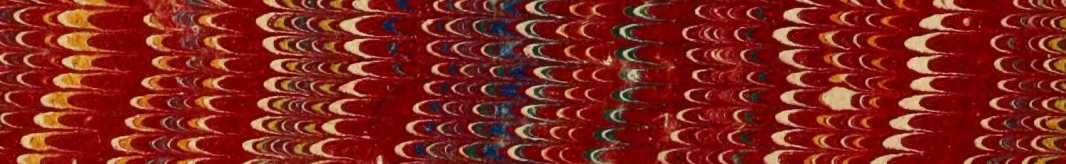

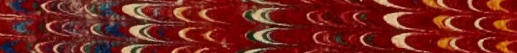

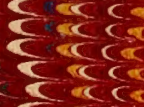

हाँरा है

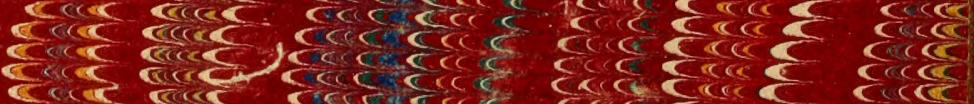

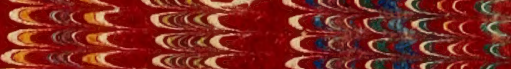

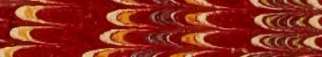

c

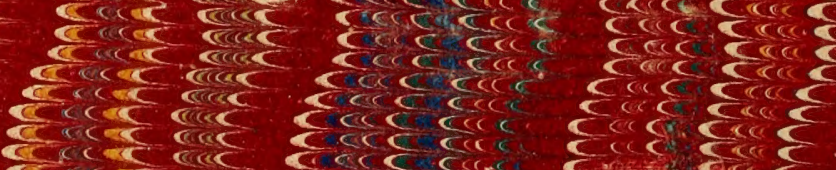

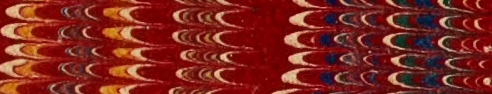

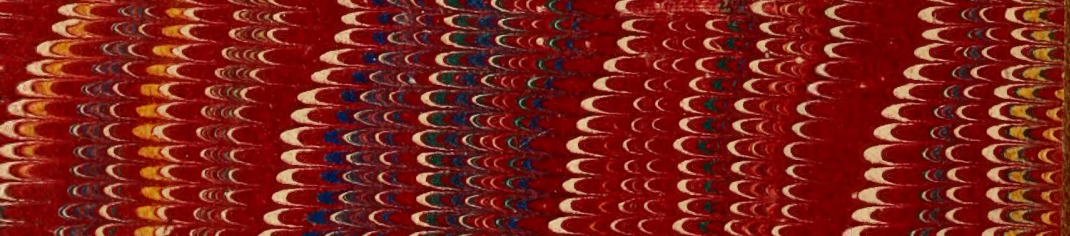

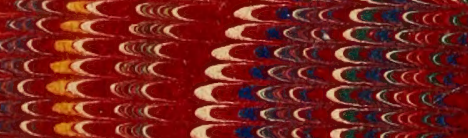

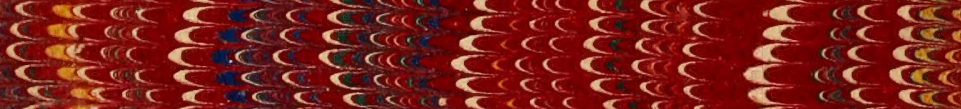

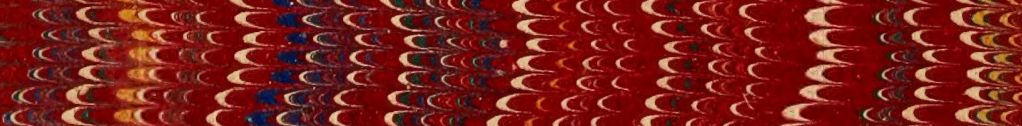

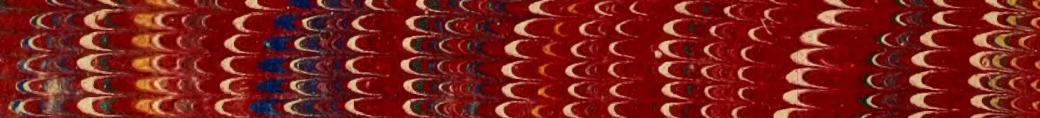

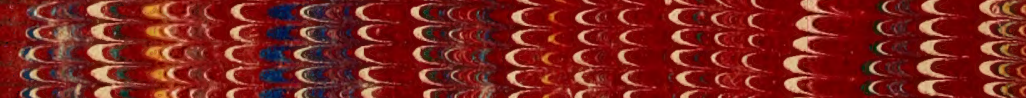

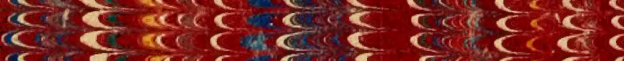

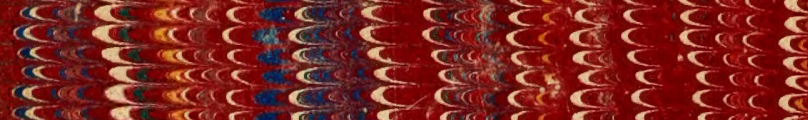

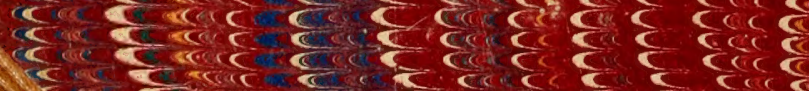

एक हैं रे है है है है

होतो

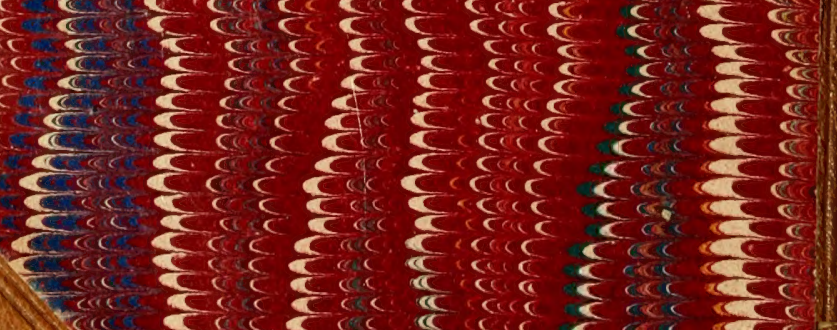

